\title{
(2) NWU \\ Developing a costing system for a digital technology service firm
}

\section{HC Holtzhausen \\ (iD) orcid.org/0000-0003-0582-4394}

\begin{abstract}
Mini-dissertation accepted in partial fulfilment of the requirements for the degree Master of Commerce in Management Accountancy at the North-West University
\end{abstract}

Supervisor: Prof M Oberholzer

Co-Supervisor: Prof DP Schutte

Graduation: June 2021

Student number: 32907575 


\section{ACKNOWLEDGEMENT}

Before I start, I want to express my appreciation, gratitude and acknowledgement to the following people that enabled me to successfully finish this mini-dissertation:

- Firstly, I want to thank my supervisor, Prof. Merwe Oberholzer. He guided me through the whole research, provided me with feedback, insight and knowledge. He gave me confidence not just with his knowledge, but also with his people skills - always communicating in a mature and respectful manner. I could not have asked for a better supervisor in the whole world. I also want to thank my co-supervisor, Prof. Danie Schutte.

- I want to thank Nico Steyn and the team for allowing the case study to be conducted.

- To my parents that supported me until the end. I could not thank you enough for your sacrifice, prayers, motivation, encouragement and endless support. This would not have been possible without your contributions. I love you two from the inside out and will forever be grateful.

- My siblings, Louis and Charmara, thank you for always pushing and encouraging me to become a better human being. Thank you for always believing in me.

- To Christian Revival Church Potchefstroom (CRC), thank you that I could be part of the family and serving under the best leadership. The impartation and wisdom that I received each week was irreplaceable. I will still contribute to the Church, as I am determined to see God's kingdom expand.

- Lastly and most importantly, I want to thank and give honour to my Lord and Saviour, Jesus Christ. Thank You for my life, family and talents, this would be impossible without Your grace. I love You with my heart, soul, spirit and body.

\section{Dedication:}

This mini-dissertation is dedicated in remembrance of my grandfather and my namesake, Ds. Henno Cronjé. 


\section{ABSTRACT}

Companies are adopting digital technology at a rapid speed, with business spending on technology transformation reaching an outstanding $\$ 1.25$ trillion in 2019. Founded in 2015, the case study principle is a fast growing South African based global digital technology service firm that offers software developing services. Emanated from the view expressed by the firm's Chief Executive Officer, the current costing mainly focuses on firm growth which was a priority in the past, without giving consideration to the appropriateness of the costing system. Within the context of the systems theory, this study investigated the current costing model of the case study principle to establish a reliable system that will improve cost management and provide data for informed decision-making in an effort to maximise value and to remain relevant in the market. Digital service firms are relatively new as a business concept. Other than manufacturing and other wellestablished service firms, the processes/systems of a typical digital service firm are not widely known. Consequently, the literature lacks examples of practices to allocate and manage cost in such a firm. This necessitated the investigation, including activity-based costing ( $A B C)$ as an alternative to the current costing system. Documents (e.g. general ledger, cost reports and budgets) were obtained and studied. Furthermore, semi-structured interviews were conducted with five senior employees, of which the collected data was manually transformed (coded) using a spreadsheet. With an inductive approach, principles of action design research were followed to build an improved costing system.

After the coding of the interviews' responses into themes, there was a clear indication that time was the main factor for each participant. The digital technology service firm's internal operations are all about time consumption and the profit that the specific service/department delivers. Therefore, each service that the firm provides for their clients differs, as it depends on what the specific client wants/requires from the firm. The study concluded that time-driven activity-based costing (TDABC) could be implemented as an alternative costing method in the digital technology service firm, by connecting it to their Enterprise Resource Planning (ERP) system. Based on the concluded research, it is therefore crucial for the firm to fully buy into the TDABC to ensure that the costing system is implemented successfully. What is also important is that the system will be much more beneficial, as digital costing will arise, which will enable the firm to save costs and reinvest it back into the firm.

Keywords: activity-based costing, digital technology, digital service firm, systems theory, timedriven activity-based costing 
Table of Contents

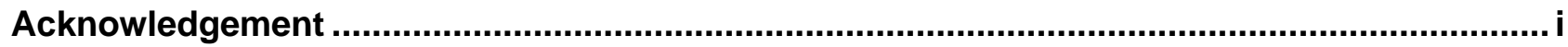

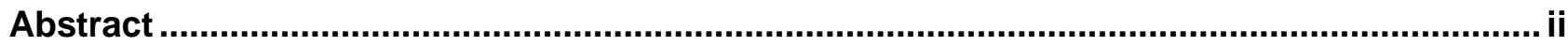

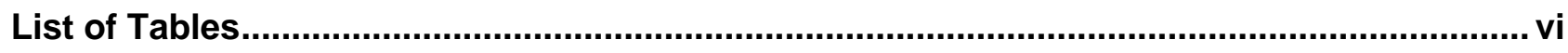

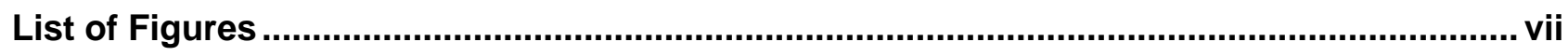

List of abbreviations: ...................................................................................................... viii

Chapter 1: Introduction .............................................................................................................

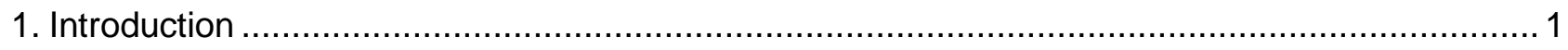

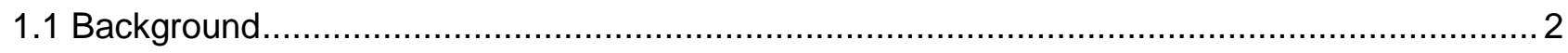

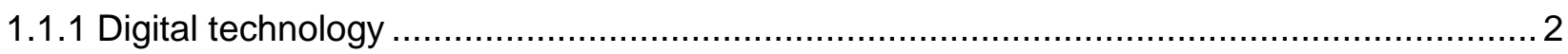

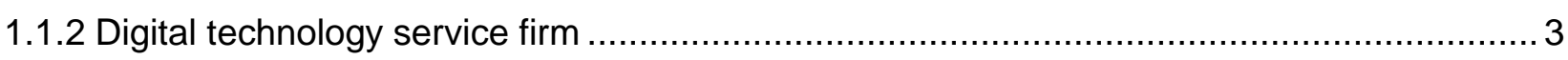

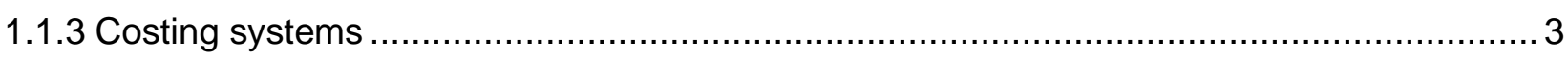

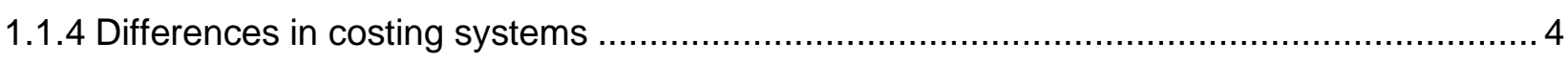

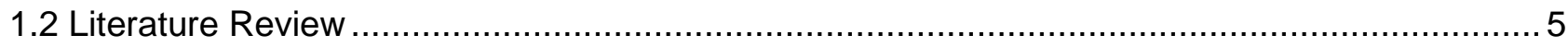

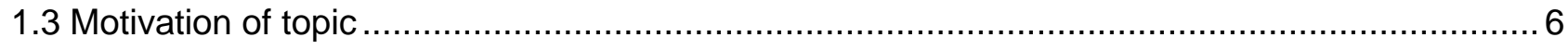

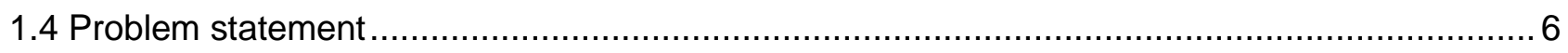

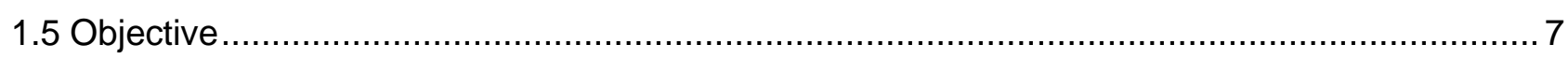

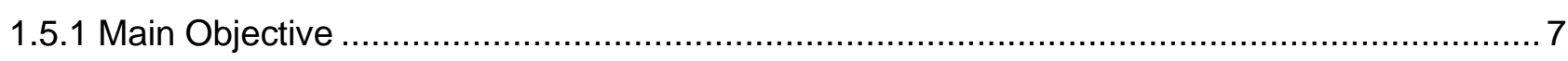

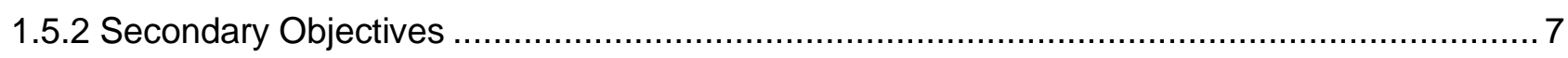

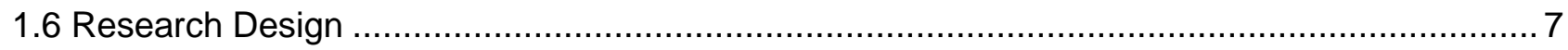

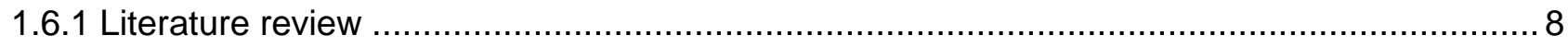

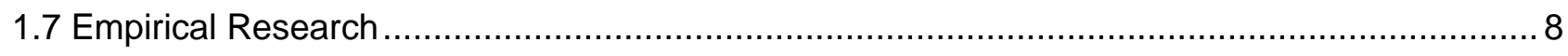

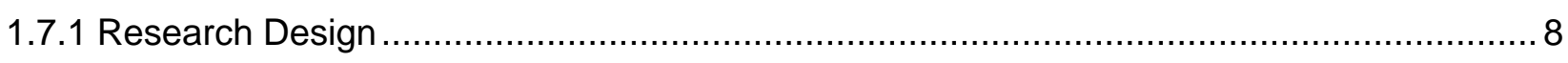

1.7.2 Population, sampling and data collection techniques ......................................... 9

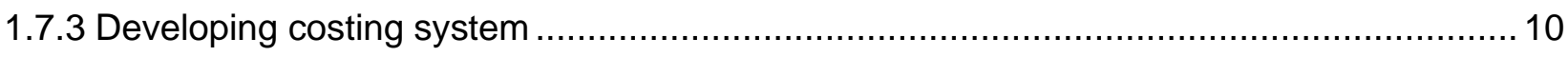

1.8 Paradigmatic assumptions and perspectives............................................................... 10

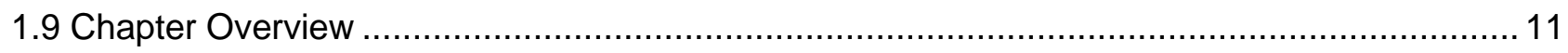

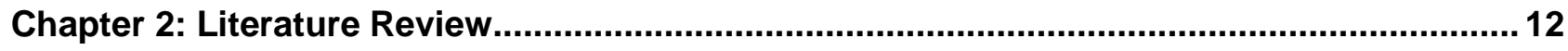

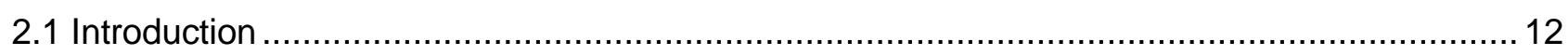

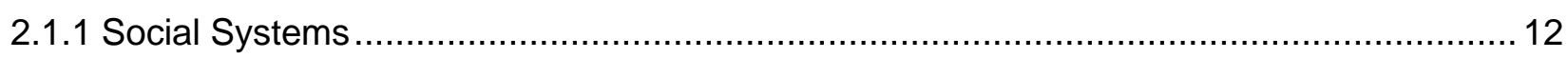

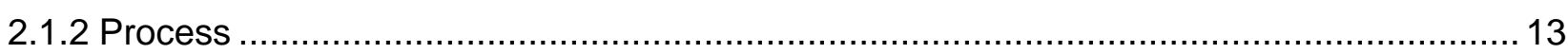

2.2 Nature of a Traditional Costing System (TCS) ................................................................ 14

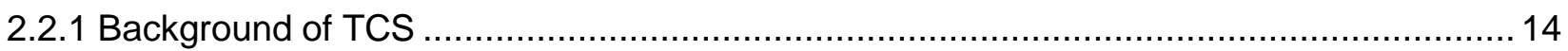

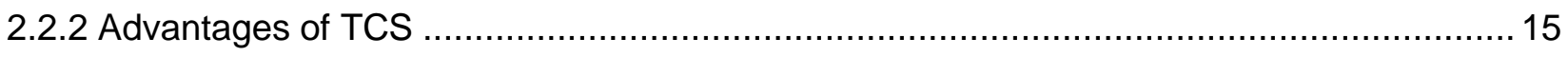

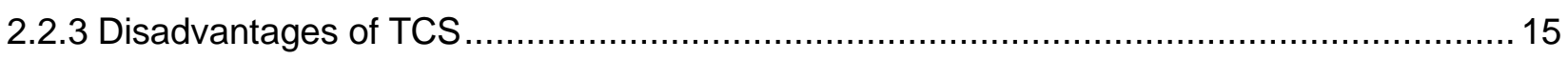

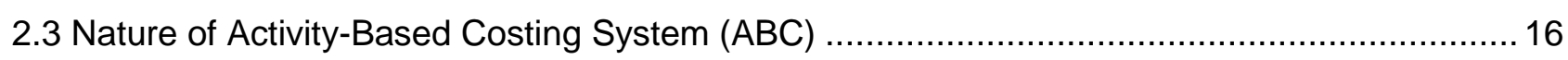

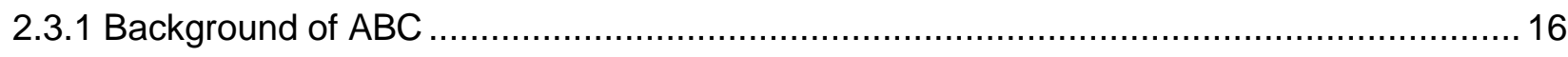

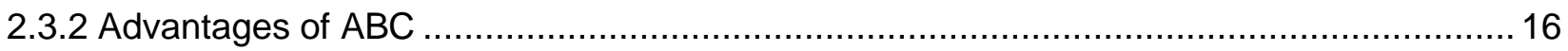




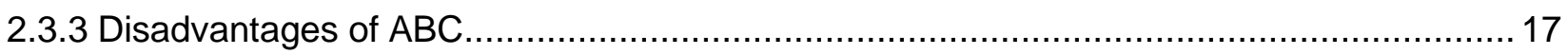

2.4 Nature of Time-Driven Activity-Based Costing (TDABC) …............................................. 18

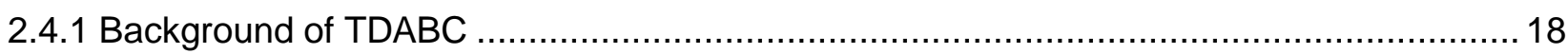

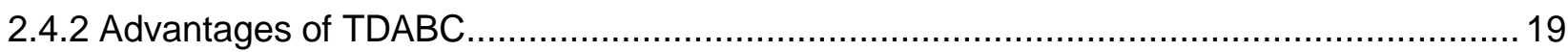

2.4.3 Disadvantages of TDABC ............................................................................... 19

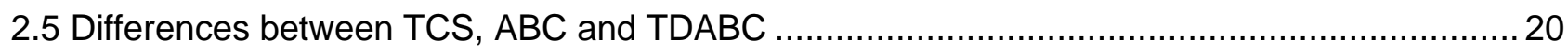

2.6 Previous studies on developing costing systems........................................................ 22

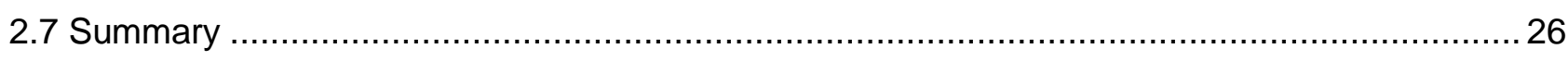

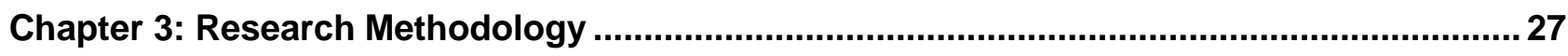

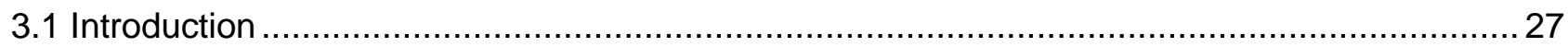

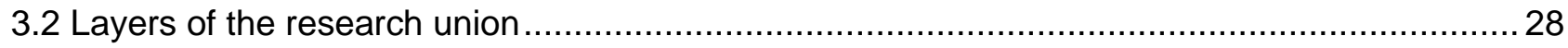

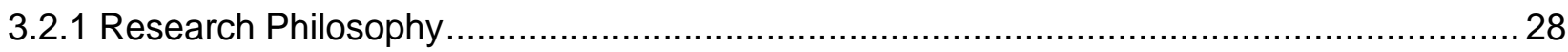

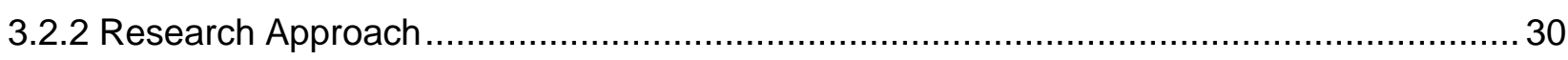

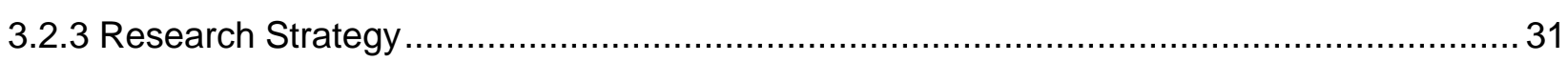

3.2.4 Research Method Choice .................................................................................. 33

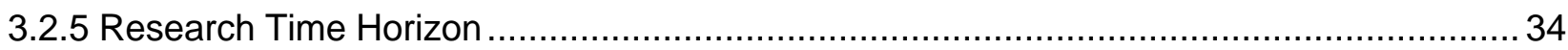

3.2.6 Research Techniques and Procedures ................................................................. 34

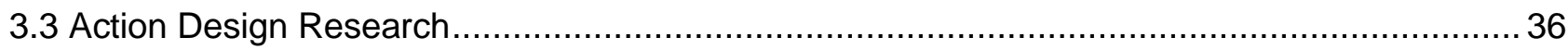

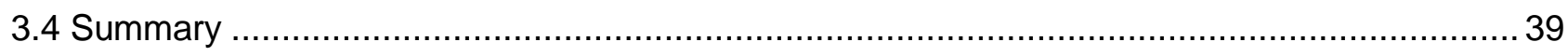

Chapter 4: Data Collection and Findings ............................................................................. 40

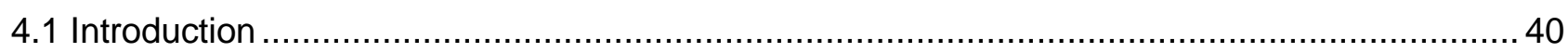

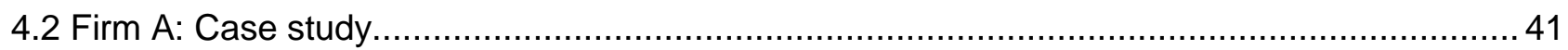

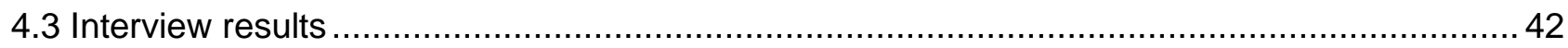

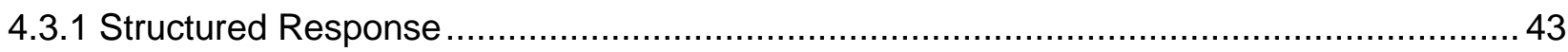

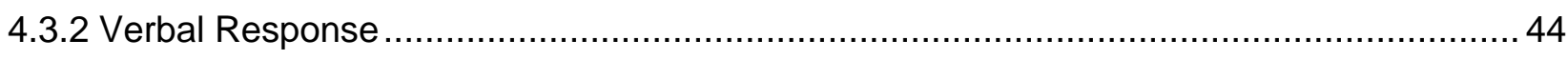

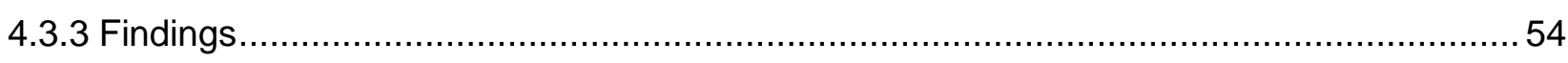

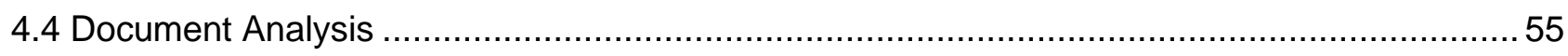

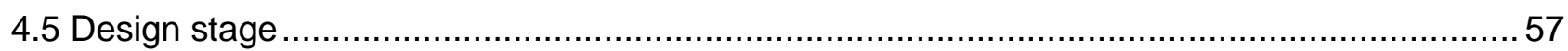

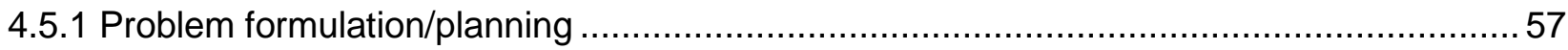

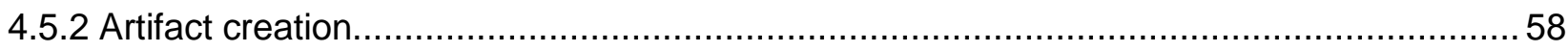

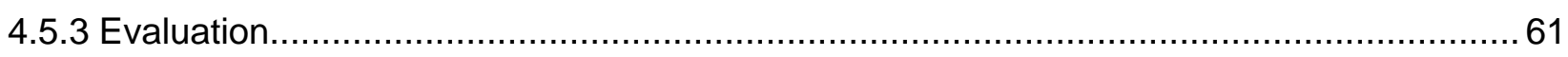

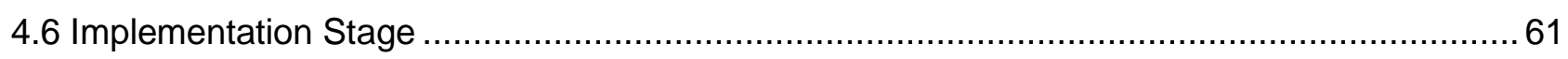

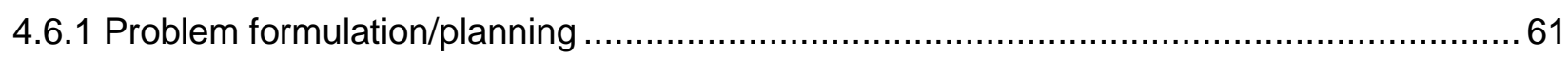

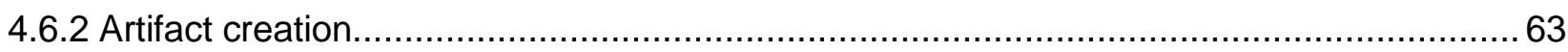

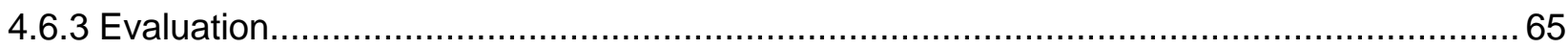

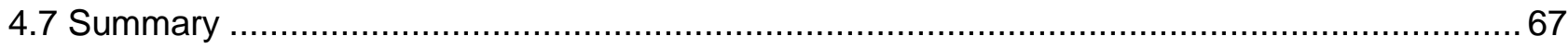

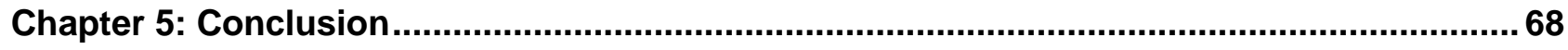

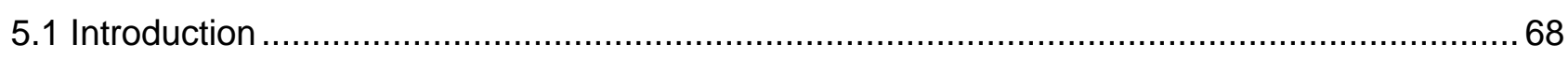

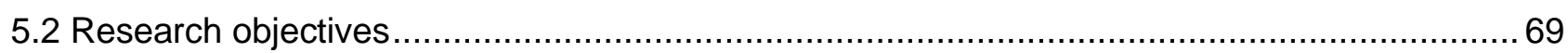




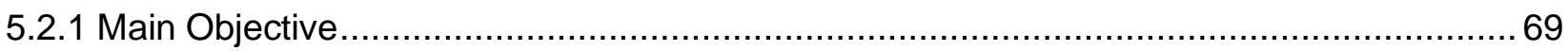

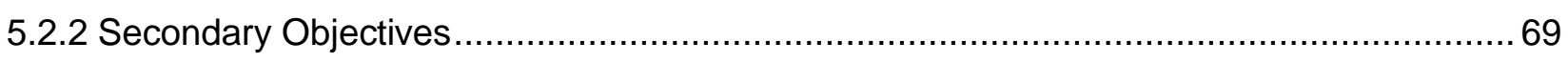

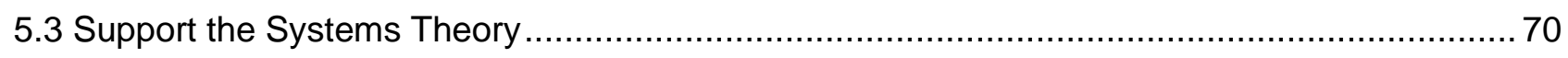

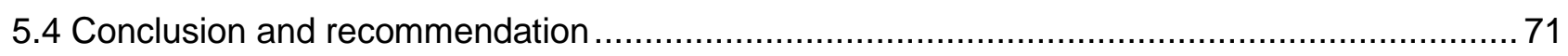

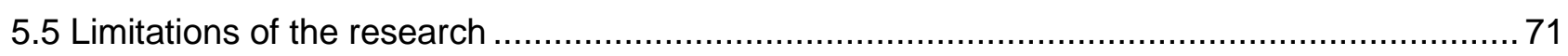

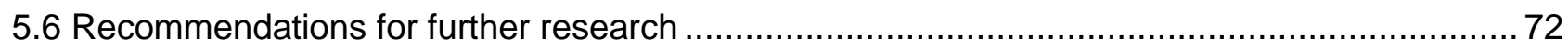

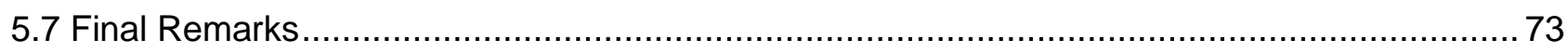

Referencing List........................................................................................................... 74

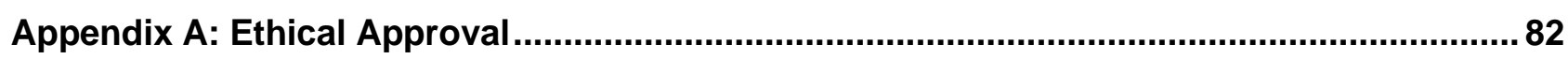

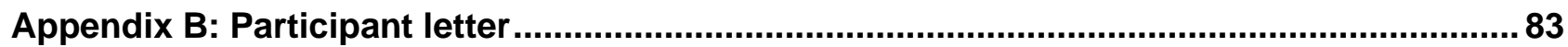

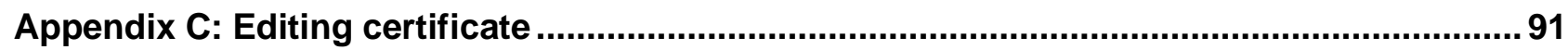

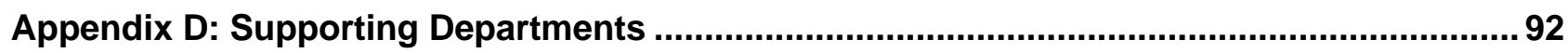




\section{LIST OF TABLES}

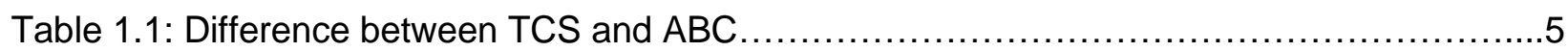

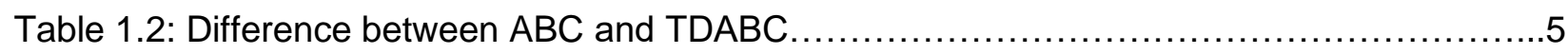

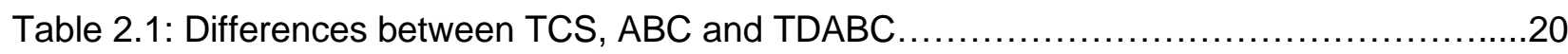

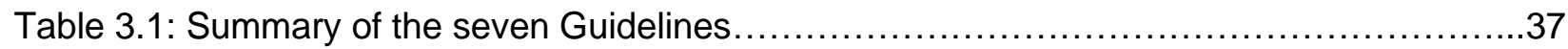

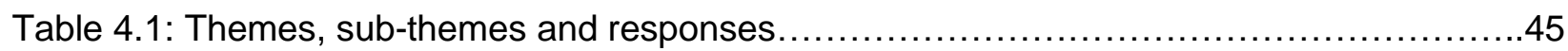

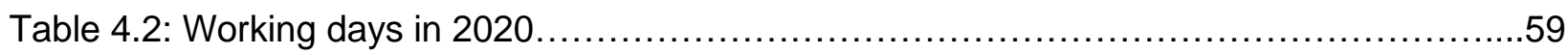

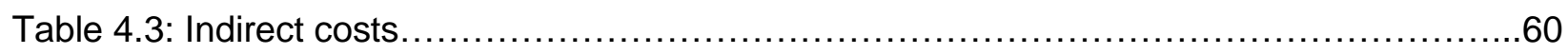

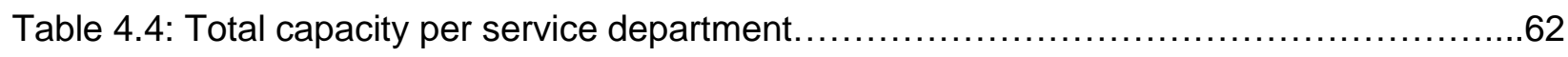

Table 4.5: Hours allocated to activities and management levels............................62

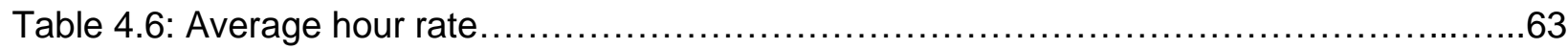

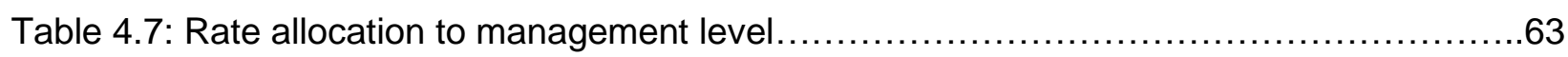

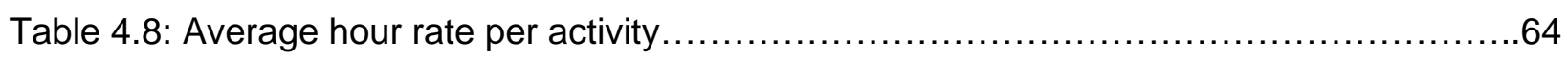

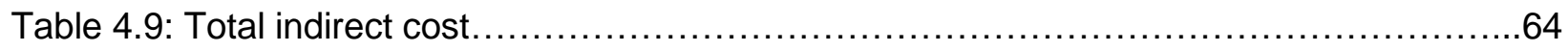

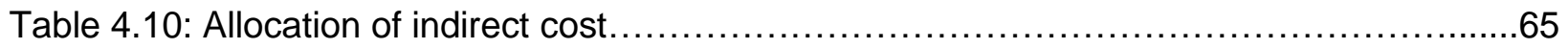

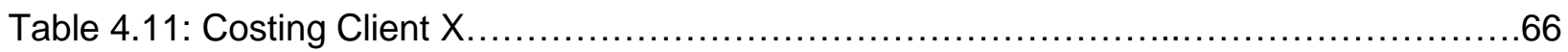




\section{LIST OF FIGURES}

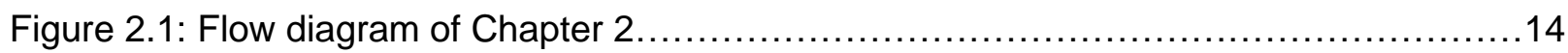

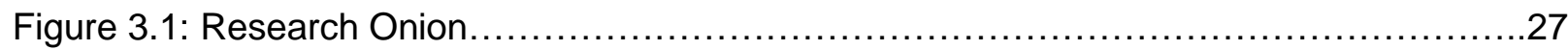

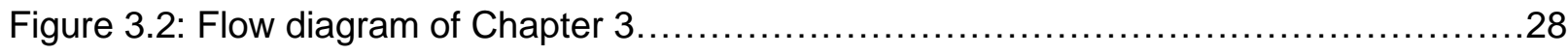

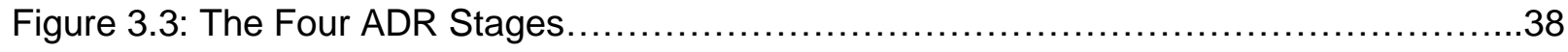

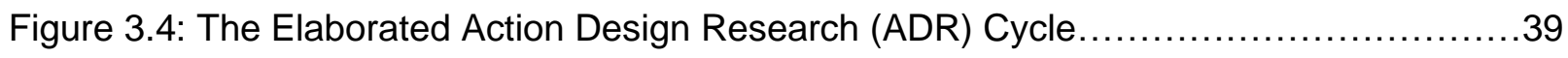

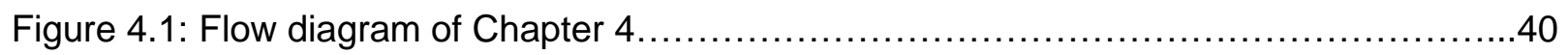

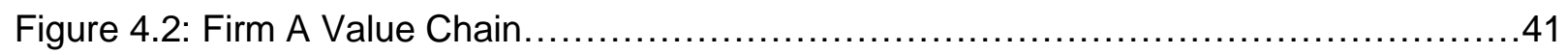

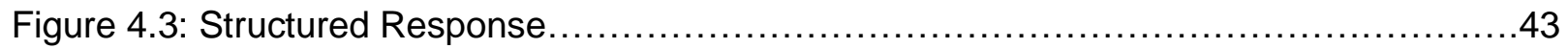

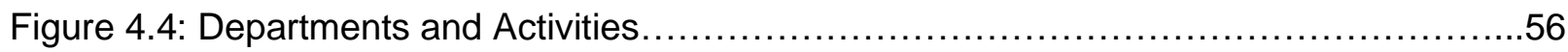

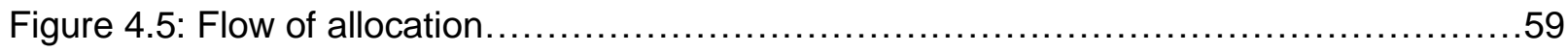

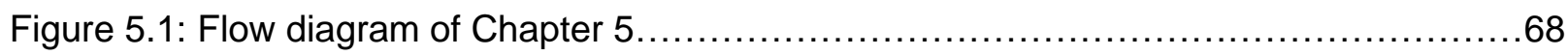




\section{LIST OF ABBREVIATIONS:}

ABC Activity-Based Costing

ABM Activity-Based Management

ADR Action Design Research

Al Artificial Intelligence

CIMA Chartered Institute of Management Accountants

ERP Enterprise Resource Planning

TCS Traditional Costing System

TDABC Time-Driven Activity-Based Costing 


\section{CHAPTER 1: INTRODUCTION}

\section{INTRODUCTION}

This study will investigate and develop a costing system for a relatively new, fast growing digital technology service firm, referred to as Firm A for purposes of the selected case study. Since both the traditional costing system (TCS) and the activity-based costing (ABC) systems vary in their respective levels of sophistication, Drury (2012:48) suggests that cost versus benefit criteria should be used to determine the level of sophistication when such a system is developed.

Although $A B C$ is generally regarded as superior to the TCS, the specific needs and operating environment of the investigated firm have to be taken into account. Consequently, many previous studies developed costing systems for various industries, for example in manufacturing (Van der Linde, 2011), agriculture (Viljoen, 2018), cash services (Nkuna, 2018), electricity supply (Ngcobo, 2019) and government departments (Stouthuysen et al., 2014; Bvumbi, 2017; Maluleke, 2019).

The value of this study is, however, that it investigated a digital service firm which operations are modern and unique when compared to other industries, and as such requires the development of a costing system on an equal level of sophistication.

This study will be conducted within the context of the systems theory of organisations. Kessler (2017:816) emphasises that, since most modern organisational theories may be regarded as systems theories, it should rather be viewed as a general paradigm. Its usefulness for this study is that it offers a broad overview for understanding change processes and the complexity thereof (Wicander, 2011). Understanding these processes will help to develop a new and appropriate costing system for Firm A.

The contribution of the study is therefore that it serves as an example of the development of a costing system in the context of the systems theory. In support of the relevancy of the above approach, it is worth noting that the Chartered Institute of Management Accountants (CIMA) recently updated their syllabus to include finance in a digital world with a focus on the use of digital technology (CIMA, 2019). Therefore, the development and implementation of a costing system and the impact of the digital world will influence the conventional role of financial management (Bhimani \& Bromwich, 2009). The costing system will help to optimise the company's use of digital costing, also known as cost management, which enables the freeing up of financial resources to be reinvested back into the company (Aguilar \& Ittner, 2018). 


\subsection{BACKGROUND}

This study will focus on some aspects that may impact the development of a costing system for a digital technology service firm, including the rapid growth in the application of digital technology, the history of costing systems, as well as the differences between the various costing systems. The aspects that are discussed below will form the background to the study.

\subsubsection{Digital technology}

Companies are adopting digital technology at a rapid speed, with business spending on technology transformation reaching an outstanding \$1.25 trillion in 2019 (IDC, 2018). Digital technology is expected to increase over the next five years, for the period 2017 to 2022 as the forecast period, at an annual compound growth rate of $16.7 \%$ (IDC, 2018). The result of the worldwide spending on digital technology indicates that it is becoming part of core business operating systems. According to a 2019 report, The Post-Digital Era Is Upon Us, approximately $79 \%$ of the more than 6,600 business and IT executives world-wide confirmed that Social, Mobile, Analytics and Cloud (SMAC) digital technology is part of their companies' fundamental technology pillar (Accenture, 2019).

According to Daugherty (2019), and supported by Aguilar and Ittner (2018), new technology for consideration in digital applications are the following:

- Distributed ledger technology (DLT): This category includes blockchain that uses cryptography, which enables different departments to have access to the same data.

- Artificial intelligence (Al): This is a group of technologies that involve a set of human behaviour including learn, sense, act and react.

- Extended reality (XR): A set of technologies which includes virtual reality and newly founded immersive technology that enables humans to interact, connect and engage naturally with technology.

- Quantum computing: This technology represents a new paradigm to assist and solve computational problems, as it provides quantum solutions for better cost-effective results for the business.

Noah (2019) argues that the future of financial management is embedded in the digital age. Technology emerged as the main driver of change, providing new insights into the generation of profits and the creation of wealth. Over and above the impact of digitalisation, Bhimani and Bromwich (2009) are of the opinion that it is in the best interest of businesses to anticipate what the future may require of them to remain competitive and relevant. This desired outcome is fully supported by Reynolds and Van der Poll (2015:126) and by Moorthy et al. (2012:13). The timeous adoption of digital technology will positively contribute to the maintenance and enhancement of business's participation in a highly competitive market. 


\subsubsection{Digital technology service firm}

Firm A is a global digital technology service firm in South Africa that offers software developing services. Founded in 2015, it has grown from a small firm based in South-Africa to an international firm. In 2017, the firm opened an office in the Netherlands and in 2018 they expanded to the USA. In terms of the $4^{\text {th }}$ Industrial Revolution, the firm has been recognised as the leader in the Internet of Things (IoT) industry in South-Africa.

Firm A creates interoperability, rapid deployment and technology agnostics across their clients' supply chain that enables them to have a deep insight into their value chain. This is because Firm A offers their clients real-time data feedback from a variety of resources by utilising inhouse systems (Firm's A website). Although Firm A is a digital technology service firm with its operations rooted in the innovative application of digital technology, it is not known to what extent they apply new technology in their accounting and cost management departments. Additionally, it is not known whether the current costing system is offering them the best possible value. This study will investigate the current costing system used at Firm $A$ and determine if it delivers optimum results, or whether a new costing system should be developed. An example of service (smart solution) that Firm A provides to clients is as follows: this solution integrates data from a building management, water metering, electricity metering and diesel tank monitoring system from a building. The reports are used by building managers to assess the performance of the building and to make decisions to improve building management. Fan coil units (FCU) are responsible for cooling. The data shows run-times and the heat at which the units run. Run-times enable predictive maintenance and can help to budget for expected maintenance activities in advance. The data obtained also enables decision makers to understand which models of these units perform the best. This informs decisions on which brands/models of equipment to invest in in future for optimal performance.

The data from the energy meters is trended to give total energy usage values and Rand values associated to usage. Energy usage is also split up by floor and by wing on each floor. The data enables decision makers to track usage, to measure billed usage against actual usage, to identify areas where electricity savings initiatives have been effective and ineffective and to identify areas to invest in to further reduce energy consumption. It enables insights to be drawn such as total usage, leak detection events, and total spent on water usage. Data can be used for billing verification, tracking against water saving targets and implementation of measures that save water and ultimately costs.

\subsubsection{Costing systems}

A costing system is a framework used by businesses to estimate the cost of their products for profitability analysis, inventory valuation and cost control (Jan, 2013). This view is independently 
supported by Chea (2011:4). The three costing systems are identified, namely TC, ABC and time-driven activity-based costing (TDABC).

During the early $20^{\text {th }}$ century, companies started to use what is known as the TCS for the allocation of overhead costs. Owing to its simplicity of use, it was the preferred costing system. The system worked well for businesses that used higher direct hours and manufactured mass volumes of products. This system changed in recent times due to two major reasons, the first of which is the increased competitiveness in the marketplace, and the second being the change in the cost structures of companies (Popesko, 2009).

ABC was developed during 1987 (Kaplan \& Bruns, 1987). The focus was on the production industry where the adoption of technology and productivity tools enabled companies to have a reduction in the relative proportion of the direct cost of materials and labour (Johnson \& Kaplan, 1987). However, it did impact negatively on indirect costs that have escalated. At the same time the global trend to automate production lines contributed to reduced labour cost, which is a direct cost, but resulted in increased maintenance cost, which is an indirect cost (Cooper \& Kaplan, 1991). CIMA's official terminology describes the ABC system as "an approach to the monitoring and costing of activities, which determines the resource consumption and costing of the final product. Resources are attached to activities and activities are attached to cost drivers" (CIMA, 2013:1).

A later development by Kaplan and Anderson (2004 and 2007) can be regarded as a new type of $A B C$, which is called TDABC. This new costing system was built to simplify the complexity of the activity cost calculation.

\subsubsection{Differences in costing systems}

In the tables below the general differences on the allocation of overheads between the different costings systems are summarised by Kaplan (2003), and by Mishra and Vaysman (2001). Table 1.1 shows the differences between the TCS and the ABC. 
Table 1.1: Difference between TCS and ABC

\begin{tabular}{|c|l|l|}
\hline & \multicolumn{1}{|c|}{ TCS } & \multicolumn{1}{c|}{ ABC } \\
\hline Overhead assigned & Single cost driver & Multiple cost drivers \\
\hline Optimal usage & When direct labour is a & $\begin{array}{l}\text { When technology is a } \\
\text { large portion of the } \\
\end{array}$ \\
& $\begin{array}{c}\text { large portion of the } \\
\text { product cost. }\end{array}$ & \begin{tabular}{l} 
Process driven \\
\hline Orientation
\end{tabular} \\
\hline
\end{tabular}

Source: Kaplan (2003)

Table 1.2 below is a summary that shows the difference between $A B C$ and TDABC.

Table 1.2: Difference between $A B C$ and TDABC

\begin{tabular}{|c|l|l|}
\hline & \multicolumn{1}{|c|}{ ABC } & \multicolumn{1}{c|}{ TDABC } \\
\hline Overhead assigned & Multiple cost drivers & Time-based driver \\
\hline Optimal usage & When technology is a & Delivering fast processing \\
& large portion of the & times and real-time \\
& reporting. \\
\hline Orientation & Process driven & Time driven \\
\hline
\end{tabular}

Source: Kaplan (2003); Mishra and Vaysman (2001)

\subsection{LITERATURE REVIEW}

Although a brief overview of literature is covered in the background of this mini-dissertation, some additional views will be discussed with specific reference to recently conducted research published in theses, dissertations and academic articles.

The topics of research done by Nkuna (2018), Stouthuysen et al. (2014), Van Der Linde (2011), Malukele (2019), Ngcobo (2019) and Bvumbi (2017) all relate to the reasons and benefits of implementing some version of $A B C$ to improve on what the TCS offered. The above studies cover a variety of industries including the public sector, private sector and parastatals. As mentioned by Chea (2011) and Jan (2013), businesses need to analyse profitability, value inventories and ultimately control cost for beneficial reasons and therefore need a suitable and/or improved costing system. There is clear indication from the literature review that $A B C$ is globally a well-established and researched field favoured by various industries.

Phan et al. (2014:787) assert that ABC is not a whole system by itself. It is a system that is part of the activity-based management (ABM). The Consortium for Advanced ManufacturingInternational (CAM-I) defined ABM as "a discipline that pays attention to the management of activities with the target to continuously improve client and the profit received value when providing such a value." This view supports the findings from studies done by Reynolds and 
Van der Poll (2015:126), and Cardos and Pete (2011:158), who both pointed out that ABM uses $A B C$ information as performance indicators to inform management decision-making action. ABM achieves its objectives through two complementary approaches, namely strategic-based management, and operational activity-based management.

Research done by Mackenzi (2014) found that companies with the intension to revolutionise their decision-making processes are migrating towards the adoption of a digital culture. Thinking processes and the way people share knowledge are changing, as new technologies and algorithms are evolving in the business environment and influence decision-making choices (Danbolt et al., 2015).

The above brief literature review provided insight into the tactical application of cost management and its evolution to strategic importance. The world is changing fast and companies have to respond accordingly by thinking digitally. As knowledge is evolving faster, and performance reporting are required more often, companies need to process more information at a quicker pace to translate it into useful data that allows for strategic decisionmaking. The researcher could not find research aimed at developing a costing system for a digital technology service firm, which is therefore the identified knowledge gap for this study.

\subsection{MOTIVATION OF TOPIC}

The motivation for the research is to determine if the current costing system used by Firm $A$ offers reliable costing information. This emanated from the view expressed by the firm's Chief Executive Officer (CEO) that the current costing mainly focuses on firm growth - which was a priority in the past - without giving consideration to the appropriateness of the costing system.

It is therefore unknown whether the current costing system is appropriate and adding value. The aim of this study is thus to investigate and determine whether an alternative costing solution would be desirable for Firm A. Should an alternative be proposed, it should provide management with relevant and up-to-date information about the costing of their services to enable them to make informed business decisions.

\subsection{PROBLEM STATEMENT}

Over the past 18 months, Firm A has expanded into 14 different industry sectors and grown from 8 to 200+ staff internationally. The firm competes with similar service providers in a highly competitive global market. Increasing global competitiveness has forced many organisations to render services at a competitive cost and price. In order to achieve the above, service providers such as Firm $A$ has to adopt a more proactive approach to cost management, rather than being reactive when they are already facing financial challenges (Aguilar \& Ittner, 2018). The allocation of overheads and direct cost should be reviewed to establish where resources 
are not optimally utilised.

None of the studies covered in the literature review investigated the implementation of a costing system in a digital service firm. Therefore, this study cannot duplicate or adjust an existing system previously designed. A completely new system needs to be developed. The costing system will however be based on the general guidelines that were developed and enhanced by authors such as Kaplan and Bruns (1987), Johnson and Kaplan (1987) and Kaplan (1998), and as also presented in current literature by Drury (2012).

A digital technology firm may face different challenges with their costing systems and/or processes compared to a conventional business. The question arises what a costing system for a digital technology service firm should look like.

\subsection{OBJECTIVE}

This research intends to achieve the following objectives, split between a main and secondary objectives.

\subsubsection{MAIN OBJECTIVE}

The main objective of this study is to investigate the current costing model of a digital technology service firm to determine where and how it can be improved. The information obtained will be used in identifying the components for the development of a costing system that will improve cost management and provide data for informed decision-making in an effort to maximise value and to remain relevant in the market.

\subsubsection{SECONDARY OBJECTIVES}

To reach the main objective, the following secondary objectives were formulated:

- Review the literature on the nature and benefits of TCS, ABC and TDABC (Chapter 2);

- Discuss and select an appropriate research methodology and design to reach the primary objective (Chapter 3);

- Collect, review and analyse data obtained through interviews, document analysis and observations from the digital service firm to develop a new costing system (Chapter 4);

- Conclude the study and indicate how the results of this study may benefit Firm A (Chapter $5)$.

\subsection{RESEARCH DESIGN}

The research design comprises a literature review and an empirical study. 


\subsubsection{LITERATURE REVIEW}

A literature review is a summary of studies done on previous research topics. It assists with understanding how the investigations were executed, described, summarised, objectively evaluated and clarified to solve a research problem (Mouton, 2015:87).

The literature review comprised of research on the various cost accounting systems (also referred to as costing systems) and a review of the processes and/or systems used by a digital technology firm compared to a traditional business. This will be described in more detail in Chapter 2. The review included sources of information from scholarly articles, books, magazines, internet resources, relevant dissertations/theses and other sources relevant to this area of research. A literature review should enumerate, describe, summarise, objectively evaluate and clarify the previous research.

In this study the focus will be on the identification of existing costing systems, the impact of new technology on cost management and the subsequent benefits thereof.

\subsection{EMPIRICAL RESEARCH}

\subsubsection{Research Design}

The objective of a research design is to clearly explain the procedures used when conducting a study with the main purpose to assist in finding answers to research questions (Mouton, 2015:49). Collis and Hussey (2003:2) have a similar view by defining research as a systematic process of creating a better understanding and knowledge through investigation. Saunders et al. (2007), on the other hand, define research as the application of different approaches in order to collect reliable data or information.

Typically, objectives of research include the review and thorough investigation of existing knowledge with the ultimate purpose to find solutions and/or recommendations to a specific research problem. Either a qualitative, a quantitative or a mixed (or multiple) method of investigation can be adopted (Ivankova et al., 2016:312). Qualitative research is where "the issue of quality can be addressed by dealing with issues of validity, practicality and effectiveness." (Maree, 2016:40). It consists of research that results from real-world situations where the "phenomenon of interest unfolds naturally" (Patton, 2002:39).

A case study approach was followed and conducted owing to Firm A being a digital service firm which operations are modern and unique. Yin (2009:23) defines a case study research method "as an empirical inquiry that investigates a contemporary phenomenon within its real-life context; when the boundaries between phenomenon and context are not clearly evident; and in which multiple sources of evidence are used". 


\subsubsection{Population, sampling and data collection techniques}

In cases where the decision-making of firms is strongly centralised within a small core team, the researcher's discernment and judgement is used to find people who can, and are willing, to provide the information by virtue of knowledge or experience (Lewis \& Sheppard, 2006). The purposive sampling method was an appropriate choice for this study. It is also known as judgement sampling, allowing the deliberate choice of informants as participants owing to their qualities, knowledge and experience. It is a non-random sampling method that does not need to be based on theories or a set number of informants, but it has a specific purpose in mind (Lewis \& Sheppard, 2006; Maree \& Pietersen, 2016:198). The primary decision makers of the firm that is central in the case study, are the ones with the ability to understand the allocation of costs (e.g. overheads and direct costs) and the impact thereof on business operations. These participants are the senior management and some members of the finance department.

The majority of research referred to in the literature review was conducted in businesses, and the samples consisted of selected senior managers and managers as the research population. The methods used included in-depth interviews and qualitative data analysis which were conducted using the interview transcripts of the open-ended questions. A similar approach was followed in this study and incorporated adapted questions from existing or previously used questionnaires in the studies discussed above (Bvumbi, 2017; Maluleke, 2019).

Qualitative data was gathered through conducting semi-structured face-to-face interviews, with the use of previous research study's questionnaires by adjusting and contextualising the questions. In addition flowcharts, hierarchal charts and documents (e.g. general ledger, cost reports and budgets) were obtained for analysis. The interviews included the following personnel from Firm A:

\footnotetext{
- $\quad$ Chief Technology Officer

- Chief Financial Officer

- Head of Project Management

- Head of Human Resource Management

- Head of Financial Management
}

Interviews with the above-mentioned participants were conducted, recorded and analysed. Content analysis was applied to help identify possible cost relationships in the collected qualitative data. The insights gained helped the researcher to improve the level of understanding regarding the status of the current costing system. 


\subsubsection{Developing costing system}

In this study, the above-mentioned approach supports the use of qualitative analysis over quantitative analysis. It enabled the researcher to achieve the research objectives and to answer the research question. An action design science approach was used to build the new costing system (artifact). The ADR process model is a four-stage approach (Hevner et al., 2004) that includes:

\section{Diagnosis stage \\ 2. Design stage \\ 3. Implementation stage \\ 4. Evolution stage}

The ADR guideline and systems theory was used to develop a new costing system for the digital technology service firm.

\subsection{PARADIGMATIC ASSUMPTIONS AND PERSPECTIVES}

Different research designs are impacted by the different research methodologies (McKerchar, 2008:6). According to Howell (2013), methodology can be defined as the strategy that the researcher uses to work on the research project. Saunder's et al. (2007) research onion will be used to develop, identify and apply the research methodology and design.

In this study, the researcher was a participative observer during the interviewing sessions and the collection of qualitative data. Interpretivism allows the researcher to interpret elements of the study by allowing integration of human interest. According to an interpretivist approach, it is important for the researcher, as a social actor, to appreciate differences between people and to attempt to make sense of what people perceive as reality (Bisman, 2010:12). An interpretivist approach was applied in this research to cater for the differences in perceptions amongst the respondents.

Theoretical framework is the "blueprint" or guideline for a research study (Osanloo \& Grant, 2016). It is a framework based on a pre-existing theory in a specific field of inquiry that is related or that reflects the concept of a study. Inductive reasoning was the appropriate process used through observation and the data received to reach the conclusion.

The systems theory was used as the theoretical framework in the development of a costing system. Boulding (1956) describes systems theory as a level of theoretical model-building which lies somewhere between the highly generalised constructions of pure mathematics and the specific theories of specialised disciplines. A key aspect of empirical work using the systems 
theory is that the organisation is reviewed as a whole and not through its parts (Stewart, 1996:25).

\subsection{CHAPTER OVERVIEW}

\section{Chapter 1: Introduction and background}

The purpose of this chapter is to introduce the study that is going to be researched and to provide an overall view of what the research entails. This chapter also includes the background of the study and the problem statement that led to the motivation of the topic. Also included is a summary of the research methodology and the set objectives to be achieved.

\section{Chapter 2: Literature Review}

This chapter aims to present previous research conducted on the topic of costing methods (TCS, ABC, TDABC). The chapter also outlines the history and development of the various costing systems and includes an overview on the impact of new digital technologies in costing systems.

\section{Chapter 3: Research Methodology}

The discussion and selection of the research methodology were dealt with in this chapter and will include the actions required to achieve the primary objectives. This includes the use of design science research (DSR) guidelines to develop a new costing system for the digital technology service firm.

\section{Chapter 4: Data collection and Findings}

This chapter introduces the empirical study conducted on the selected case study and the findings thereof, namely to investigate the firm's current costing system through interviewing, observation and questionnaires presented to the research participants. This enabled the researcher to collect and analyse data obtained from the firm to develop the costing system.

\section{Chapter 5: Conclusion}

This chapter concludes the study and shows how the results support the systems theory. The conclusion also indicates to what extent the main objectives have been achieved, namely to develop a costing system for a digital technology service firm. 


\section{CHAPTER 2: LITERATURE REVIEW}

\subsection{INTRODUCTION}

This chapter aims to achieve the secondary objective, as set out in Chapter 1, by reviewing the literature on the nature and benefits of TCS, ABC and TDABC (section 2.2; 2.3; 2.4). Furthermore, the differences in costing systems (section 2.5) will be discussed. Previous studies done on developing a costing system in various industries will be reviewed and used as a benchmark (section 2.6). This should indicate the type of system to be considered for the development of a suitable costing system for use by a digital technology service firm. It is interesting to take note that research done by Mackenzi (2014) found that many organisations outside the digital technology industry, with the intension to revolutionise their decision-making processes, are increasingly migrating towards the adoption of a digital culture.

The use of the systems theory as a contextual framework is an underexplored theory in management studies, seemingly owing to its integrated approach (Teece, 2018:366). Therefore research needs to cover this theory to clarify key components and their inter-relationships. The dynamic capabilities of this framework hold a promise to improve the long-term sustainability for managers (Teece, 2018:367). Systems thinking is going to be applied within the systems theory approach to identify elements that are related towards a suitable costing system. Although systems thinking is not systems theory, the two share common elements (Richmond, 1994).

Checkland (1981:12) argues that "systems thinking starts from noticing the unquestioned Cartesian assumption: namely that a component part is the same when separated out as when it is part of the whole". Furthermore, the systems theory indicates that the scientific method is incomplete but valid to use. The two pillars of systems theory, social and process, strongly indicate the relevance of this theoretical framework in this study.

\subsubsection{Social Systems}

Social systems are complex and do not serve one purpose (Hutchins, 1996). Hutchins further believes that the individual perspectives on the purpose of a system could not be set or attached to it, due to its diversity of perspectives. The purpose of using a costing system could differ when you ask different people their reason for applying it in a business. For instance, the CEO of a firm might believe that a costing system is merely a tool to calculate the cost and to be used for budgeting purposes. On the other hand, the cost accountant might believe that a costing system becomes more important to make appropriate decisions and for planning and control (EduPristine, 2017). Therefore, the observer defines the purpose of the system. 


\subsubsection{Process}

The second pillar of systems theory is that one should understand the ways and purpose of a system to understand the process as a whole. To understand the Hutchins (1996) framework, the systems theory should be divided into the following four components:

- the description of the aspects/nature of the specific system;

- the explanation of how the components in the system interacts;

- the determination whether the system is effective;

- the Identification to which extent the systems can function in practice, compared to the ideal jointed use of archival material.

These four components will be touched on and evaluated applying the costing systems (TCS, $A B C$ and $T D A B C$ ) throughout this chapter. It clarifies the applicability of the systems theory when developing a costing system for a digital technology service firm.

Thinking processes and the way people share knowledge are changing as new technologies and algorithms evolve in the business environment, influencing decision-making choices (Danbolt et al., 2015). In a study by Gunasekaran et al. (2005:524), it is highlighted that the development of new costing systems is important to businesses, due to the following reasons:

- inaccurate product costing systems;

- current costing systems are not improved or updated;

- large sections of costs are presented by overheads; and

- insufficient non-financial information.

Therefore, the need for the development of new and suitable costing systems has become essential in the present-day business environment for each specific industry (Gunasekaran et al., 2005). 
Chapter 2 is constructed in accordance with the diagram below and flows as follows:

Figure 2.1: Flow diagram of Chapter 2

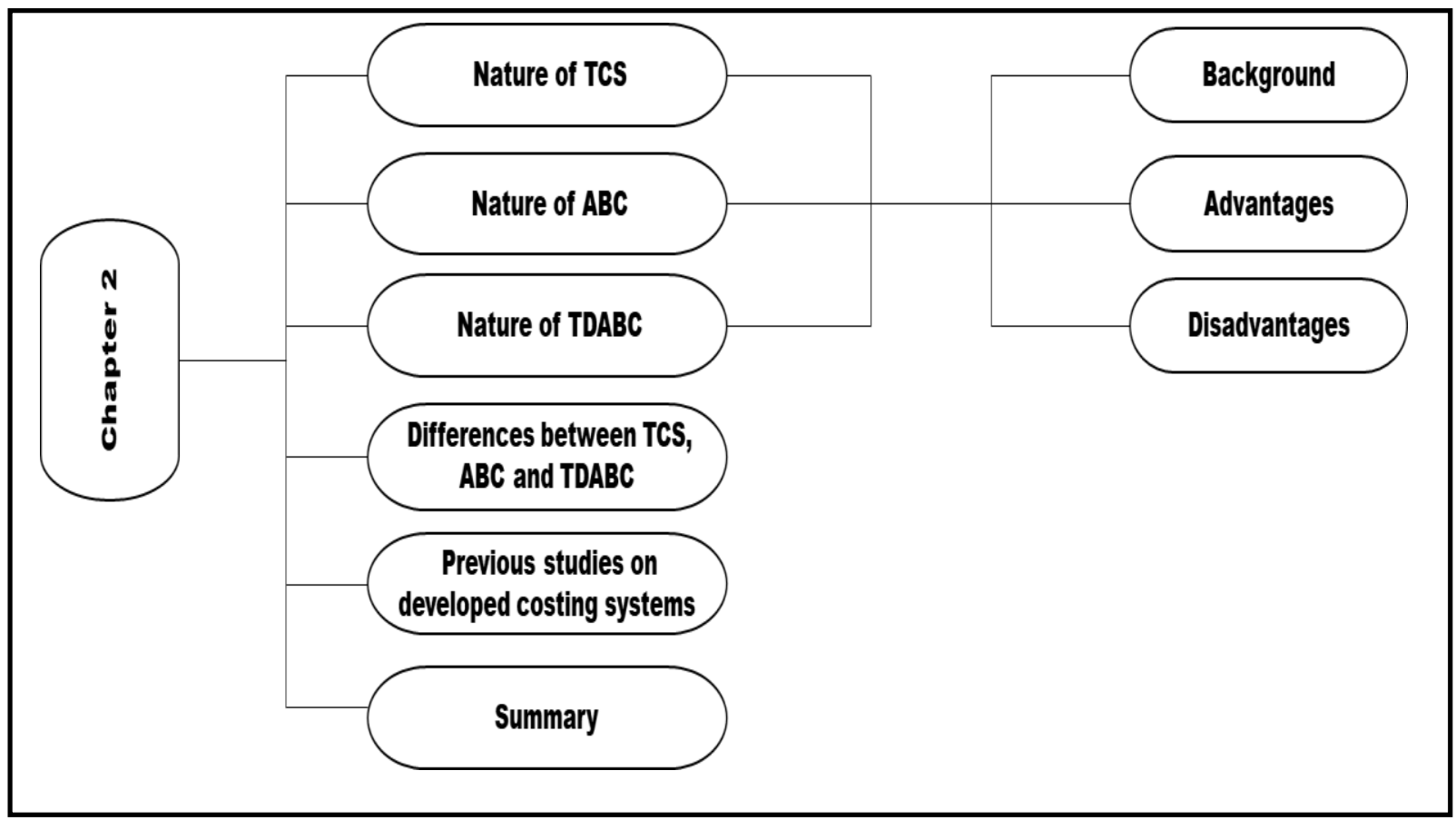

Source: Own Research

\subsection{NATURE OF A TRADITIONAL COSTING SYSTEM (TCS)}

\subsubsection{Background of TCS}

During the early $20^{\text {th }}$ century, companies started to use what is known as the TCS for the allocation of overhead costs (Popesko, 2009). It was the preferred costing system due to its simplicity of use. The system worked well for businesses that used higher direct hours and manufactured mass volumes of products. This system has changed in recent times due to two major reasons, the first of which is the increased competitiveness in the marketplace, and the second being the change in the cost structures of companies (Popesko, 2009).

Chea (2011:4) points out that the system works well for companies that use a high level of direct hours to manufacture mass volumes of items, and which mostly incur variable costs. Popesko (2009) points out that the TCS uses only one predetermined overhead that often resulted in inaccurate calculation of product costs.

Both Accenture (2019) and Aguilar and Ittner (2018) are of the opinion that this approach has changed over the past three decades, mainly due to the revision and change in the cost structures of companies, the increased competitiveness in the marketplace that increasingly became a global playfield, and the benefits of new digital technology. 


\subsubsection{Advantages of TCS}

According to Gaille (2018) and Woodruff (2019) there are still some advantages to consider in TCS, such as the following:

- It indicates accurate cost figures when using large production volumes.

- The implementation cost is cheap.

- It develops external reports which is simpler to understand for the outsider.

- It uses one pre-determined overhead rate (simplicity).

- It streamlines accounting processes when produce only one product.

- It is best used by manufacturers that only produce one or a few different products.

As indicated above, there are still some advantages that a firm should be aware of and not just write-off the option of TCS. The two main advantages of TCS are cost-effective costing and the use for mass production, where the single cost driver is sufficient.

\subsubsection{Disadvantages of TCS}

Glad and Becker (1996) identified a number of disadvantages regarding traditional costing:

- There is no relationship to labour costs of labour hours, indicating that labour is irrelevant.

- Service-related costs increased significantly, whereby these services were previously nonexistent.

- Customer-related costs such as discounts, promotions, distribution and finance are not related to the product's cost objects.

Furthermore, Lind (2001) declares that the major disadvantages of TCS can be summarised as follows:

- cross-subsidisation of costs in products;

- the cost of technology (capital) being handled as a period cost;

- $\quad$ specific groups of products costed and not processes; and

- TCS being volume based, and therefore hard to accurately account for different products since it is volume based (Lind, 2001:78).

The above disadvantages show that firms face difficult times when using TCS, as the cost information is not accurate and transparent when the firm tries to calculate the specific product cost. TCS is regarded as a one-dimensional system due to its fixed costing structure on products (not services) and therefore struggles to adapt to the application of new technology. 


\subsection{NATURE OF ACTIVITY-BASED COSTING SYSTEM (ABC)}

\subsubsection{Background of $A B C$}

ABC was developed during 1987 (Kaplan \& Bruns, 1987). The focus was on the production industry where the adoption of technology and productivity tools enabled companies to have a reduction in the relative proportion of the direct cost of materials and labour (Johnson \& Kaplan, 1987). However, it did impact negatively on indirect costs, which had escalated. At the same time, the global trend to automate production lines contributed to reduced labour cost which is a direct cost, but resulted in increased maintenance cost, which is an indirect cost (Cooper \& Kaplan, 1991). CIMA's official terminology describes the ABC system as "a tool for monitoring and costing of activities, which determines the resource consumption and costing of the final product. Resources are attached to activities and activities are attached to cost drivers" (CIMA, 2013:1).

Further research done by Kaplan (1991) almost 30 years ago showed that companies had developed a reduced appetite for the application of TCS owing to the adoption of ABC systems. Reynolds and Van der Poll (2015:126) found that companies viewed the ABC system to be a more accurate management tool to calculate the product cost of the product and/or service. Ittner et al. (2002) and Cagwin and Bouwman (2002:39) support the view of Reynolds and Van der Poll's (2015:126), mentioned above, but add that the ABC system can also be identified as another useful tool for management decision-making towards the enhancement of the profitability for the company. Turney (1996) asserts that managers are enabled to have a better picture and overview of how revenues are generated and resource consumption is utilised. His support for using $A B C$ systems in businesses as a method of measuring the cost and performance of activities grew in popularity (Krishnan, 2007:75).

Wegmann (2009) and Back et.al. (2000:48) agree that $A B C$ is considered to be a more advanced cost allocation system than TCS. ABC enables the classification of more direct costs with the goal to reduce the amount of indirect cost by allocating cost drivers to the cost pools (also referred to as activities). Wegmann (2009) attributes the above to the fact that ABC uses smaller cost pools that would help develop a more precise optimal allocation. The cost drivers are then allocated to these activities, linked to other cost items such as products or services (Wegmann, 2009; Back et al., 2000:48). Kowsari (2014) indicates that there is evidence that an increasing number of companies are using enterprise resource planning systems to change their costing systems.

\subsubsection{Advantages of $A B C$}

Srinivasan (2008:6) states that $A B C$ includes the following advantages: 
- $\quad A B C$ assists to enhance the forecasting of total cost of services, products and unused capacity.

- Flexibility is offered owing to the visibility of processes and activities.

- It helps to identify and review the most costly activities to increase efficiency and restructuring options.

- $\quad A B C$ enables management to understand the business and the environment it operates in and to identify gaps and areas of possible research towards improved products at different costs.

- It includes all the benefits that are connected to output based budgeting.

Cokins and Căpuşneanu (2010:15) also add that, when using ABC (cost drivers), the following advantages may occur:

- Improving enterprise performance: $A B C$ can obtain reliable and accurate information that enables better decision-making for the long-term.

- Improving staff and manager awareness: When the managers and staff are aware of the benefits and knowledge of the ABC system, performance may improve.

- Eliminating costs: Non-value-adding activities could be eliminated by removing the root cause, as the cost drivers contribute to this effect.

From the above, it can be concluded that the utilisation of $A B C$ offers various benefits in both the products and/or service industries. When the firm accepts the responsibility, time and cost to implement the costing system, then additional information could be retrieved and used (including budgeting and forecasts). The major advantages of $\mathrm{ABC}$ are the accurate information that could be used by businesses for long-term decision-making, because $A B C$ is a resource consumption model and calculates costs that are related to cycle time (Campbell, 1995).

\subsubsection{Disadvantages of $A B C$}

Mahal and Hossain (2015:71) argue that the following disadvantages of the ABC system are as follows:

- Managers find the $A B C$ process and the implementation thereof challenging owing to the complexity of collecting high volumes of data, and the activity measures over and above the checking and interpretation thereof.

- The complexity of the process makes decision-making a lengthier process, compared to conventional processes.

- There may be resistance to change from TCS to ABC, owing to managers being comfortable to use the TCS and therefore resistant to change from TCS to ABC to run the firm's operations.

- Using $A B C$ there is a risk that high volumes of unrelated data could be misinterpreted. 
- Managers' discretion to allocate all costs to cost objects allows for potential over- or underestimating of costs, which may result in incorrect pricing.

- Management often hesitates and/or fails to implement the outcomes of the new ABC system that demotivates the implementation team.

- The input and support from external consulting firms are not always sufficiently reliable, owing to them not fully understanding the firm's operations.

- There may be resistance by employees to accept the new $A B C$ system, owing to uncertainty and fear that it could impact negatively on their roles and responsibilities.

Kaplan and Anderson (2003) discovered reasons why firms discontinued the use of an ABC system: i) it did not accomplish the complications and complexity of their operations; ii) the implementation took too long; and iii) the implementation and maintenance costs were too high.

The ABC could be problematic, as stated above, because the system is more complex than the other costing systems. Therefore management may fail to implement the costing system and keeping it updated. The system makes it unpleasant for the manager/employee, because it requires full commitment, responsibility and is timely. Although $A B C$ offers quality accurate information, it requires time and can therefore not always provide information immediately if market dynamics require businesses to make quick decisions (Campbell, 1995).

\subsection{NATURE OF TIME-DRIVEN ACTIVITY-BASED COSTING (TDABC)}

\subsubsection{Background of TDABC}

A later development by Kaplan and Anderson $(2004,2007)$ can be regarded as a new type of $A B C$, which is called TDABC. This new costing system was built to simplify the complexity of the activity cost calculation.

TDABC is meant to make implementation easier, therefore it requires the manager to predict the capacity of the supplied resources as a percentage of the total capacity (Szychta, 2010:53). This system changed the model of collecting data. The ABC system uses the different cost drivers that are allocated to activity cost pools to calculate the cost, whilst TDABC focusses on activity times and on the modification of activity cost calculation (Wegmann, 2009; Back et al., 2000:48; Kaplan \& Anderson, 2007:23). The view consists of different types of resources, e.g. materials, labour and outside services. Time is the primary and main cost driver of TDABC by allocating resource costs directly to objects (e.g. transactions, orders, finished products, services and clients) through the use of time. The advantage of using TDABC over the use of $A B C$ is the possibility to leave out the difficult step to assign resource costs to the activities prior to allocating them to the different cost objects (Kaplan \& Anderson, 2007:23). 


\subsubsection{Advantages of TDABC}

According to Kaplan and Anderson (2007), TDABC has the following advantages:

- Inefficiencies in the process are identified.

- Quick and easy implementation to calculate the unit cost.

- Modifications are easy and allow for alignment with operational changes.

- $\quad$ TDABC can be applied to all firms in the same industry.

- The cost calculation process is simpler.

- Relevant and adequate information is provided for managerial decision-making.

- It can be implemented and applied in any industry or firm with complex cost objects.

The major benefits of TDABC are that it is quick to implement and easy to understand, costing processes are simple and it is very economical (Demeere, et al., 2009). TDABC enables managers and third parties to easily interpret and understand the whole system, therefore making it comfortable to use due to its compatibility and simplicity.

\subsubsection{Disadvantages of TDABC}

The disadvantages of a TDABC system, according to Szychta (2010:57), are the following:

- The calculations of TDABC are mainly based on estimates.

- Misrepresentation of the outcomes of the activity cost calculations could potentially inform inadequate decision-making.

Furthermore Namazi (2016) states that TDABC includes drawbacks such as:

- It lacks the ability to identify activities in the first step of implementation.

- It lacks data accuracy.

- $\quad$ Limitations of decision-making may occur due to behaviour issues.

The disadvantages of the TDABC system do not outrank the advantages. The TDABC is based on estimates, therefore decision-making can be difficult due to the estimated time that could lead to inaccurate results. 


\subsection{DIFFERENCES BETWEEN TCS, ABC AND TDABC}

Table 2.1 below exhibits the differences between TCS, ABC and TDABC.

Table 2.1: Differences between TCS, ABC and TDABC

\begin{tabular}{|c|c|c|c|}
\hline & TCS & ABC & TDABC \\
\hline $\begin{array}{l}\text { Overhead } \\
\text { Assign }\end{array}$ & Single cost driver. & Multiple cost driver. & Time-based driver. \\
\hline Orientation & Cost driven. & Activity driven. & Time driven. \\
\hline Cost Pools & $\begin{array}{l}\text { Accumulate costs into } \\
\text { departmental cost } \\
\text { pools. The costs are } \\
\text { heterogeneous, that } \\
\text { indicates the costs of } \\
\text { huge processes and } \\
\text { are overall not caused } \\
\text { by a single factor. }\end{array}$ & $\begin{array}{l}\text { Accumulate costs into activity } \\
\text { cost pools that are connected } \\
\text { to specific activities or } \\
\text { business processes. The cost } \\
\text { pool is mostly caused by a } \\
\text { single factor such as the cost } \\
\text { driver. }\end{array}$ & $\begin{array}{l}\text { TDABC identifies } \\
\text { resource pools to be } \\
\text { used with the } \\
\text { collaboration of an } \\
\text { effective ERP system. }\end{array}$ \\
\hline $\begin{array}{l}\text { Allocation } \\
\text { Bases }\end{array}$ & $\begin{array}{l}\text { TCS allocates cost } \\
\text { using volume-based } \\
\text { allocation bases such } \\
\text { as units, direct labour } \\
\text { hours or machine } \\
\text { hours. }\end{array}$ & $\begin{array}{l}\text { ABC allocates costs to } \\
\text { products, services and } \\
\text { specialised cost objects that } \\
\text { are extracted from the activity } \\
\text { cost pools using allocation } \\
\text { bases. These allocation } \\
\text { bases should correlate with } \\
\text { cost drivers of the activity } \\
\text { costs. }\end{array}$ & $\begin{array}{l}\text { TDABC allocates costs } \\
\text { through using time } \\
\text { equations that show the } \\
\text { time involved in a } \\
\text { particular process. }\end{array}$ \\
\hline $\begin{array}{l}\text { Costs } \\
\text { Hierarchy }\end{array}$ & $\begin{array}{l}\text { TCS estimates all the } \\
\text { costs of a firm that are } \\
\text { driven by product } \\
\text { volumes or services } \\
\text { delivered. }\end{array}$ & $\begin{array}{l}\text { The ABC Indicates some } \\
\text { costs not recognised by the } \\
\text { number of units produced, } \\
\text { thus allowing for non-linearity } \\
\text { of costs within the firm. }\end{array}$ & $\begin{array}{l}\text { TDABC identifies the } \\
\text { cost centers to be used } \\
\text { and therefore } \\
\text { calculates the capacity } \\
\text { cost rate. }\end{array}$ \\
\hline $\begin{array}{l}\text { Cost } \\
\text { Objects }\end{array}$ & $\begin{array}{l}\text { TCS only focuses on a } \\
\text { single cost object such } \\
\text { as the units of products } \\
\text { or services. }\end{array}$ & $\begin{array}{l}\text { ABC mainly focuses on } \\
\text { estimating the costs of } \\
\text { different cost objects such as } \\
\text { customers, suppliers, } \\
\text { batches, product lines and } \\
\text { operational processes. }\end{array}$ & $\begin{array}{l}\text { The cost objects are } \\
\text { the estimated unit time } \\
\text { required to perform the } \\
\text { activities in the specific } \\
\text { cost centres. }\end{array}$ \\
\hline $\begin{array}{l}\text { Decision- } \\
\text { Making }\end{array}$ & $\begin{array}{l}\text { Over-costing and } \\
\text { under-costing problems } \\
\text { occur due to the } \\
\text { inadequate line-up } \\
\text { between the cost } \\
\text { drivers and allocation } \\
\text { bases. }\end{array}$ & $\begin{array}{l}\text { With the ability to connect } \\
\text { allocation bases with cost } \\
\text { drivers, it provides more } \\
\text { accurate cost information that } \\
\text { enables better decision- } \\
\text { making. }\end{array}$ & $\begin{array}{l}\text { TDABC enables } \\
\text { accurate representation } \\
\text { of under- or over- } \\
\text { capacity by showing } \\
\text { capacity in units of } \\
\text { time. }\end{array}$ \\
\hline Cost Control & $\begin{array}{l}\text { The cost control is seen } \\
\text { as a departmental } \\
\text { practice rather than a } \\
\text { cross-function practice. }\end{array}$ & $\begin{array}{l}\text { Providing cost reports that } \\
\text { summarise the firm's } \\
\text { activities, the ABC system } \\
\text { enables management to } \\
\text { prioritise and budget more } \\
\text { precisely. }\end{array}$ & $\begin{array}{l}\text { Managers could easily } \\
\text { adapt and update } \\
\text { capacity cost rates } \\
\text { when the conditions } \\
\text { change in the } \\
\text { operations. }\end{array}$ \\
\hline Price & $\begin{array}{l}\text { To a degree cheap to } \\
\text { implement and } \\
\text { maintain. }\end{array}$ & $\begin{array}{l}\text { To a degree expensive to } \\
\text { implement and maintain. }\end{array}$ & $\begin{array}{l}\text { TDABC is very } \\
\text { economical as the } \\
\text { system is easy to } \\
\text { maintain and to be }\end{array}$ \\
\hline
\end{tabular}


\begin{tabular}{|l|l|l|}
\hline & & $\begin{array}{l}\text { updated (compatibility } \\
\text { with ERP system). }\end{array}$ \\
\hline
\end{tabular}

Source: Kaplan (2003); Granof et al. (2000); Stout and Propri (2011)

The differences between TCS, ABC and TDABC, as stated above in the table, show that each costing system functions differently but still aims to achieve the same objective. TCS uses a single cost driver that allocates costs in a departmental cost pool that is usually used in mass production in identical products, whereby $A B C$ accumulates cost into activity cost pools that are connected with specific activities, and TDABC uses resource pools through a time cost driver. TDABC is a more advanced costing system when it is in collaboration with an ERP system, because it could easily be updated and more simplified than the original $A B C$ system. $A B C$ uses multiple cost drivers in the different activity cost pools, which indicates that $A B C$ is very accurate and specific.

TCS focuses only on one cost object, for instance the units of products, whereas ABC focuses on different cost objects that depend on the type of activity it is in. With TDABC the cost objects are the estimated unit time that is required to perform in the specific cost centre. The cost objects obviously depend on the type of firm/industry to decide how its internal operating system works, when having to decide which costing system would be the most appropriate. When decision-making on the different costing systems comes to the front, $A B C$ is the most accurate due to the different activities that it takes into consideration. However, TDABC is also effective and represents accurate under- or over-capacity. TCS indicates that over-costing and undercosting problems occur due to the inadequate allocation of the single cost driver that is used in general.

The cost control in TCS is seen as a departmental practice, whereby ABC could get cost reports from the different activities in a summarised format. The edge that TDABC gets on the cost control is that managers could easily adapt and update the cost rates that occur when conditions or processes change. TCS could be seen as easy to implement and cheap, but lacks performance in terms of accuracy. $A B C$ is the most expensive due to its different activities and multiple cost drivers that make it complex to understand, but it could be seen as the most accurate costing system. TDABC can be considered as cheap and economical, because the system is easy to maintain and to update. The compatibility makes TDABC very useful, because when it is used with an ERP system, the costing system would function on its optimal performance. As stated above, due to the differences in the costing systems, it is essential to determine in which environment the firm operates when implementing a specific costing system. 


\subsection{PREVIOUS STUDIES ON DEVELOPING COSTING SYSTEMS}

The topics of research that was completed by Nkuna (2018), Stouthuysen et al. (2014), Van Der Linde (2011), Malukele (2019), Ngcobo (2019) and Bvumbi (2017) all relate to the reasons and benefits of implementing some version of $A B C$ to improve on what the TCS offered. The above studies cover a variety of industries including the public sector, private sector and parastatals. As mentioned by Chea (2011) and Jan (2013), businesses need to analyse profitability, value inventories and ultimately control costs for beneficial reasons, and therefore need a suitable and/or improved costing system.

A study done by Van Der Linde (2011) confirms that in a competitive market, such as the fertilizer industry, the actual cost of the final product or output is of critical importance. Activities which are not adding value to the process must be identified and eliminated or else costs will be inflated unnecessarily. Competitors will get a higher market share and sales because they might be able to enter the market at a lower price, due to the fertilizer market being extremely pricesensitive, and end-users being willing to accept the lower monetary value offer if the quality is equivalent.

Further refinements in TCS to reduce the relative proportion of the direct cost of materials and labour, known as ABC, were developed by Johnson and Kaplan (1987). The allocation of cost to each activity, based on its current use of resources, and assigning objects to a cost-to-cost basis on their use of the applicable activities, was value adding (Turney, 1996).

A study was done by Maluleke (2019) on the South African Social Security Agency (SASSA) for implementing an $\mathrm{ABC}$ as an alternative system to the TCS. This study points out that budget constraints triggered the review of the allocation of administrative costs. The higher the administration cost, the less social grants could be paid. The administrative cost was calculated for each type of social grant, using TBC, ABC and TDABC, and the results were compared thereafter. Although the study was done on a pilot project basis, the results highlighted that the use of $A B C$ was the most beneficial solution.

A paper on a time-driven activity-based costing framework for a South African cash service company (presented at the International Business Conference (IBC), illustrated how a business in the cash services industry had to reshape itself, as the company no longer had the monopoly in the industry (Schutte et al., 2019). New entrants to the market resulted in increased competition and prompted the business to improve its efficiency and costing without sacrificing quality. In the study, the results from both TCS and $A B C$ were compared. $A B C$ revealed superior results and highlighted cross subsidy between departments. It supported views by 
Wegmann (2009) that businesses require more precise information to accurately cost products and services to improve resource planning, elimination of waste and inform management decision-making.

Over time new types of $A B C$ have emerged. TDABC was developed by Kaplan and Anderson (2004) and changed the model of collecting data on activity times and on the modification of activity cost calculation. Studies done by Stouthuysen et al. (2014) and Ngcobo (2019) independently applied the TDABC with success in sectors directly and indirectly connected to the public sector.

A pilot study done by Stouthuysen et al. (2014) was triggered by the residents of a medium sized town in Belgium who questioned the high costs of accessing public swimming pools. The public was reluctant to pay high entrance fees for using public facilities, as they believed it should be covered by tax contributions for public services. The onus was on management to reduce costs, but also to produce a costing system that would allow users to understand the cost structure. A detailed process was followed to identify swimming-pool activities, task contents, types of customers and organisational structures. The required time to perform each activity was measured with a stopwatch over a three day period. Costs were allocated to each of these activities, based on the time it took to be completed. The outcome of the TDABC provided sufficient information for management to calculate accurate price brackets for access to swimming pools. The transparency that TDABC offered resulted in the public being more willing to pay the entrance fee.

The application of an activity-driven operational cost accounting framework to an electricity distributing company in South Africa generating, transmitting and distributing electricity was evaluated in a study by Ngcobo (2019). The long-term strategy of the company was to improve sales and to add neighbouring countries to their customer base as a growth initiative. However, their more immediate focus was to stabilise the company and to expand capital infrastructure investment. It was a priority for the company to identify options to reduce costs, but was hampered by the lack of a reliable accounting system. Ngcobo's study showed that, at the time of the study, the company was using a "3-factor" formula to allocate overhead costs. This comprised average employee costs, revenue and net assets. It was established that there was distorted information on costs owing to the fact that there was no direct correlation between cost behaviour and cost estimation. The solution that was developed for the company followed Kaplan and Anderson's (2004) TDABC model for the manufacturing industry. The current costing system of the company was compared to that of TDABC. The results between the two costing methods revealed:

- Under-absorption of overheads in departments with a low 3-factor formula, and 
- over-absorption where the 3-factor formula was high.

The result was distortion in the financial reporting and the possible misrepresentation of costs. Cost management decisions were potentially compromised and at a risk of informing poor cost management decision-making. The study proved that TDABC was an improvement to the existing costing method being used. One of the company's objectives was to become a low cost electricity producer, therefore the required information was needed to be factual and relevant to inform cost saving initiatives without losing value.

Lelkes (2009) claims that, in most instances, TDABC has been analytically proven to be as accurate as $\mathrm{ABC}$.

There seems to be limited research done on suitable or preferred costing systems for digital technology service firms, although there is clear indication from the literature review that $A B C$ is globally a well-established and researched field favoured by various industries. This study used previous studies that recommended costing systems (such as $A B C$ and TDABC) as a foundation to develop a suitable costing system for a digital technology service firm.

According to Accounting for Management (2020), there are three types of service department costing methods:

1. Direct method: The service departments are divided into the operational departments based on the measurement they consume from the service departments. This method is very simple and easy to execute, but can be seen as less accurate as the reciprocal method as it does not consider the interdepartmental services.

2. Step-down method: Each service department firstly allocate their cost to all the other service departments. Thereafter the secondary allocation allocates the new total costs to the different operational departments.

3. Reciprocal method: The reciprocal includes the interdepartmental services and also uses the simultaneous equations technique as a method of departmental cost allocation. This method is more accurate than the direct and step-down method, as it takes into account all the interdepartmental services. However, the downside of this method is that it is very complex in comparison to the other two methods.

Typical activities identified in ABC (including its modification models) could be directly linked to the cost drivers, and thereafter identifying the category of cost hierarchy (Akyol et al., 2007:136). It is not always easy or possible to assign costs to products/services, and therefore the cost hierarchy provides a guideline towards a type of cost driver:

- $\quad$ For every unit in production, unit-level drivers indicate the inputs increase/rise. 
- For each batch that is produced, batch-level drivers indicate the required alterations to the inputs.

- For specific products that are being produced, product-level drivers will indicate the required inputs of resources.

- For the production of services/facilities, facility-level drivers will inform the production process.

Akyol et al. (2007:136) clarifies that $A B C$ and its activities could make use of the various level drivers to positively connect the production cost to its production type; thus the user can easily understand how the product is produced, how much time the product/service needs to successfully finish an activity and how much resources are required to achieve the task.

Phan et al. (2014:787) assert that ABC is not a holistic system by itself, it is a system that is part of activity-based management (ABM). This view supports the findings from studies done by Reynolds and Van der Poll (2015:126) and by Cardos and Pete (2011:158) who both pointed out that $A B M$ uses $A B C$ information as performance indicators to inform management decisionmaking action. ABM achieves its objectives through two complementary approaches, namely strategic-based management, and operational activity-based management.

The role of cost management has become increasingly crucial in the identification and supply of distinctive financial information. It informs strategic direction and the implementation of viable technological applications (Bhimani \& Bromwich, 2009). Research done by Noah (2019) supports the above statement by mentioning that digital technology is regarded as a key driver of change for companies and their financial functions.

According to Aguilar and Ittner (2018), it is generally accepted that the term cost management refers to the calculation of product costs on the one hand and the reduction of current expenses on the other hand. The concept of digital costing was created to deliver a flexible and accessible tool to address the need of cost optimisation. The term digital costing should be understood as a concept, meaning how digital technology can be applied to transform cost management. Moorthy et al. (2012:13) indicate that, over time, the digital world has evolved to be flatter and that this development has a direct impact on how companies are doing business. Business has become more volatile and it is increasingly challenging to find new opportunities of competitive advantage. It has become increasingly important for firms to have high-quality decision-making capabilities if they want to remain participants of successful, sustainable businesses in future.

A critical finding of a survey done by Deloitte (2019) showed that the information systems used to support high quality cost management decision-making is a key element to a company's success to remain competitive. The survey confirmed that companies who achieved their cost targets and saved more money, were the ones who used new digital technologies. These 
technologies had a direct impact on the accuracy of forecasting and budgets. Another finding by Deloitte (2019) was that companies that were able to both cut costs and increase revenues were the ones that utilised new technologies instead of attempting to improve the existing technologies and processes.

Several new key elements in the technology environment have been developed for use in digital technology solutions (Daugherty, 2019), including Al, stochastic modelling, robotic process automation, predictive analytic, DLT and quantum computing. Therefore, the digital technology solutions have changed the business environment drastically - as indicated in Chapter 1. Al provides brand new insights that companies did not have before and which management can take advantage of. It delivers a lot more than what was originally anticipated in terms of information to transform businesses (Aguilar \& Ittner, 2018).

Lessons learned from the literature review is that the costing systems (TCS, ABC and TDABC) are well established as a researched field, although limited research has been done in a digital technology service environment and a suitable/preferred costing system in this environment. In this environment, digital technology is mainly used and is evolving day after day.

\subsection{SUMMARY}

The aim of this chapter was to address the secondary objective, as was set in Chapter 1 and in the chapter overview (page 11), namely to review the literature on the nature and benefits of TCS, ABC and TDABC.

The three costing systems (TCS, ABC and TDABC) were compared and analysed to identify the best option for the digital technology service firm. TCS was highlighted as a cheaper and easier way to implement and to maintain than ABC. TCS mainly focuses on the mass production of products that are identical, but lacks performance in terms of accuracy. The shortcomings of TCS led to the development of $A B C$ as an alternative costing model. $A B C$ is an activity driven system that uses activity cost pools and allocates a specific cost driver to them. Therefore accurate cost allocation of overhead costs provides better costing information for decisionmaking. Although $\mathrm{ABC}$ delivers accurate information, it is costly and time consuming for a firm. TDABC was developed, making it possible and simple for service firms to use, as it only uses time as a cost driver. This costing system reduces time consumption, which leads to overall cost saving. TDABC may be suitable to be implemented for the digital technology service firm to enable better performance and to improve digital costing/cost management. The use of new digital technology would improve the digital costing effect and increase cost savings, thus freeing up resources to reinvest back into the firm.

The next chapter, Chapter 3, will present the research methodology. 


\section{CHAPTER 3: RESEARCH METHODOLOGY}

\subsection{INTRODUCTION}

This chapter aims to achieve the secondary objective, as set in Chapter 1, namely to discuss and select an appropriate research methodology and design. Furthermore, in this chapter, the discussion and selection of the research methodology will be dealt with, including the actions required to achieve the primary objective.

Kothari (2004:8) defines research methodology as a comprehensive process of finding a solution for a research problem. The methods that are going to be used will be discussed and motivated to address the research problem. The researcher should understand the process and the principles of how to scientifically find a solution for a problem. Kothari (2004:23) further describes research as the search of knowledge and a skill of investigation, and could also be defined as a systematic and scientific search for a detailed/precise topic. Mouton (2015:56) adds that the research methodology focuses on the research process and the use of different tools and procedures. Therefore, different techniques and methods of collecting data and data analysis are used in the research method that a researcher chooses for interpretation (Creswell, 2014:295).

To understand the research process, the research onion developed by Saunders et al. (2007) was be applied. The research onion was developed to understand the research process and consists of the following six categories: philosophies, approaches, strategies, method choices, time horizons and techniques/procedures. Each category in the research onion was used to complete the research methodology. In Figure 3.1 the research onion is illustrated.

Figure 3.1: Research Onion

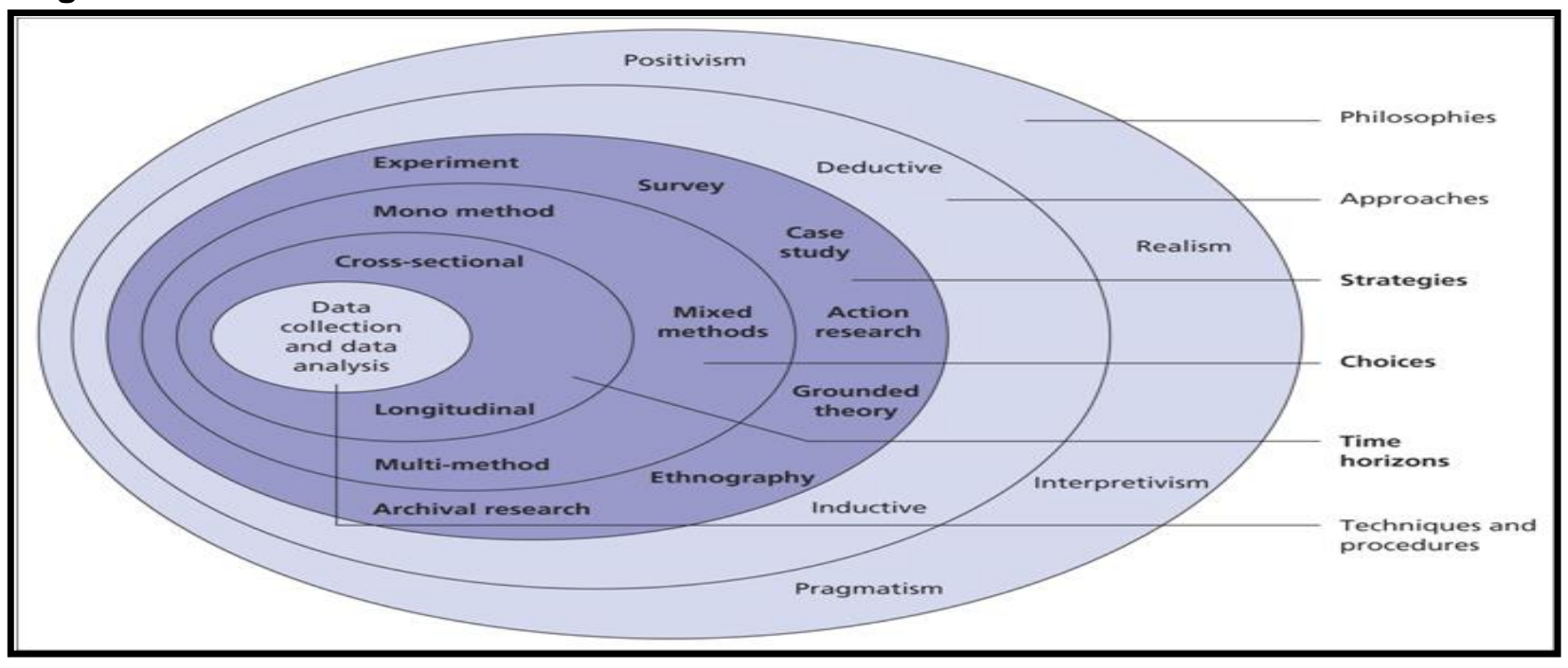

Source: Saunders et al. (2007) 
Chapter 3 is constructed in accordance with the diagram below and flows as follows:

Figure 3.2: Flow diagram of Chapter 3

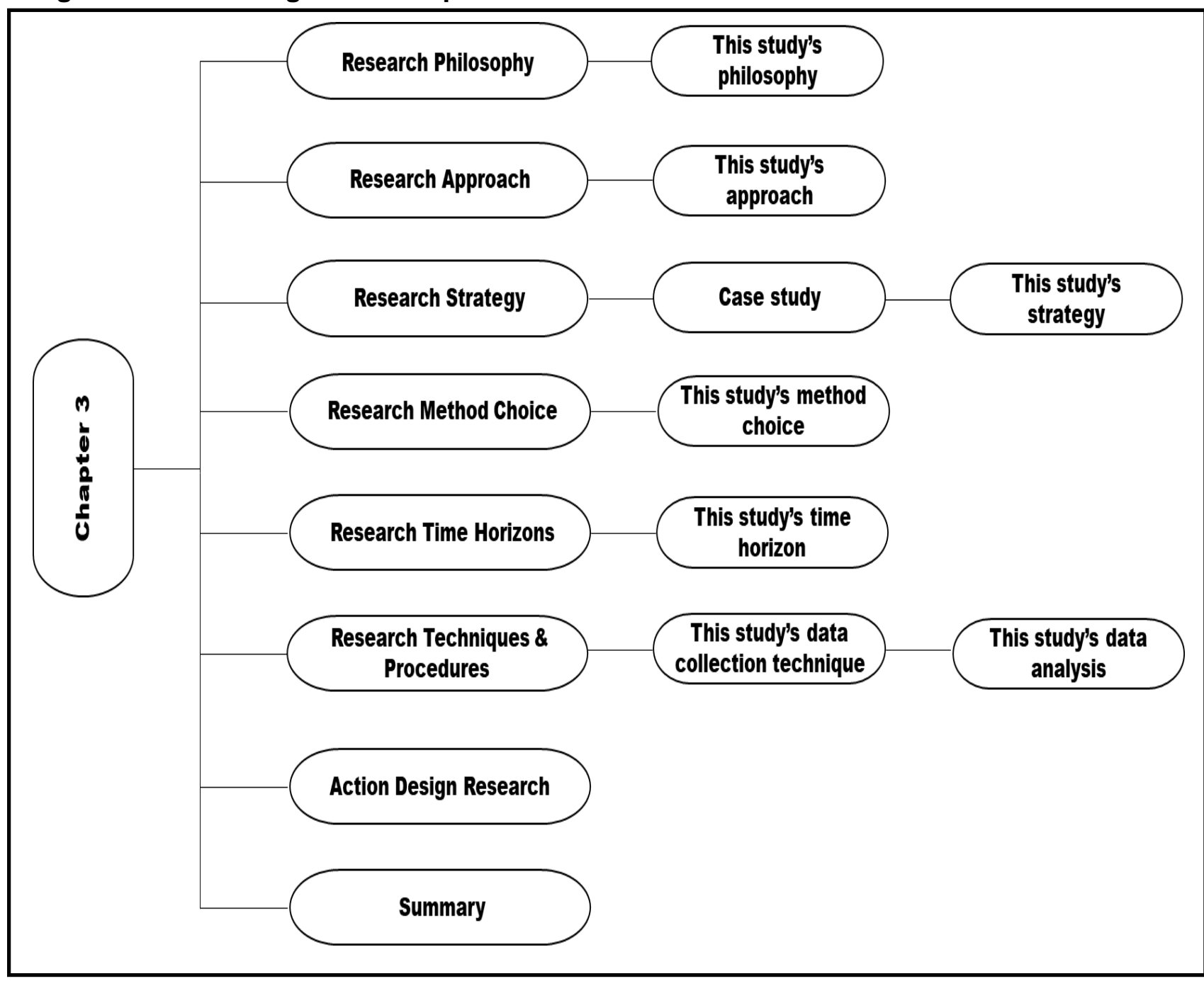

Source: Own Research

\subsection{LAYERS OF THE RESEARCH UNION}

\subsubsection{Research Philosophy}

A research philosophy refers to a system of beliefs about the way in which information and assumptions about a specific phenomenon should be collected, analysed and used. Researchers distinct between two big research philosophies, namely the positivist and interpretivist philosophies (Maree, 2016:33) and are described in more detail below.

Positivism assists a deterministic philosophy where causes determine effects and outcomes (Creswell, 2014:36). Positivism encourages the view of factual knowledge with the use of observation, therefore the typical research study is limited to data collection and interpretation in an objective manner. Crowther \& Lancaster (2008) state that positivist studies (as a general rule) usually assume a deductive approach, however an inductive approach is more likely to be linked to a phenomenology philosophy. 
Interpretivism allows that researchers' backgrounds influence their interpretation, and therefore they place themselves in the research and how they interpret it is based or associated with their moral values, beliefs, culture or past experiences. The researcher's objective is to make sense and clarify the perspective for the world to find an understanding (Creswell, 2014:37). Interpretivists avoid fixed structural frameworks, other than positivist research, and use more customised research structures (Carson et al., 2001). Thus, for the customised research structure it is necessary to be open-minded to be able to trace meanings in human interaction (Black, 2006) and to make sense - in a simple manner - of what is regarded as reality (Carson et al., 2001).

The assumptions (of the research paradigm) could further be divided into ontology, epistemology and axiology. The assumption of ontology is about the nature of reality. Ontology is about the choice between being subjective or objective. Therefore, the ontological assumption influences the way the researcher addresses the research and its objectives. Different ontological assumptions mean, for example, that a firm focused on how resistance to change could be beneficial to the change, rather than to do it in a manner to eliminate resistance (Thomas \& Hardy, 2011). The epistemology assumption is about knowledge, whether it is acceptable, valid and legitimate knowledge and how it could be communicated to others (Burrell \& Morgan, 1979). The positivism epistemological assumption is that of the researcher being independent from the world, and thus the researcher and what is being researched is independent (De Villiers, 2015:30). Furthermore, epistemology indicates whether the researcher is independent or reacts with the subject.

The position of values and ethics within a research method is referred to as axiology. Heron (1996) states that "people's values are the proposed reason for all human action and argues that researchers demonstrate axiological skills by being able to implement their own values as a foundation for making judgement in the researcher's study."

This study makes use of interpretivism, as it is based on human interactions and understandings, relying on participants during multiple different interviews. There are different perspectives from each participant due to distinct backgrounds, beliefs, values and past human experiences. The case study, as stated above in Chapter 1 (4.2.2.), makes use of human interactions and therefore the researcher interprets it in a logical manner. The nature of this case study is interpretive and can be clearly supported by the discussion above and the interviews that were held. Furthermore, this study is making use of a subjective approach and the researcher interacts with the subject. No other costing model is going to look the same as this study's model, because of personal judgement and interaction. Thus, this model is unique in its own manner with the use of its own frame of reference. 


\subsubsection{Research Approach}

The research approach of the second layer of the research onion could either be deductive or inductive and the preference for one of the two would usually depend on methodological choices made historically, as well as on personal perspectives, research goals and restrictions.

According to Wilson (2010:7) the deductive approach is focused on developing a hypothesis based on existing theory, and thereafter creating a research strategy to test the hypothesis. The deductive reasoning means "reasoning from the general to the specific." (Gulati, 2009:42). Gulati (2009:42) further states that the deductive approach may test if the connection did draw from more overall circumstances. The deductive reasoning is concerned with taking away conclusions from hypothesises. This approach fits the best to a context where the study is concerned about the appropriateness of observed phenomena, based on previous studies (Wiles et al., 2011).

On the one side, the inductive approach begins with the observations and theories that are proposed towards the research process and ends as a result of observations (Goddard \& Melville, 2004). This Inductive approach is "from the particular to the general" and "involves the search for patterns derived from observations and the development of explanations (theories) for those patterns through series of hypotheses" (Bernard, 2017:7). The inductive approach could be identified as a bottom-up approach, in which the researcher uses observations to develop or to describe a picture of the phenomenon that is being studied (Lodico et al., 2010). Therefore, the use of inductive reasoning is that it is based on experiences that have been observed to draw conclusions.

The 'particular' is, for example Firm A, as defined in this study. The systems of Firm A were studied and from the findings a new costing system was developed. The new system is the general, meaning that there is no specific requirements how it should look like. This study can be classified as having an inductive approach, as it entails observations in Firm $A$. The participants shared their opinions, based on experience within the firm, through the interviews. Therefore, this study is going to draw a conclusion based on the information gained (including observations) from the selected participants from Firm A. 


\subsubsection{Research Strategy}

The research strategy (the third layer of the research onion) is about how the researcher or study intends to collect data to achieve its objectives (Saunders et al., 2007). There are various research strategies that could be used to obtain the data that is needed with the seven mainly used strategies.

i. Experiment: The experimental strategy indicates a strategy where a research process is developed by examining and comparing the experiment's outcome against anticipated outcome. The strategy could be used in different parts of research, with the use of a limited number of factors involved (Saunders et al., 2007).

ii. Survey: The survey strategy is usually used with the deductive approach. Furthermore, the survey can collect valuable and reliable data through this strategy. Although this strategy leans more towards quantitative studies, it involves sampling a typical segment of the population (Bryman \& Bell, 2011).

iii. Grounded theory: The Grounded Theory Methodology (GTM) is defined as a method that is intended for the findings of inductive theory (Wiesche et al., 2017:686). Saunders, Lewis and Thornhill (2007) agree that this theory is based in - or developed inductively from - data that has been gathered. This theory is useful for newly research topics or where little research has been done in a specific field.

iv. Ethnography: According to Creswell (1998:271), ethnography is the study of an essential cultural/social group formed mostly on observations over a time period. De Vos et al. $(2005: 271)$ state that this strategy of inquiry is classified by the interpretations and descriptions of a small-scale of cases.

v. Archival research: An archival research strategy uses existing material to lead or direct the specific research study (Flick, 2011). This strategy examines existing research behaviour to conclude knowledge on a specific study or the applications thereof.

vi. Case study: Creswell (1998:61) defines a case study as "an investigation or an in-depth analysis of a specific case, or different cases, over a period of time. De Vos et al. (2005:272) support Yin (2009), namely that an investigation of a case takes place through extensive data collection methods such as interviews, documents, observations or archived records of previous research studies." Yin (2009:23) defines a case study research method "as an empirical inquiry that investigates a contemporary phenomenon within its real-life context; when the boundaries between phenomenon and context are not clearly evident; and in which multiple sources of evidence are used". According to Yin (1993) most used and well-known approaches with case studies are exploratory, explanatory and descriptive 
case studies. These three case studies can be either single or multiple-case studies, depending on the purpose of the study. The three studies can be distinguished as follows:

- Explanatory case study: Baxter and Jack (2008:547) state that the explanatory case study is used when the presumed underlying relationship with real-life events, that survey or experimental strategies are inadequate to use due to its complexity, is questioned. Explanatory case studies strive to explain the reason what or why something happens in a specific case or scenario (Rule \& John, 2011:8).

- Exploratory case study: Rule and John (2011:8) explain that an exploratory case study examines an unexplored phenomenon that sets a fundamental basis for future research.

- Descriptive case study: Baxter and Jack (2008:548) describe a descriptive case study as the type of case study that describes the real-life conditions in which a phenomenon can happen. An overall description of a phenomenon that also includes the background is given in this type of case study (Rule \& John, 2011:8).

vii. Action research: This type of research is usually used in careers such nursing or teaching, where the specialist can evaluate ways in which they can improve their professional perspective and understanding (Wiles et al., 2011). This approach is most often used to solve a specific problem by finding a solution or answer. There are two parts in action research, the one is more focused on the practical part of solving real-life events (improving practises). The other part of action research is more focused on the research/development of new insight or knowledge. Therefore, the real-life events/experiences enable the action researcher to gain deeper insights or to develop new theory or knowledge in a specific field (Elden \& Chisholm, 1993; Shanks et al., 1993). However, the action research should be guided by an existing theoretical framework that is appropriate towards the study's interest and within the context thereof (Checkland 1991).

This study made use of an exploratory case study on Firm A, applying a single case study strategy. The development of a costing system for a digital technology service firm will be breaking ground, as this business environment is still fairly new. Therefore, it is of the utter most importance to understand Firm A's current costing system and internal control operations. This would only be possible through the use of a case study combined with the use of interviews and observation. The respondents' internal knowledge as employees of Firm A should be shared with the interviewer to enable full understanding of the systems, environment and controls in use. In this study action research, which led to the integration of Design-Science Research (DSR) and action research, was also used. The guidelines will be fully explained and every step within the guidelines of DSR will be discussed in this chapter. Furthermore, DSR was 
elaborated to the Action Design Research (ADR) that is going to be used to develop the costing system (for a digital technology service firm).

\subsubsection{Research Method Choice}

The research method choices showed in the research onion includes the following three methods: mono-method, mixed-method and multi-method (Saunders et al., 2007). According to Herbst and Coldwell (2004:15), a quantitative research approach defines, infers and solves problems through the use of numbers and numerical data. Herbst and Coldwell (2004:15) further state that this method's focus is based on the collection of data (numerical), the summary of those data and the illustration of assumptions made from the data. Zikmund et al. (2010) found that quantitative research is unbiased and could be set within a positivistic context.

Qualitative research, according to Herbst and Coldwell (2004:13), is based on words, feelings, emotions, sounds and non-numerical and unquantifiable elements. It is therefore considered qualitative if it cannot be analysed with the use of mathematical techniques (Herbst \& Coldwell, 2004:13). Qualitative research can consist of one of the three methods such as the monomethod, mixed-method or multi-method.

i. Mono-method: This method entails the use of a single, namely a qualitative or a quantitative study (Bryman, 2012)

ii. Mixed-method: The mixed-method approach makes use of more than one and allows for the use of both qualitative and quantitative methodology (Bryman, 2012). The mixedmethod involves a combined methodology that builds a single dataset - this is usually the biggest difference between the mixed- and the multi-method (Flick, 2011).

iii. Multi-method: This method is making use of a wider selection of methods (Bryman, 2012). The multi-method approach divides the research into separate departments; each one is then analysed using techniques derived from quantitative or qualitative methodologies (Feilzer, 2010).

This research made use of the mono-method and therefore confirmed a qualitative research approach. The research could not be conducted through mathematical techniques, but through semi-structured interviews and observations. In support of the above, it can be mentioned that Maluleke (2019) similarly did research on the South African Social Security Agency (SASSA) for implementing an $A B C$ as an alternative system to the TCS, applying a qualitative research approach. Stouthuysen et al. (2014), as well as Ngcobo (2019), independently applied the TDABC with success in sectors directly and indirectly connected to the public sector, and they 
also used a qualitative research approach. Qualitative research makes use of an in-depth analysis on a specific subject and is exploratory in nature.

\subsubsection{Research Time Horizon}

The Time Horizon is the time framework within which the research, study or project is intended to be concluded (Saunders et al., 2007). Saunders et al. (2007) further state that the time horizon selected is not dependent on a type of research approach or methodology. There are two types of time frameworks, such as cross-sectional and longitudinal.

i. Cross-sectional: The required data should be collected at a specific time period and at a certain point (Flick, 2011). When the investigation is concerned with the research of a particular phenomenon at a specific time, it warrants the use of a cross-sectional approach.

ii. Longitudinal: According to (Goddard \& Melville, 2004), longitudinal time horizon is when data collection entails the collection of data constantly over a stretched period and where the research is examining the change of data, as an essential element, over time. Furthermore, it enables the establishment of minor control over the variables being studied.

This study made use of the cross-sectional time horizon. The research collected data through interviews and observations that happens in a short period of time. Therefore, the investigation to develop a costing system for Firm $A$ is a particular phenomenon at a specific time. The study will focus more on the snapshot time collection than on obtaining data and information over a long period of time.

\subsubsection{Research Techniques and Procedures}

The data collection and data analysis are the last layer of the research union (Saunders et al., 2007). The different data collection techniques differ between qualitative and quantitative research, therefore this study only focused on the qualitative research methods.

i. Interviews: This type of interview is used to collect data aligned to the research question, the characteristics of the participants and the method of choice by the researcher. Interviews are most often carried out face-to-face, although the use of telephonic interviews can be used where geographical limitations are present (Smith, 2005). An open or unstructured interview will mostly be based on one question, with the interviewer and interviewee then guiding the conversation, rather than following a structured question list. These methods are usually used where participants are encouraged to share their work life experiences, such as narrative enquiry (Chan et al., 2013). The most common approach in qualitative research is the semi-structured interview, where the interviewer asks specific questions to understand a specific topic or phenomenon that is being studied. A well- 
designed semi-structured interview should ensure a rich source of data when the data are captured in essential areas and the interviews are done adequately (Gillham, 2008:65).

ii. Focus groups: The focus group provides qualitative researchers an effective method of gathering the perspectives of many participants at one time. Different people are discussing the same issue together, which can lead to a debate with the moderator usually excluded from the conversation and which enables the focus group to enter into a free-flowing discussion (Plummer, 2017).

iii. Observation: Participant and non-participant observation is a powerful tool for collecting qualitative data, as this gives researchers an opportunity to capture a wide range of information such as verbal and non-verbal communication, actions and environmental factors. Therefore, the researcher gains a first-hand image of how the firm operates (Twycross et al., 2016). What makes the qualitative data technique unique is the fact that observation provides a huge amount of data to be captured and analysed. A method to help improve the process of data collection and analysis is to digitally record observations that would enable the researcher to replay the recording afterwards (Meriläinen et al., 2010).

iv. Documentation: Documentation information can be used in many forms and should be the object of apparent data collection procedures (Yin, 2009:101). Documentation does have advantages, such as reviewing the source of information as much as the researcher like, and that the documents consist of the exact amount/fields/details. On the down-side, documentation could be difficult to find and the selection thereof could be biased (Yin, 2009:102).

Qualitative data was gathered through conducting semi-structured face-to-face interviews with open-ended questions. The interviews mainly included the following personnel from Firm A:

- Chief Technology Officer (responsible for the technology development, and understanding the technological flow of the firm).

- Chief Financial Officer (managing the firm's finances and understand the financial flow of the firm).

- Head of Project Management (managing multiple projects at one time to ensure the projects succeed).

- Head of Human Resource Management (managing the procurement, recruitment process and maintaining of human resource).

- Head of Financial Management (managing the financial planning, directing and controlling the financial activities). 
Interviews with the above-mentioned participants were conducted, recorded and analysed. Content analysis was applied to help identify possible cost relationships in the collected qualitative data. The researcher was a participative observer in this case study during the interviewing sessions and the collection of qualitative data. Documents such as the general ledger, income statements and the payroll of Firm A were also used to collect data. The document analysis will deeply be discussed in Chapter 4 .

Marshall and Rossman (1999:150) describe data analysis as the process of putting in place structure, order and meaning to the large amount of collected data. The data analysis of this study will be treated fairly and will produce analytical conclusions. The interview results in the structured (yes or no) section will be extracted into graphs and the limiting factors to develop the costing system will be discussed. The verbal response answers will be highlighted by the researcher's discretion, as well as the answers that have been overlapped repeatedly (pointed out a multiple of times) - thus coding the data/feedback into main themes. The interviews will give a direct indication towards the goal (secondary objectives) to be achieved. Thereafter, the study will conclude what type of costing system will be used and developed for Firm A. This will be accomplished through analysing the overall pattern of the data received and the comparison between the old costing system and the newly developed costing system for Firm A.

\subsection{ACTION DESIGN RESEARCH}

Design-science is mainly used as a process of solving problems. The core principle of designscience research, in which the seven guidelines are used, is that it enables the researcher to understand the underlying problem and to find a solution in the developing and application of an artifact. Therefore, the purpose of the design-science research is to assist researchers and readers to understand the process of building an artifact (Hevner et al., 2004).

Table 3.1 below shows the original summary of the seven guidelines of the DSR (designscience research). 
Table 3.1: Summary of the seven Guidelines

\begin{tabular}{|c|c|}
\hline Guideline & Description \\
\hline 1. Design as an Artifact & $\begin{array}{l}\text { The DSR must produce a viable artifact and } \\
\text { should be constructed in the form of a model, } \\
\text { method or installation. }\end{array}$ \\
\hline 2. Problem Relevance & $\begin{array}{l}\text { The DSR is to develop technology-based } \\
\text { solutions for appropriate business problems. A } \\
\text { costing system is going to develop decision } \\
\text { solutions for the digital technology service firm. }\end{array}$ \\
\hline 3. Design Evaluation & $\begin{array}{l}\text { The design artifact should be clearly } \\
\text { demonstrated through well-executed evaluation } \\
\text { methods. }\end{array}$ \\
\hline 4. Research Contributions & $\begin{array}{l}\text { Effective DSR must provide clear and adequate } \\
\text { contributions in the areas of the design artifact, } \\
\text { foundation or methodology. }\end{array}$ \\
\hline 5. Research Rigor & $\begin{array}{l}\text { DSR relies on the application of meticulous } \\
\text { methods in both the evaluation and construction } \\
\text { thereof. }\end{array}$ \\
\hline 6. Design as a Search Process & $\begin{array}{l}\text { The search for an effective artifact requires the } \\
\text { availability of resources to reach the desired goal } \\
\text { while obeying laws. All necessary resources will } \\
\text { be obtained from the digital technology service } \\
\text { firm to enable this artifact to function. }\end{array}$ \\
\hline 7. Communication of Research & $\begin{array}{l}\text { The DSR must be presented effectively for both } \\
\text { technology- and management-oriented } \\
\text { audiences. This study will be presented in the } \\
\text { technology world as the system is going to be } \\
\text { developed in this environment, while the results } \\
\text { thereof will enable management to make more } \\
\text { precise decisions. }\end{array}$ \\
\hline
\end{tabular}

Source: Hevner et al. (2004)

Mullarkey and Hevner (2019) used this model in building on the original DSR and developing it into an elaborated action design research (ADR) process model. The ADR process model is a four-stage approach that includes the following:
1. Diagnosis stage
2. Design stage
3. Implementation stage 


\section{Evolution stage}

The diagnosis stage is the part of the process to discover and define the problem domain in which the process in going to be operating in. The intended artifact that is going to be built in this stage may require definitions, technical specifications and the concepts of the solutions and problem domains. The design stage is part of the problem-solving part as the research project is evolving. The design stage also includes design principles, methods, systems and the implementation methods that are going to be used. The implementation stage is where the artifact is engaged in building and implementing the project/model. Therefore, the artifacts in the ADR implementation stage can be systems, programs, databases, algorithms or/and processes. The evolution stage of the artifact happens over a period of time, as the problem environment changes and the artifact solution develops to meet these changes (and can be a more longterm stage).

Below is an illustration of the four stages:

Figure 3.3: The Four ADR Stages

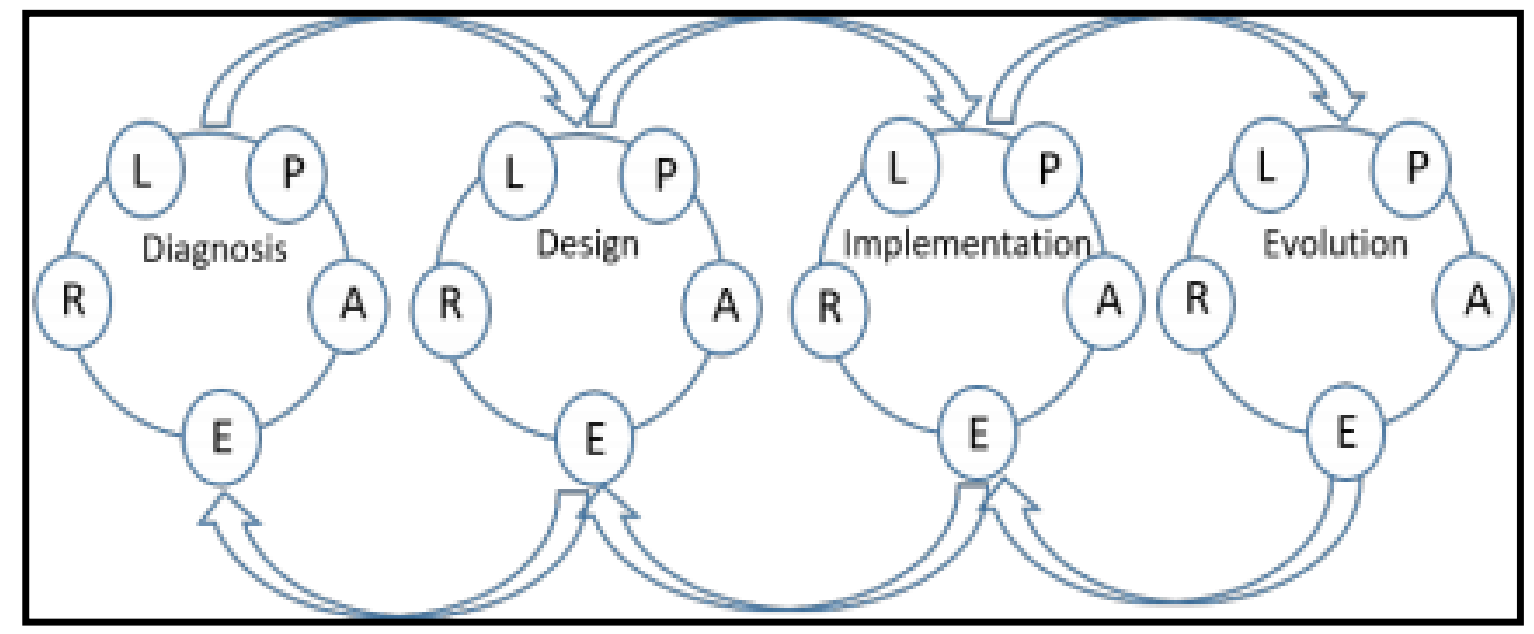

Source: Mullarkey and Hevner (2019)

The entry point in this study is going to be the design stage and the implementation stage. Only these 2 stages are going to be used to develop the costing system for Firm A for the purposes of this mini-dissertation. Each of the stages will include the elaborated ADR cycle that will complete the ADR model. The acronyms in the table above are the following:

1. P: Problem formulation/Planning

2. A: Artifact creation

3. E: Evaluation

4. R: Reflection

5. L: Learning

Illustration of the elaborated (ADR) cycle within each of the four-stages: 
Figure 3.4: The Elaborated Action Design Research (ADR) Cycle

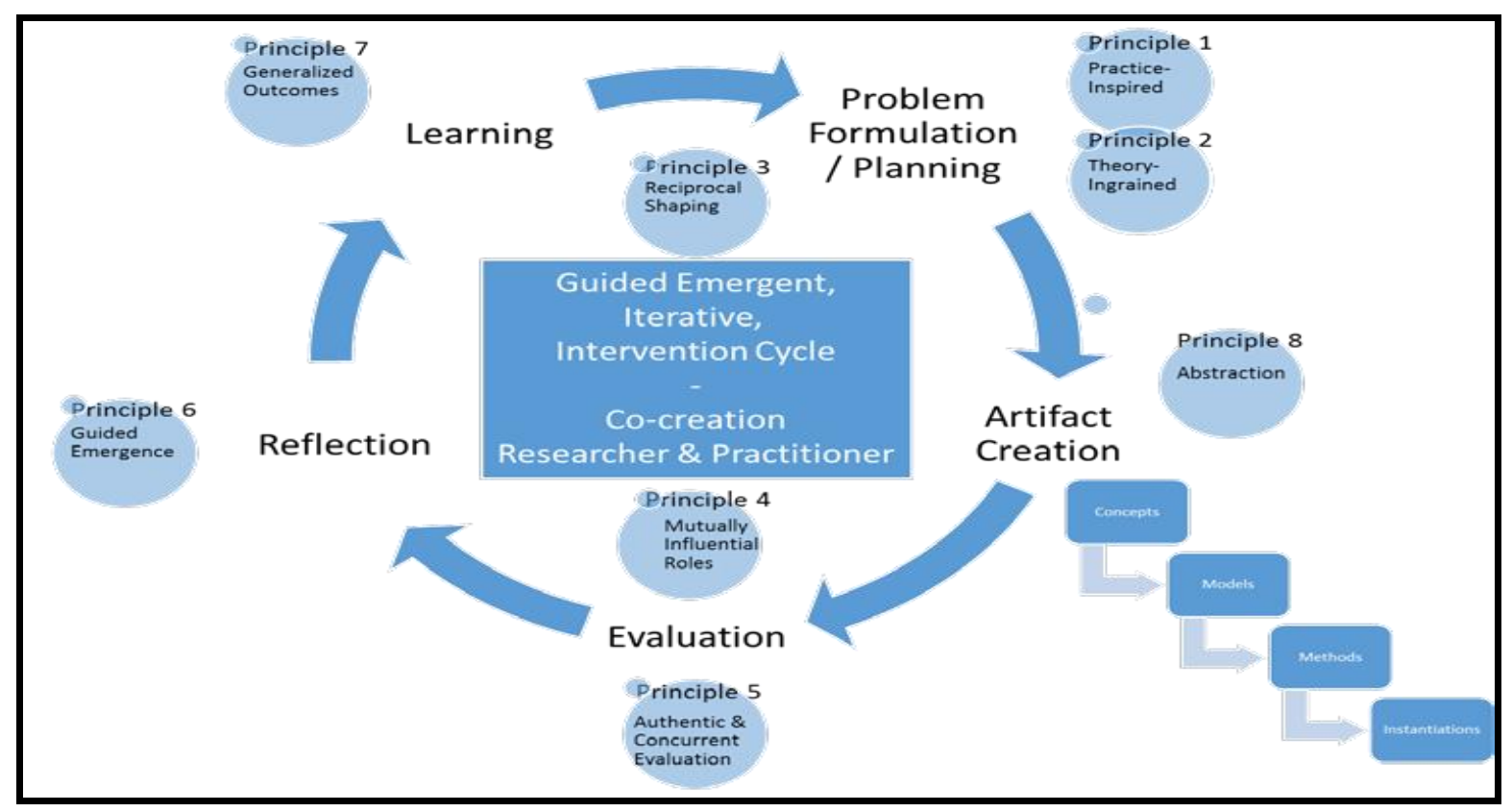

Source: Mullarkey and Hevner (2019)

As indicated in Figure 3.5 the elaborated ADR cycle contains five main segments and the minidissertation will only allow the first three segments to be completed. Therefore, the segments that are going to be used will be the problem formulation/planning, artifact creation and the evaluation. The whole ADR model will be used adequately within the limitations of the study.

\subsection{SUMMARY}

The aim of this chapter was to address the secondary objective, as was set in Chapter 1, namely to discuss and select an appropriate research methodology and design to reach the primary objective.

The discussion and selection of the research methodology was dealt with in this chapter and included the actions required to achieve the primary objectives. This included the use of ADR guidelines to develop a new costing system for the digital technology service firm.

This chapter mainly applied the research onion concept that covered the following six topics: philosophies, approaches, strategies, method choices, time horizons and techniques/ procedures. Each one of these topics was used and discussed in detail to conclude the research methodology. 


\section{CHAPTER 4: DATA COLLECTION AND FINDINGS}

\subsection{INTRODUCTION}

In this chapter, data collected via interviews, the document analysis and observations from the digital service firm will be discussed, followed by the revision and analysis of the data with the aim to achieve the secondary objective as stated in Chapter 1. This chapter introduces the empirical study conducted on the development of a new costing system for the digital service firm.

In order to ensure that this mini-dissertation is executed in an ethical manner, the study has been approved by the ethical committee of the NWU (Appendix A). Consent was requested from and granted by Firm A's management and permission from interviewees was obtained prior to all semi-structured interviews (Appendix B).

Chapter 4 is constructed in accordance with the diagram below and flows as follows:

Figure 4.1: Flow diagram of Chapter 4

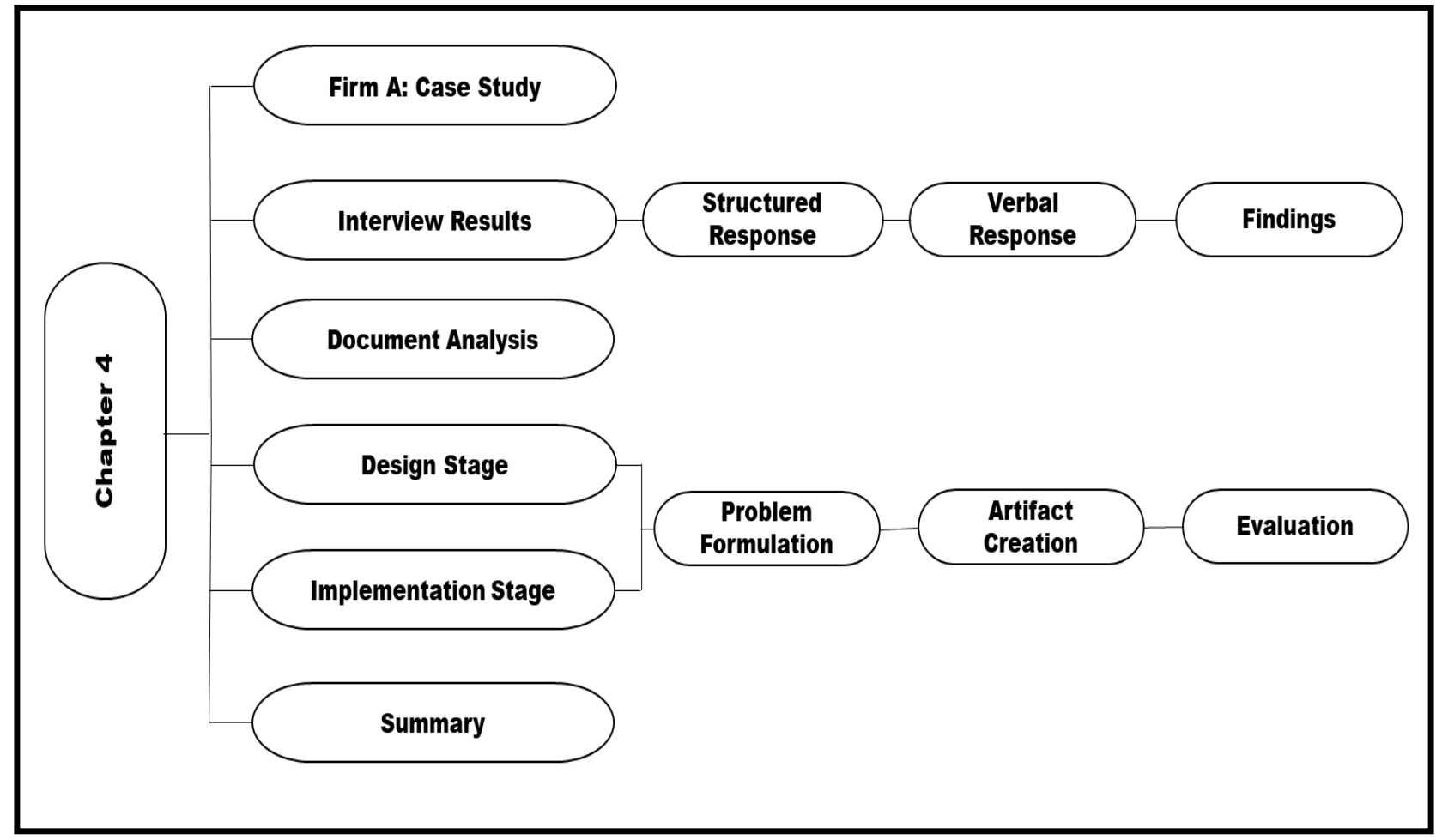

Source: Own Research 


\subsection{FIRM A: CASE STUDY}

As discussed in Chapter 1, Firm $A$ is a digital technology service firm that is growing at a rapid pace. Therefore, Firm A allowed this research to be conducted to enable the researcher to develop a costing system (or alternative) for them. The firm's value chain gave the study an idea of its types of services, products, software, hardware, functions, departments and activities (etc.) that could give an indication of how the firm's operations and flows are working.

Figure 4.2: Firm A Value Chain

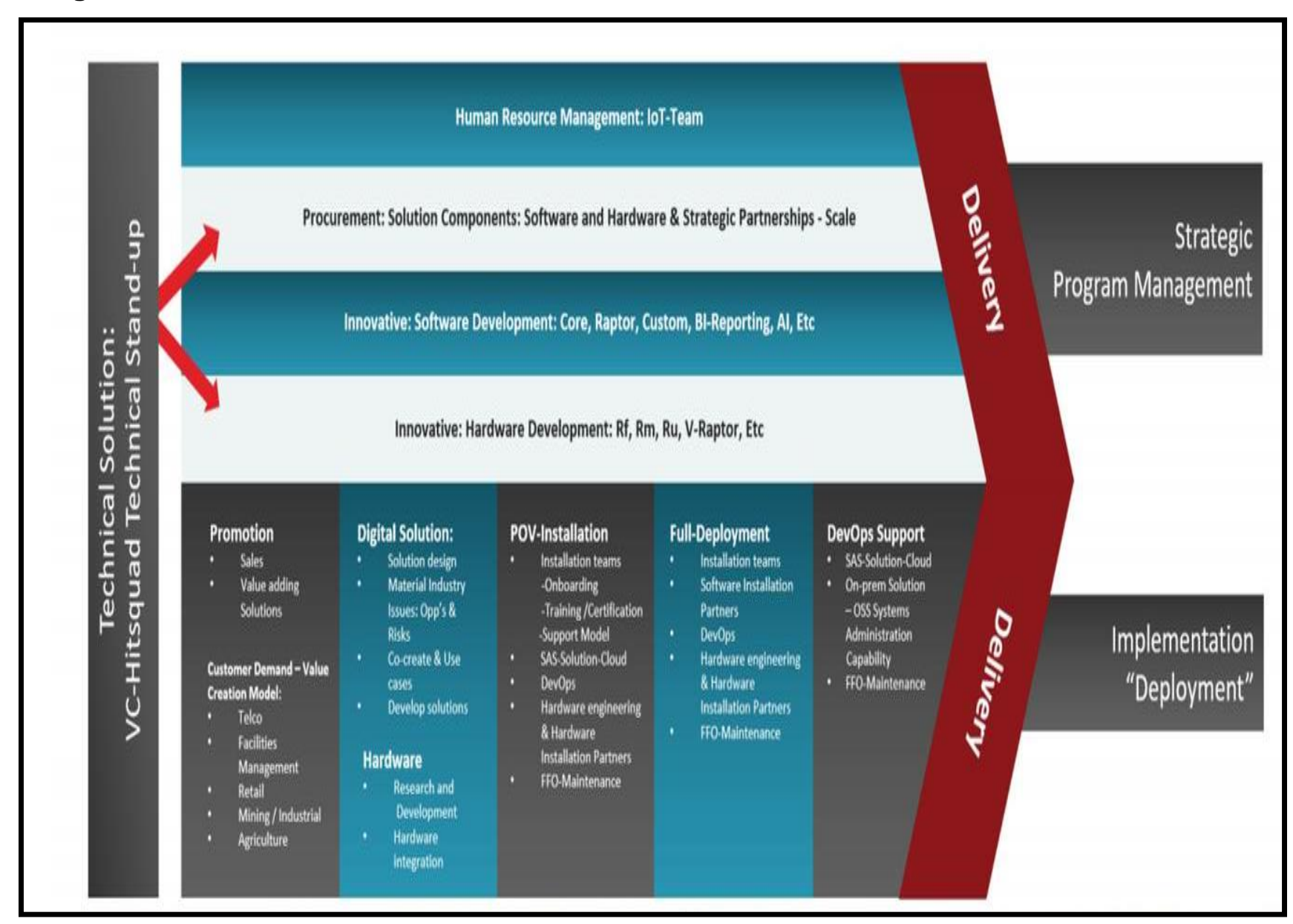

Source: Own Research

Firm's A value chain, as illustrated above, shows clearly how a service for customers/clients (customised per client's request/needs) develops. The chain is split into two main segments, namely Strategic Management and Implementation Management.

Strategic Management: Firstly, the Human Resource Management department identifies the opportunity that has been created and therefore determines whether Firm $A$ is fully adequate and equipped to perform the service as requested by clients. The type of solution that is required for the suggested problem should then be decided, namely whether it is software, hardware or a mix. The innovative/software development is mostly done by a solutions architect 
to find the recommended software to solve the problem. Thereafter, the hardware component (if needed) is developed to fit the specific solution/software that is required to operate.

Implementation Management: The second segment entails the implementation of the solution service/product to be implemented for the client. This allows the business support function to start the implementation phase and to decide whether specific activities should be outsourced to lay off workload.

\subsection{INTERVIEW RESULTS}

The semi-structured interviews were done with the following five participants:

- Chief Technology Officer

- Chief Financial Officer

- Head of Project Management

- Head of Human Resource Management

- Head of Financial Management

The semi-structured interviews included structured and verbal responses, therefore the results will be split and discussed. Both sections of the questionnaire are exhibited in Appendix $B$. The structured responses were only 'yes' or 'no' answers. When the answer was yes, the participants had to reason why they said yes. The verbal responses were more open-ended responses that enabled the researcher to understand the firm's activities, processes and internal operating systems.

The semi-structured interviews could not be conducted at Firm's A office, as was planned, due to the COVID-19 pandemic that forced people/firms/companies to be in lockdown. Therefore the semi-structured interviews were done through Microsoft Teams and Zoom meetings. All the interviews were voice-recorded with the consent of each participant. Appendix B shows the participants' consent form.

Reliability indicates the consistency of producing the same results between groups of people at different times through the application of the same measuring instrument. The reliability of the measuring instrument of the case study was conducted through the use of semi-structured interviews. Interview questions was designed in consultation with industry experts. This was to ensure that the questions were appropriate and in support of the research objectives, before engaging with the participants. The process was endorsed by the ethical committee of the North West University (Appendix A) and they confirmed questions were relevant and in accordance with the research objectives. 


\subsubsection{Structured Response}

The structured interview was about whether the participant was of the opinion that the following conditions might be a problem/concern for Firm A to implement the costing system. The following were the seven questions and conditions:

1. $\mathrm{Q} 1=$ Resistance to change

2. $\mathrm{Q} 2=$ High implementation cost

3. Q3 = Lack of time

4. $\mathrm{Q} 4=$ Lack of commitment and cooperation amongst department

5. $\mathrm{Q} 5=$ Lack of top management support

6. $\mathrm{Q6}=$ The importance of project

7. $\mathrm{Q7}=$ Not capable to implement the costing system

Each of the five participants answered these seven questions (conditions) to determine whether Firm A would be able to implement the costing system and how much slack it might receive. The only conditions discussed in depth were when the majority answered "yes" to a specific condition, as the specific condition might influence the implementation of the costing system for Firm $A$. Note that the questions could be regarded as qualitative, since the respondents were also given the opportunity to explain/discuss their reasons for selecting "yes".

Figure 4.3: Structured Response

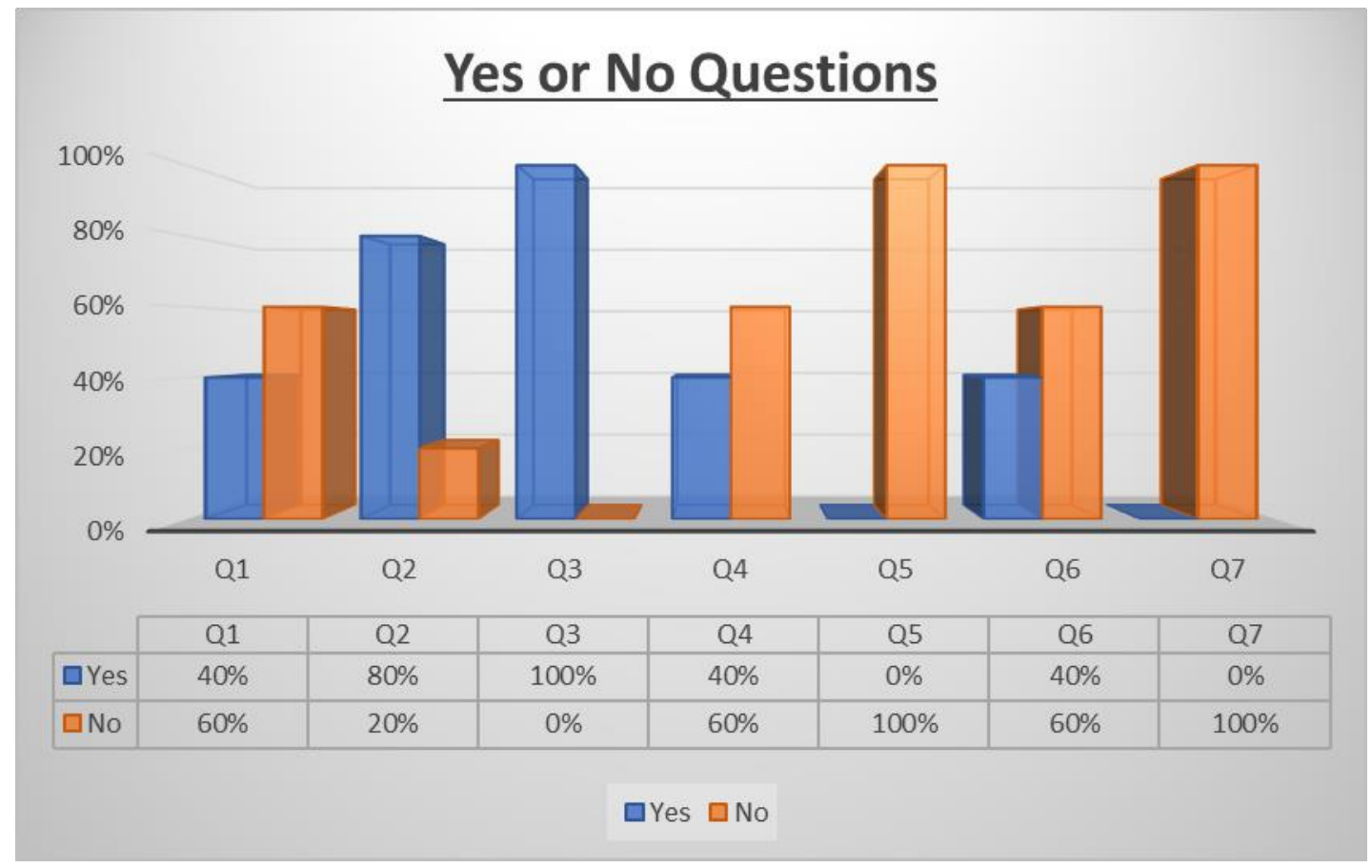

Source: Own Research 
As indicated in Figure 4.3 above, there are two questions whereby the participants believed there might be constraints when implementing the costing system. Firstly, the high implementation cost (Q2) got $80 \%$ of the participants' attention as a concern. The participants believed it "depends on the cost-effective" ability of the costing system, as the firm was still in a "start-up" phase that wanted to minimise unnecessary costs.

Secondly, the lack of time (Q3) aspect got all five participants' attention at $100 \%$. It was not a surprise that this was the case, as the whole firm (services) are based on "time". The participants agreed to some extent that the "implementation of the costing system will not be stopped, rather get slack (slow down) due to the growing phase" of the firm. Furthermore, it appeared that it also "depends who is going to be involved" as the work time is limited to "12 hours a day".

The rest of the conditions were not a concern for Firm A to implement the costing system. Furthermore, the lack of top management support, and management not being capable to implement the costing system (Q5 and Q7), was of no concern/constrain. All five participants agreed to $100 \%$ on these two aspects as 'no concern'.

\subsubsection{Verbal Response}

The verbal response interviews were coded into themes, in the same way as done by Tilo (2017) and Maluleke (2019), but more specifically like Maluleke's (2019) study by using the voice-recording to code the data into sub-themes.

A data-table was developed to record the feedback of the transcripts to be analysed. The table contains the verbatim feedback and information obtained from each participant. Some themes were merged, owing to participants' comments that were regarded as out-of-context. The comments are captured in three columns namely, themes, sub-themes and verbatim responses. The five participants' feedback was cross-referenced in the table as follows (note that 1-5 is a random order and not necessarily the same order as previous discussed):

- Participant $1=[1]$

- Participant 2 = [2]

- Participant $3=[3]$

- Participant $4=[4]$

- Participant $5=[5]$ 
In order to capture the participants' experience and feedback on the interview, the following themes and sub-themes were structured:

Theme 1: The appropriateness, applicability and efficiency of the current allocation costing system.

- The current software system used for costing.

- Specific main activities and cost pools taking place when the service is delivered.

- The flow of cost/activities/works in Firm A's system/processes/operations.

- The accuracy and sufficiency of information available to make strategic decisions.

Theme 2: The development/improvements from the old to the new costing system.

- New customised costing system should be considered.

- How sophisticated should the firm's costing be.

- Improvements that could be made on the current allocation system.

Theme 3: The use of costing systems in general and the management tool thereof.

- The purpose of costing and examples thereof.

- Examples of cost-items in the cost hierarchy levels.

- What team/individuals should be recommended with the costing system initiative.

- Expectation regarding the efficiency aspect of the costing system.

- Costing system as a management tool improves budgeting, decision-making and monitoring controls.

Theme 4: Participants' open-ended discussion.

- Anything else that the participant wanted to add or to tell the interviewee on this topic.

The table below shows the themes and sub-themes that have been merged from the semistructured interviews.

Table 4.1: Themes, sub-themes and responses (next page) 


\begin{tabular}{|c|c|c|}
\hline Themes & Sub-Themes & Responses \\
\hline \multirow[b]{2}{*}{ 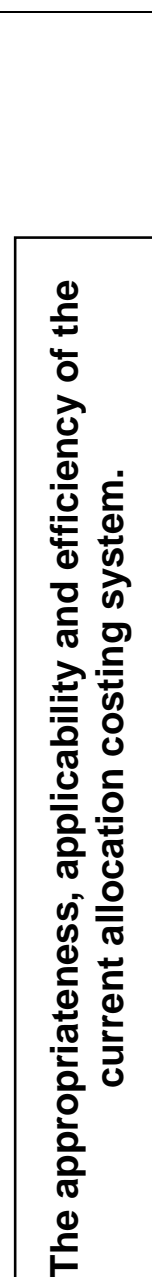 } & $\begin{array}{l}\text { The current software system } \\
\text { used for costing. }\end{array}$ & $\begin{array}{l}\text { [1] "Uhmm...there is in the financial department, } \\
\text { they use sage } x 300 . . . I \text { will not say its been used } \\
\text { at its maximum capacity..." }\end{array}$ \\
\hline & \multirow[t]{2}{*}{$\begin{array}{l}\text { Specific main activities and } \\
\text { cost pools taking place when } \\
\text { the service is delivered. }\end{array}$} & $\begin{array}{l}\text { [5] "On the development side we } \\
\text { use...uhmm...we do have a development system } \\
\text { that tracks it...then we have our accounting } \\
\text { system and our ERP system that is } \\
\text { palladium...we are currently moving from } \\
\text { palladium to sap.... within the next } 6 \text { months... and } \\
\text { then it is excel...that is our three systems we } \\
\text { currently use." } \\
\text { [2] "Ya, it can be appropriate yes... what tends to } \\
\text { happen is you find...uhmmm...like project } \\
\text { accounting right...looking at the true cost when } \\
\text { sell something...sometimes we sell hardware } \\
\text { service, sometimes we sell hosting...no so it is } \\
\text { not just time." }\end{array}$ \\
\hline & & $\begin{array}{l}\text { [5] " Yes, look the delivery to the client is about } \\
\text { what we call pre-sales...uhhmm... and solution } \\
\text { architecture where it starts...then they come up } \\
\text { with the solution and how we can deliver it, what } \\
\text { hardware and software we should use on our } \\
\text { platform...if the solution is accepted by the client, } \\
\text { then is driven by project management...when } \\
\text { they deliver, they use our service delivery } \\
\text { team...do installation of hardware and the } \\
\text { integration of our software and theirs...if the } \\
\text { client is happy then we sign-off...then it goes to } \\
\text { customer service...the customer service } \\
\text { component currently is not costed...the time and } \\
\text { integration do need a lot of work...should bring it } \\
\text { in our costings...currently just overhead costs, I } \\
\text { don't have specific cost allocations for specific }\end{array}$ \\
\hline
\end{tabular}




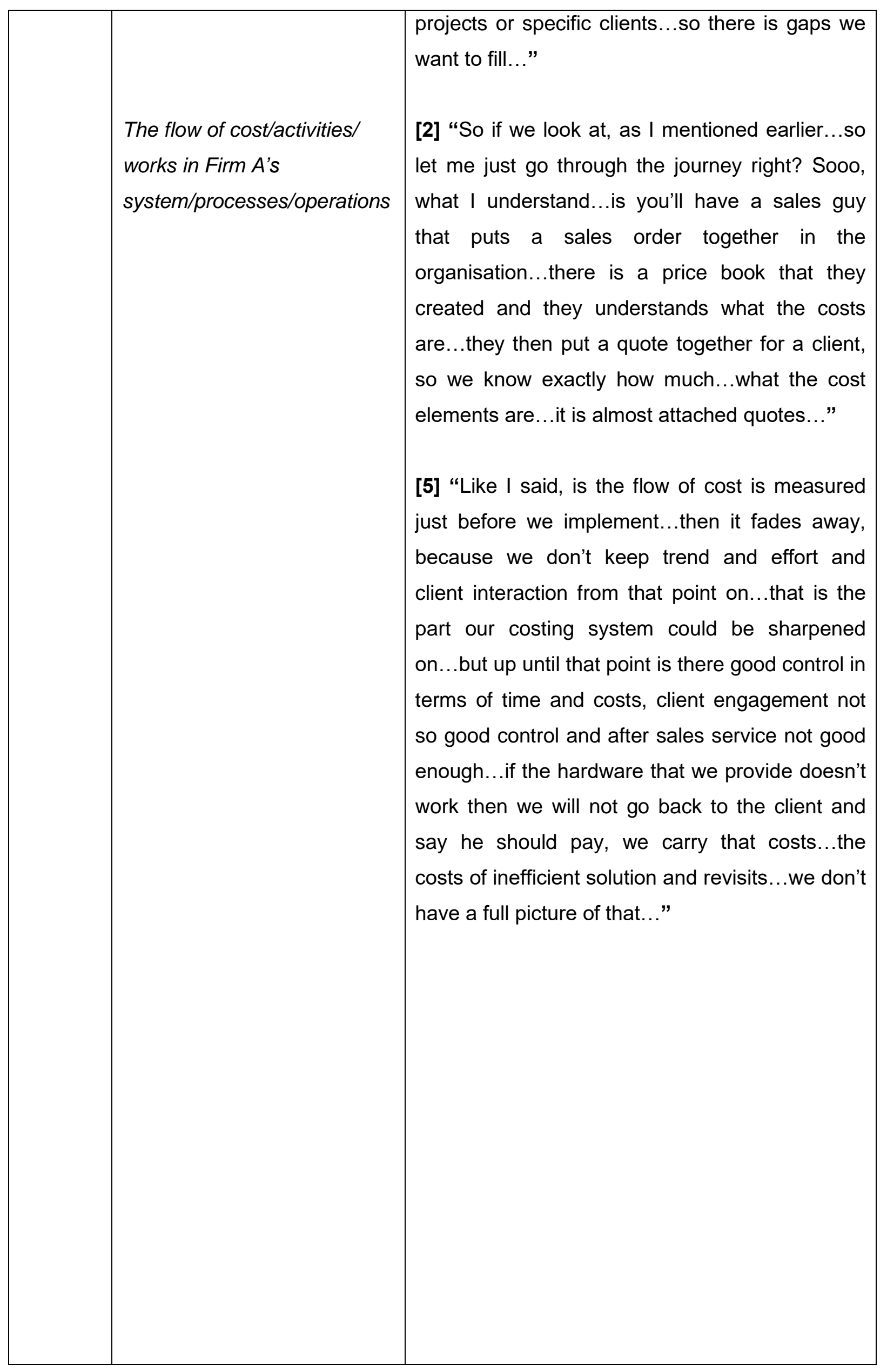




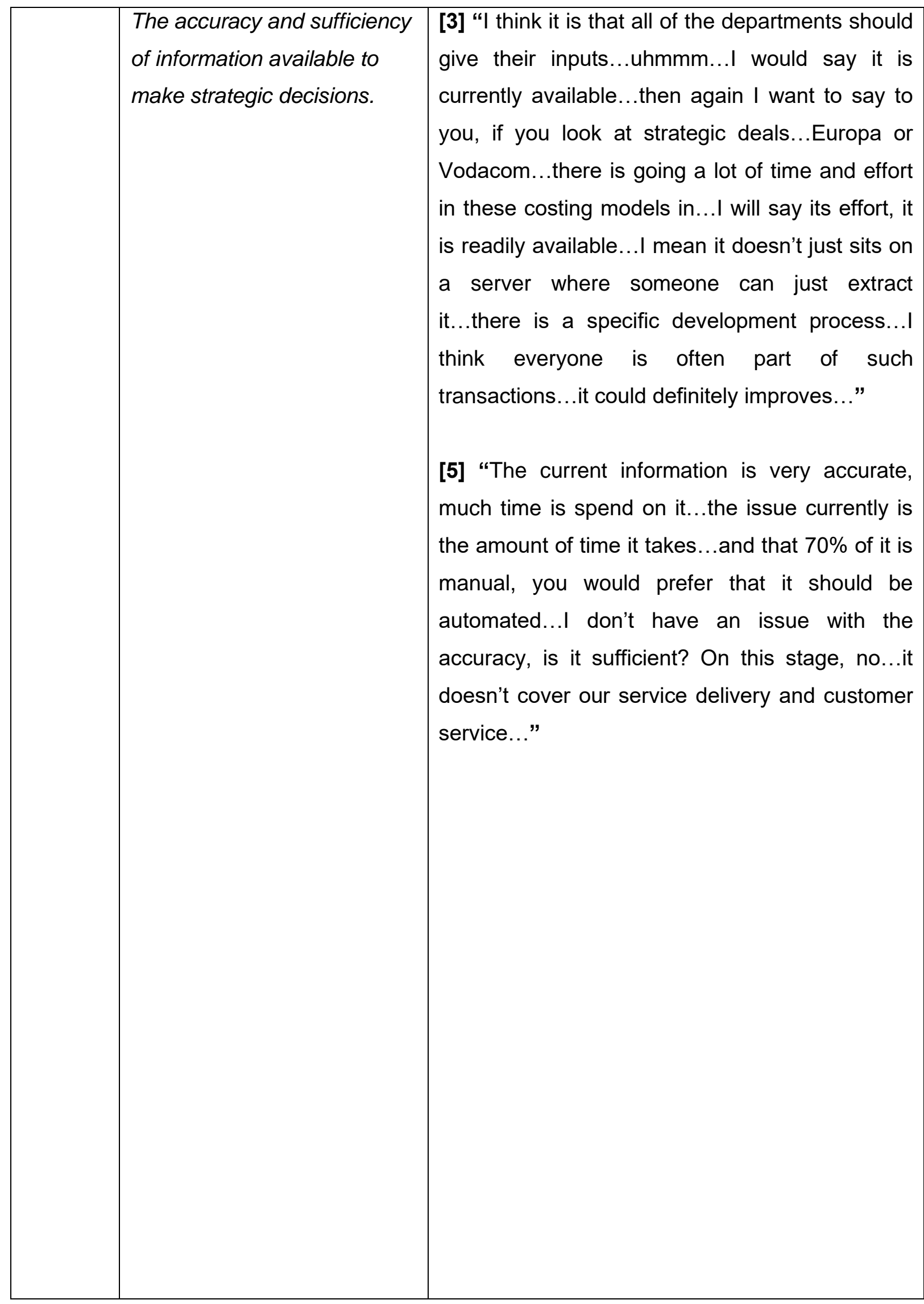




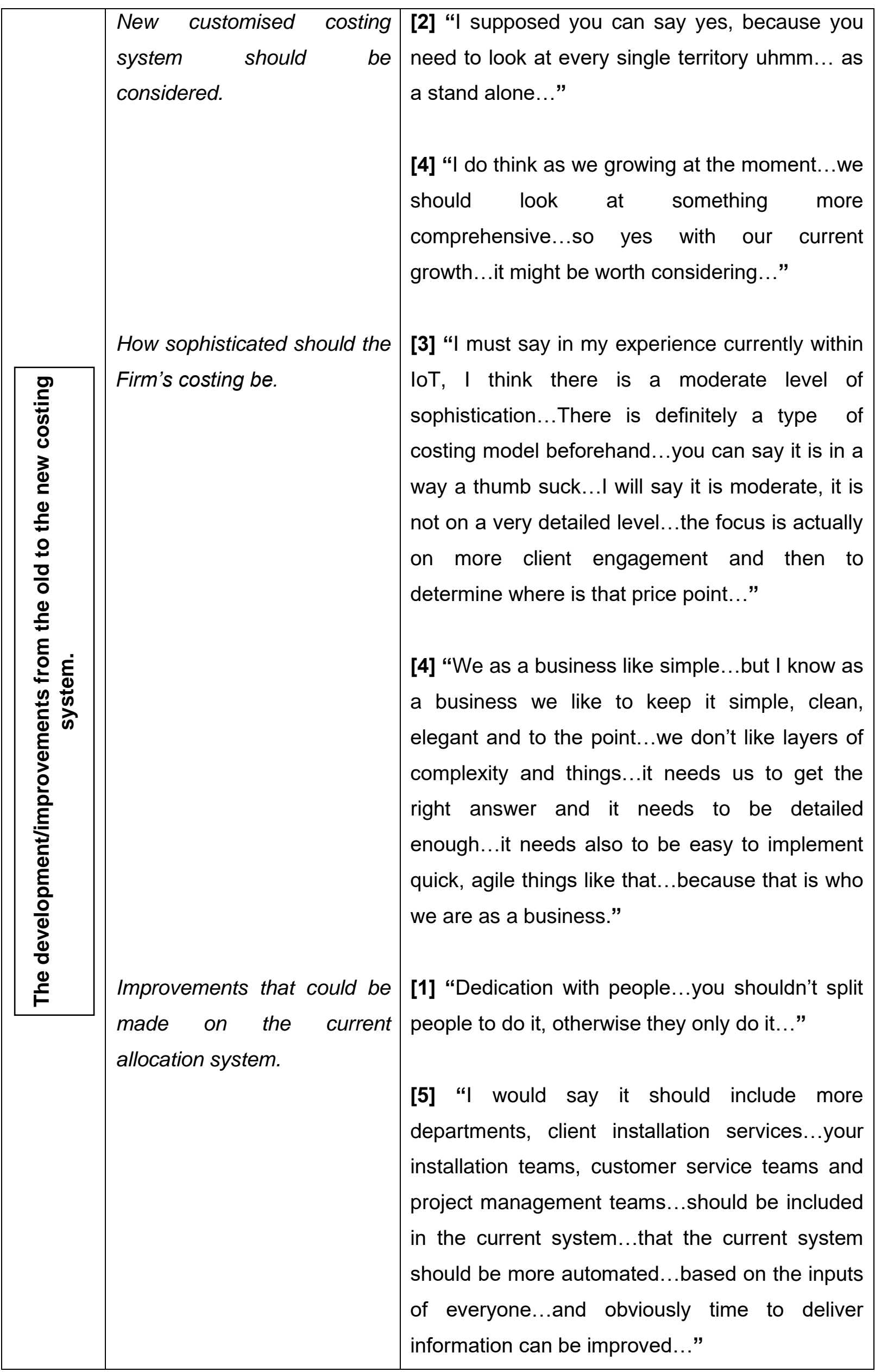




\begin{tabular}{|c|c|c|}
\hline & $\begin{array}{l}\text { The purpose of costing and } \\
\text { examples thereof. }\end{array}$ & $\begin{array}{l}\text { [1]" This will be surely inside different } \\
\text { departments, I think the development of software } \\
\text { is usually fixed so it's not really for costing, } \\
\text { unless it's done for clients..." There is another } \\
\text { department, custom development, important to } \\
\text { cost their time to know which client uses the } \\
\text { most time..." }\end{array}$ \\
\hline 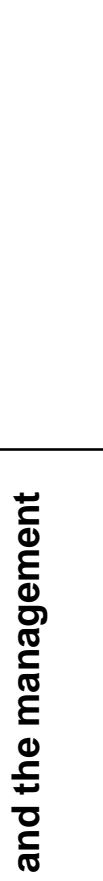 & & $\begin{array}{l}\text { [5] "We monitor all of those costs...I do have a } \\
\text { costing department...uhhh...my expenses and } \\
\text { salaries is divided in the departments...I do keep } \\
\text { trend of the service costs, we do have customer } \\
\text { development...we do have on-site services, } \\
\text { implementation, set-up, configuration....and that } \\
\text { form part of implementation of software... what } \\
\text { we don't trend to track...the plan as we move } \\
\text { forward, is the service and monitoring of our } \\
\text { clients...the fact that we charge them, but don't } \\
\text { really know how much it cost us...every client's } \\
\text { needs differ with each other...and we still need } \\
\text { to understand that..." }\end{array}$ \\
\hline 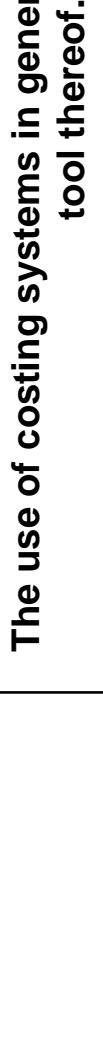 & $\begin{array}{l}\text { Examples of cost-items in the } \\
\text { cost hierarchy levels. }\end{array}$ & $\begin{array}{l}\text { [3] "Yes...so I think units is more around } \\
\text { hardware, that can be a raptor or a v-raptor for } \\
\text { example...If you look at service levels, this is } \\
\text { typical your human resource capacity that you } \\
\text { can allocate...including project management, } \\
\text { change management and even software } \\
\text { engineers...Facilities...uhmm...there is two } \\
\text { elements for me, the one is where you provide } \\
\text { hosting, with software as a service neh...then } \\
\text { you can also use facilities in value proposition, } \\
\text { license our clients per facilities for } \\
\text { example...Batch-batch is a difficult } \\
\text { one...uhmm...more historical } \\
\text { thoughts...uhmm...we do mostly real- } \\
\text { time...there is not a cost related to a batch that } \\
\text { has been processed..." }\end{array}$ \\
\hline
\end{tabular}


What team/individuals should be recommended with the costing system initiative.

Expectation regarding the efficiency aspect of the costing system.
[5] "Okay so...uhmmm...cost items...on unit level will obviously be your hardware and your time on a specific solution...on service level its obviously time and-and reworks and revisits...how much time did the implementation and integration took...important to measure it according to standards and also important to measure the actual time and effort to those standards to determine how good and efficient it is...because we are an international company, we must consider measuring ourselves to that standard...on $A B C$ in every department is in place...the service delivery department there is lack of information...usually time within a department...pareto analysis $80 / 20$ to sort out bottlenecks..."

[1] "I think there should be someone who is in control of the whole system....and there should be someone in every department that has been dedicated to ensure that it is done..."

[4] "I think our COO...uhmm...I think he is a stickler for structure and process, so I think he will buy in...our CFO also...I think they are the best bet to get momentum and then...our head of finance...maybe our project accountant...yaa."

[1] "Uhmmm...for me there is a big focus on the time that people spend....uhmmm why I say so, when we for example should buy an loT device...then decisions are made...this one is cheap and comes from China, where the expensive one is from Germany...then usually they say let's take the cheap one....then it don't work...money lost and time consuming..." 
Costing system as a

management tool improves budgeting, decision-making and monitoring controls.
[3] "Shoo...l think the expectation will be that you do achieve a certain degree of accuracy...let's say...uhhh...typical $80 \%$ accuracy of your cost vs actual situation...if you then deviate, what is the reasons...also depends on the industry in which it operates..."

[2] "So it depends right... if you got a proper costing model and your inputs are saying that I predict that I will sell $10 \ldots$.raptors that is almost like units in a hardware perspective, we know what the margins should be...Then yes, you probably get to a degree of...more accuracy...so it should-it should..."

[3]" Agree and I think there is more visibility, better planning and during the project better monitoring and evaluation...after the project lessons learned..." 


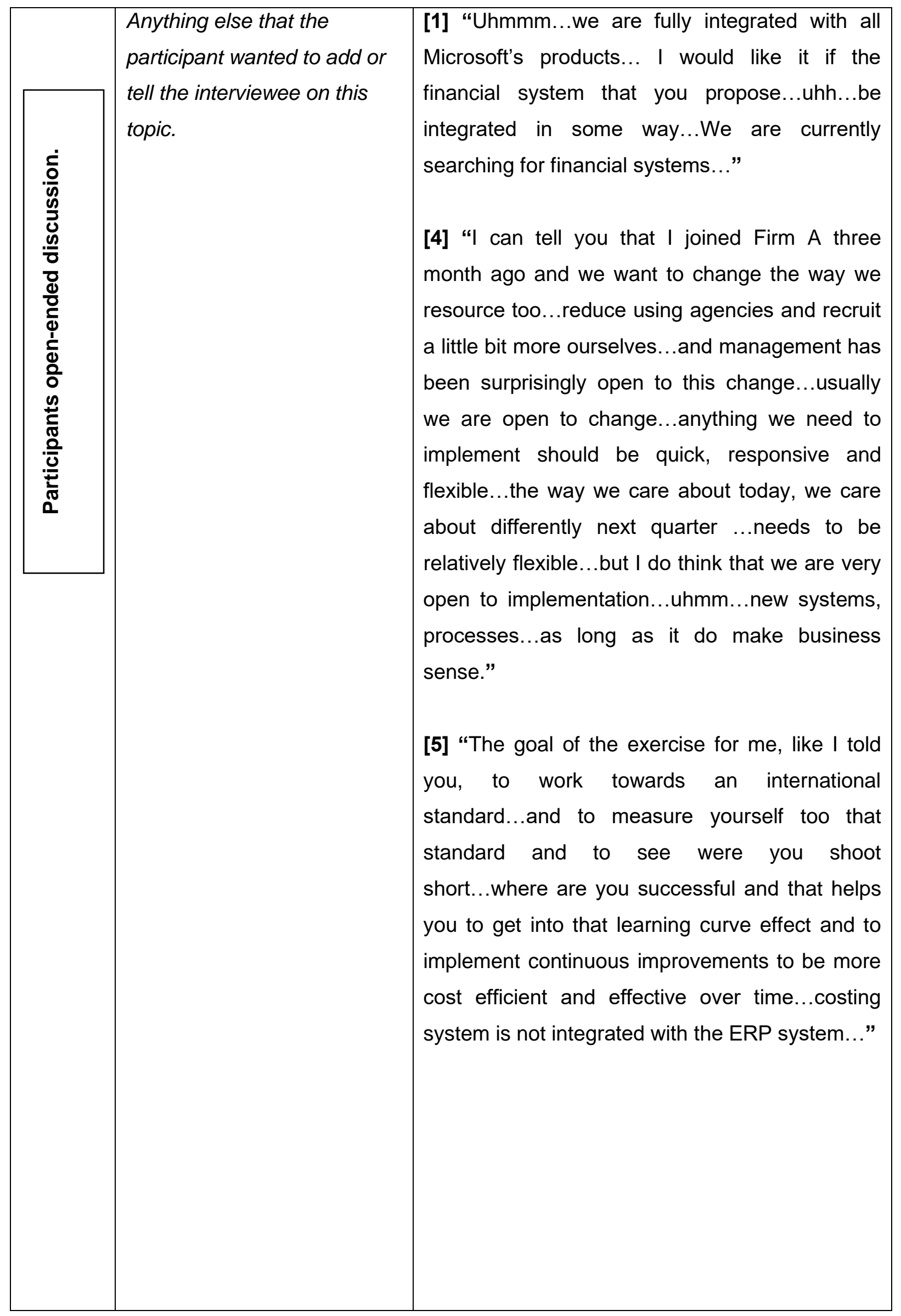




\subsubsection{Findings}

The structured response in the semi-structured interview showed that high implementation cost (Q2) could be a concern with $80 \%$ and that the lack of time (Q3) was a $100 \%$ concern (illustrated in Figure 4.3). However, this depended on the cost-effective ability of the costing system for Firm A, because of the start-up phase. The whole firm operates in real-time feedback services, thus indicating that time is an important factor for Firm A. Furthermore, 'the lack of top management support' and 'not capable to implement the costing system' (Q5 and Q7) were of no concern to the respondents, with $100 \%$ support. This showed that Firm A's top management would support the initiative and implementation of the newly developed costing system.

The verbal responses gave the researcher a better understanding of the current costing system and the flow of activities in Firm A. Throughout the interviews it was shown that Firm A is innovative and open to adapt to any situation. The main activity driver in Firm A is mostly time driven, as the software services are maintained through teams (amount of time used by employee, for example). Thereafter, the use of a time-driven activity-based costing system is going to be used to develop a costing system for Firm A. The main aspects that stood out was that Firm A currently does not cost their customer service, installation teams, project management teams and revisits. Therefore, they do not know how much these departments/sections affect their costing (or how much it costs them; it is currently just an estimated amount). There was an urge that the costing system, currently a manual system, should be converted into an automated system. Furthermore, the current costing system is not linked to or integrated with their ERP system, although they are in the process to change it over the next six months. They struggle to adapt the costing system, because every client's needs are different. They still need to sort out this challenge, because there is still an estimated amount that participates in the costing calculation for clients. It was clarified during the interviews that Firm A expected an $80 \%$ accuracy from the costing system versus actual costs. They would rather sacrifice that $20 \%$ of accuracy, to a system that is automated, quick, responsive and flexible. Yet again, because of Firm A's rapid growth nationally and internationally, they want to benchmark/compare/evaluate their systems to international standards.

Therefore, the most applicable costing system to be implemented for Firm A is a TDABC. As indicated above, the main activity driver in Firm $A$ is mostly time-driven, and a TDABC would allow for more accurate cost/time allocation in the different departments. This should indicate how much time is consumed by each department, activity and management level. 


\subsection{DOCUMENT ANALYSIS}

The document analysis included the following documents, as stated previously: the general ledger, the income statement and payroll documents. These were the only documents that Firm A allowed the researcher to use. These documents were only available at Firm A's office under supervision of management and with the appropriate Covid-19 protocol safety measurements.

- General ledger: This document enabled the researcher to identify types of transactions that took place within Firm $A$ and also to determine all the different departments within the firm.

- Income statement: This document enabled the researcher to extract specific costs that occur within each department, as well as overall costs (including activities, transactions and expenses).

- Payroll document: This document allowed the researcher to determine the different direct labour costs, which would enable this research to demonstrate a practical artifact example through the use of the newly developed costing system.

After the documents had been inspected, reviewed and used, the researcher identified ten departments and their specific activities. The departments indicated that six of them were supporting departments, and four were the service departments that delivered the service to the client. The ten departments are listed below, also indicating whether they were supporting or service departments:

1. Finance (Supporting department)

2. Human Resource Management/HR (Supporting department)

3. Information Technology/IT (Service department)

4. Sales (Service department)

5. Operations (Service department)

6. Product Engineers (Service departments)

7. Projects (Supporting department)

8. Legal (Supporting department with no trace towards the service department)

9. Marketing (Supporting department)

10. CEO Office (Supporting department with no trace towards the service department)

The direct labour cost calculated per month for the supporting departments (Appendix D) were calculated as follows: total activity cost per department per year, divided by 12 (months). 
Therefore, the direct cost per month could be added to the total indirect cost, as indicated in Table 4.9.

The following figure was created to indicate the different departments and their activities (the percentages indicate the activity's consumption):

Figure 4.4: Departments and Activities

\begin{tabular}{|c|c|}
\hline Department & Activity Capacity \\
\hline \multirow[t]{11}{*}{ Finance } & Financial Analysis (3\%) \\
\hline & Budgeting (3\%) \\
\hline & Cost Reports (3\%) \\
\hline & Cashflow Analysis (3\%) \\
\hline & Financial reporting (3\%) \\
\hline & Supply chain (10\%) \\
\hline & Regulatory and Compliance (12\%) \\
\hline & Risk Management (15\%) \\
\hline & Transactional (20\%) \\
\hline & Strategy (15\%) \\
\hline & Board Meetings (13\%) \\
\hline \multirow[t]{4}{*}{ HR } & Customer service (50\%) \\
\hline & Revisits (5\%) \\
\hline & Staff recruitment (30\%) \\
\hline & Marketing (15\%) \\
\hline \multirow[t]{4}{*}{ IT } & Smart Solutions (20\%) \\
\hline & Network \& Internet (30\%) \\
\hline & Infrastructure (30\%) \\
\hline & Security (20\%) \\
\hline \multirow[t]{4}{*}{ Sales } & Service sales (33\%) \\
\hline & Client management (33\%) \\
\hline & Eng Pre-Sales (29\%) \\
\hline & Strategy(5\%) \\
\hline \multirow[t]{4}{*}{ Operations } & Deliverables (50\%) \\
\hline & Strategic planning (10\%) \\
\hline & Project drafts (30\%) \\
\hline & RAC (10\%) \\
\hline \multirow[t]{4}{*}{ Product Engineering } & Deliverables (70\%) \\
\hline & Strategic planning (5\%) \\
\hline & Project drafts (20\%) \\
\hline & Evaluations (5\%) \\
\hline \multirow[t]{4}{*}{ Project } & Deliverables (65\%) \\
\hline & Strategic planning (5\%) \\
\hline & Project drafts (25\%) \\
\hline & Evaluations (5\%) \\
\hline \multirow[t]{4}{*}{ Legal } & Deliverables (85\%) \\
\hline & Strategic planning (5\%) \\
\hline & Project drafts (5\%) \\
\hline & Evaluations (5\%) \\
\hline \multirow[t]{4}{*}{ Marketing } & Deliverables (85\%) \\
\hline & Strategic planning (5\%) \\
\hline & Global Channel PM (5\%) \\
\hline & Evaluations (5\%) \\
\hline \multirow[t]{3}{*}{ CEO Office } & Strategic planning (50\%) \\
\hline & Execution (25\%) \\
\hline & Performance (25\%) \\
\hline
\end{tabular}


With Figure 4.4 having been established, the researcher could proceed to develop the costing system for Firm A by starting with the design stage.

\subsection{DESIGN STAGE}

Firstly, the design stage of the ADR process would be used, as discussed in Chapter 3 . This stage provides a set of activities over the search area of possible design solutions. Through one or more iterative cycles within the design stage, problem formulation, artifact creation and evaluation would be used within the cycle towards the implementation of the costing system for Firm A. Human cognitive and social skills would be added to make accurate contributions to both the problem environment and the knowledge base section (McKay \& Marshall, 2001; Hevner et al. 2004). The TDABC was to be used as the possible design solution for Firm A. This costing system would be used as the direct method, as discussed in Chapter 2 . The supporting department's direct cost was to be included in the indirect-cost pools. It would then be allocated to the specific service departments.

\subsubsection{Problem formulation/planning}

In the problem formulation/planning stage, the following steps were used to develop the specific TDABC system for Firm A. The use of the interviews and documents (general ledger, income statement and payroll) received, helped to gather information to develop the costing system for Firm A.

\subsection{1.i Working hours per year}

The working hours were to be determined by calculating a single employee's working hours per year. This would then allow the multiplication of the single employee's working hours with the total amount of employees at Firm A.

\subsection{1.ii The amount employees in Firm A and allocation in each department}

When the amount of employees was determined, the total hours per year could be calculated. Furthermore, the total amount of employees in Firm $A$ was allocated to their specific departments. Thus, each department's total hours per year could then be determined (the department max capacity supplied).

\subsection{1.iii Current costing per department}

Firm's A current costing amount per department, in other words, the total cost incurred in each department over the year, could be determined. This would be used to compare and evaluate the current versus the new developed costing system. 


\subsection{1.iv Average rate per management level (top, middle, first)}

The classification of the three management levels was to be top-level, middle-level and firstlevel. The average rate (in each level) was used, depending on how much each activity was consuming on each level.

\subsection{1.v Each department's activities and their time consumption}

The percentage of time of how much each activity consumes from the specific department, would indicate how the time consumption was allocated or distributed within each department.

\subsection{1.vi Each activity's top-level, middle-level and first-level time consumption}

Within each activity (in each department) the time consumption (in percentage) was divided into the different management levels again in order to indicate how much time (\%) was used by each management level.

\subsection{1.vii Average rate and their prospective times}

After the management level's time consumption had been allocated to each level, the average rate of each level was multiplied by its corresponding time consumption in each level. This would enable Firm A to see how much costing in each management level is allocated in their activities.

\subsubsection{Artifact creation}

The artifact creation in the design stage enabled the researcher to illustrate how the costing system would be developed, and how the planning phase would practically develop into the artifact creation in order to ensure that the artifact creation is built in the implementation phase.

The flow of the TDABC was developed through the supporting functions (departments), allocated to the service functions (departments), then to the activities within each department, and thereafter it was divided into the three management levels (how much the cost object consumed from the activity). The cost object is the client that makes use of Firm A's services. Below is an illustration of how the flow of the costs would be allocated. 
Figure 4.5: Flow of allocation

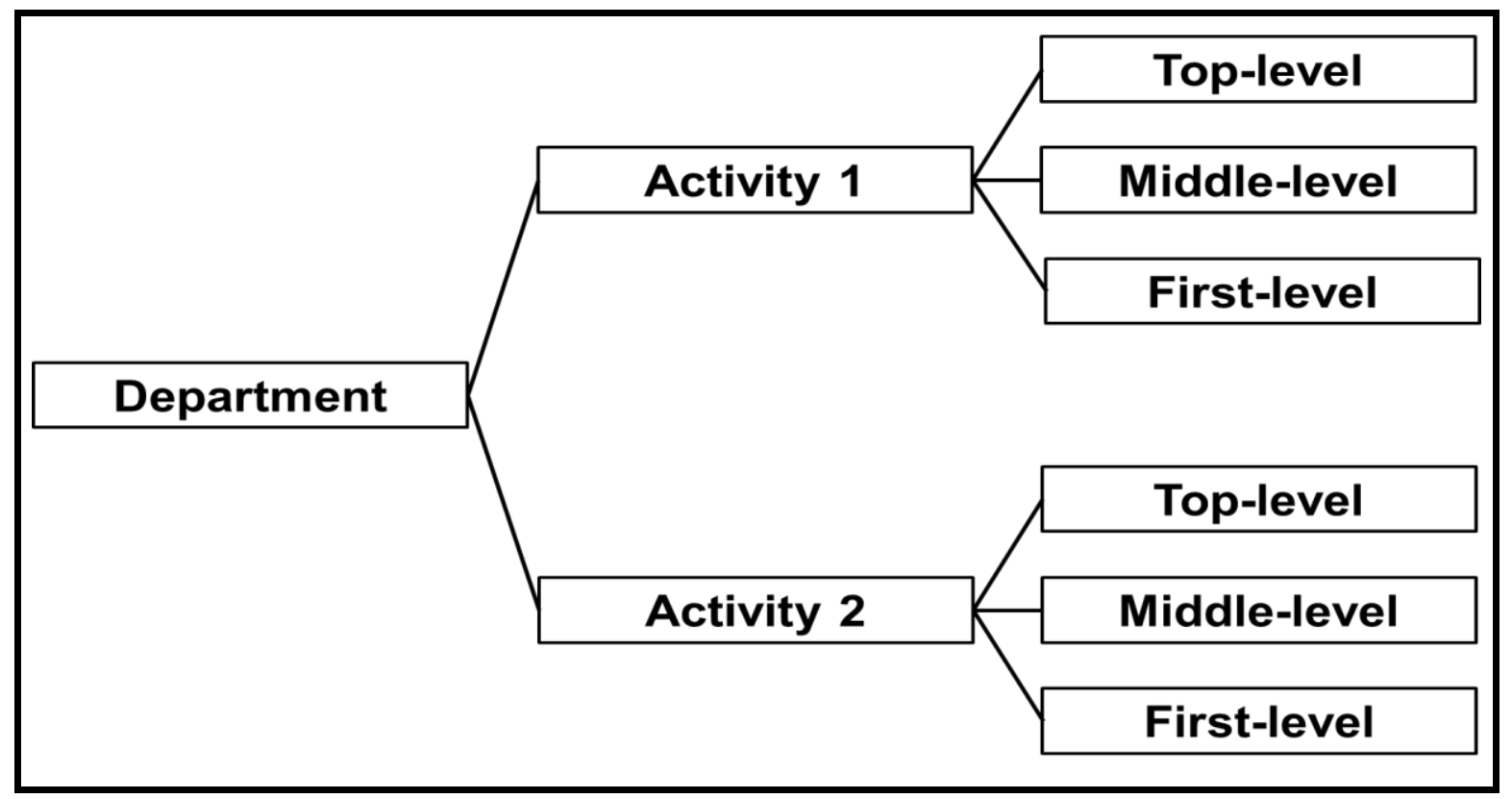

Source: Own Research

\subsection{2.i Calculations Equations}

\subsection{2.i.a Employee capacity per year}

The employee capacity per year should be calculated before the allocation process could start. Firstly, the working days in a year was calculated as follows:

Table 4.2: Working days in 2020

\begin{tabular}{|l|c|c|c|}
\hline \multicolumn{1}{|c|}{ Month } & Workdays & Weekend/Holiday & Total Days \\
\hline January & 22 & 9 & 31 \\
\hline February & 20 & 9 & 29 \\
\hline March & 21 & 10 & 31 \\
\hline April & 19 & 11 & 30 \\
\hline May & 20 & 11 & 31 \\
\hline June & 21 & 9 & 30 \\
\hline July & 23 & 8 & 31 \\
\hline August & 20 & 11 & 31 \\
\hline September & 21 & 9 & 30 \\
\hline October & 22 & 9 & 31 \\
\hline November & 21 & 9 & 30 \\
\hline December & 20 & 11 & 31 \\
\hline Total & $\mathbf{2 5 0}$ & $\mathbf{1 1 6}$ & $\mathbf{3 6 6}$ \\
\hline
\end{tabular}

Source: Own Research 
There were 250 working days in 2020 (South-Africa), as indicated, although this figure may differ from a normal year due to the COVID-19 pandemic that enforced lockdown - which might influence the working days. The researcher still used this amount of working days, as employees worked online or from home.

In Firm A, the active working hours per day is 8 hours. Therefore, the employee can be calculated in the implementation phase as follows:

Employee capacity $=$ Working days in a year $\mathbf{X}$ Working hours per day

Thus, the employee capacity per year is 2000 (250 days $\times 8$ hours) hours per employee. (Note that this is only an estimate to illustrate the costing system. The actual capacity should be less than 2000 hours as lead time was ignored, since that calculation was not part of the scope of this study.)

Furthermore, part of this step also included the apportionment of firm-wide indirect (overhead) costs to the departments. The indirect cost (which includes the property rent, water \& electricity and computer depreciation \& insurance) of the costing system was calculated through the direct method, as discussed. The table below indicates the indirect costs with its appropriate capacity and total cost per month:

Table 4.3: Indirect costs

\begin{tabular}{|l|r|r|r|}
\hline Indirect costs & Capacity (m²/kW/units) & Total cost (R value) & Cost per unit \\
\hline Property Rent $\left(\mathbf{m}^{2}\right)$ & 4000 & $\mathrm{R} 300000$ & $\mathrm{R} 75$ \\
\hline Water \& Electricity (kW) & 15000 & $\mathrm{R} 30000$ & $\mathrm{R} 2$ \\
\hline Computer Depreciation (units) & 300 & $\mathrm{R} 4500000$ & $\mathrm{R} 15000$ \\
\hline
\end{tabular}

\subsection{2.i.b Time allocation capacity equation in each segment}

In order to start implementing the costing system (direct labour), the following segments should be calculated to move onto the next segments: firstly, the departmental capacity, then the activity capacity, thereafter the management usage and lastly the management cost.

\section{* Departmental capacity}

Departmental capacity = Employee capacity (per year) $\mathbf{X}$ Number of employees

\section{* Activity capacity}

Activity capacity = Department capacity $\mathbf{X}$ Time (\%) consumption 
- Top-level cost = Top-level usage $\mathbf{X}$ Top-level rate (per hour)

- Middle-level cost = Middle-level usage $\mathbf{X}$ Middle-level rate (per hour)

- First-level cost = First-level usage $\mathbf{X}$ First-level rate (per hour)

\section{* Management cost}

- Top-level usage = Activity capacity $\mathbf{X}$ Time (\%) consumption

- Middle-level usage = Activity capacity $\mathbf{X}$ Time (\%) consumption

- First-level usage = Activity capacity $\mathbf{X}$ Time $(\%)$ consumption

\subsubsection{Evaluation}

The costing equation, as discussed above, was automatically implemented into the costing tables that would be during the implementation stage. Thereafter, the costing system was evaluated against a potential customer/client as a practical example. Therefore it should clearly illustrate how the costing system would work and which aspects should be considered when it is being used.

\subsection{IMPLEMENTATION STAGE}

Secondly, the ADR process supports the instantiation of the artifacts through an implementation phase. In the implementation cycles, the researcher engages in building and evaluating the given networking and/or accounting information to develop the costing system. Therefore, such artifacts indicate that the ADR implementation cycle includes systems, algorithms, programs, databases and processes. Through one or more iterative cycle within the implementation stage, problem formulation, artifact creation and evaluation were used within the cycle towards the development of the costing system for Firm A.

\subsubsection{Problem formulation/planning}

In the first step of the implementation phase the problem formulation needed to be done before the artifact creation. Therefore, the time-allocation had to be done before the cost-allocation could take place, hence the total capacity had to be determined in each service department. 
Table 4.4: Total capacity per service department

\begin{tabular}{|c|c|c|c|c|c|c|c|c|}
\hline Department & $\begin{array}{l}\text { Number of } \\
\text { Employees }\end{array}$ & $\begin{array}{l}\text { Hours per } \\
\text { employee }\end{array}$ & Total hours & Activity Capacity & Top-level & Middle-level & First-level & \\
\hline \multirow[t]{4}{*}{ IT } & 4 & 2000,00 & 8000,00 & Smart Solutions (20\%) & $60 \%$ & $30 \%$ & $10 \%$ & $100 \%$ \\
\hline & & & & Network \& Internet (30\%) & $60 \%$ & $30 \%$ & $10 \%$ & $100 \%$ \\
\hline & & & & Infrastructure (30\%) & $60 \%$ & $30 \%$ & $10 \%$ & $100 \%$ \\
\hline & & & & Security (20\%) & $60 \%$ & $30 \%$ & $10 \%$ & $100 \%$ \\
\hline \multirow[t]{4}{*}{ Sales } & 96 & 2000,00 & 192000,00 & Service sales (33\%) & $10 \%$ & $15 \%$ & $75 \%$ & $100 \%$ \\
\hline & & & & Client management (33\%) & $5 \%$ & $10 \%$ & $85 \%$ & $100 \%$ \\
\hline & & & & Eng Pre-Sales (29\%) & $2 \%$ & $20 \%$ & $78 \%$ & $100 \%$ \\
\hline & & & & Strategy(5\%) & $95 \%$ & $5 \%$ & $0 \%$ & $100 \%$ \\
\hline \multirow[t]{4}{*}{ Operations } & 20 & 2000,00 & 40000,00 & Deliverables (50\%) & $20 \%$ & $40 \%$ & $40 \%$ & $100 \%$ \\
\hline & & & & Strategic planning (10\%) & $95 \%$ & $5 \%$ & $0 \%$ & $100 \%$ \\
\hline & & & & Project drafts (30\%) & $5 \%$ & $40 \%$ & $55 \%$ & $100 \%$ \\
\hline & & & & RAC (10\%) & $10 \%$ & $50 \%$ & $40 \%$ & $100 \%$ \\
\hline \multirow[t]{4}{*}{ Product Engineering } & 82 & 2000,00 & 164000,00 & Deliverables (70\%) & $10 \%$ & $20 \%$ & $70 \%$ & $100 \%$ \\
\hline & & & & Strategic planning (5\%) & $95 \%$ & $5 \%$ & $0 \%$ & $100 \%$ \\
\hline & & & & Project drafts (20\%) & $5 \%$ & $15 \%$ & $80 \%$ & $100 \%$ \\
\hline & & & & Evaluations (5\%) & $30 \%$ & $0 \%$ & $70 \%$ & $100 \%$ \\
\hline
\end{tabular}

Therefore, each of the service departments' total hours/capacity could be determined and the allocation process could continue to allocate the hours to the specific activity and management level. It is important to point out that top-level, middle-level and first-level cannot equally be divided into a specific level per employee. Although there is segregation of duties between the different levels there will always be some overlapping of duties. For example a top-level manager will also execute some administrative tasks that usually are regarded as first-level management responsibility.

Table 4.5: Hours allocated to activities and management levels

\begin{tabular}{|c|c|c|c|c|c|c|}
\hline Department & Total hours & Activity Capacity & \begin{tabular}{|c|} 
Activity \\
capacity hrs
\end{tabular} & \begin{tabular}{|l|} 
Top- \\
level
\end{tabular} & Middle-level & First-level \\
\hline \multirow[t]{5}{*}{ IT } & 8000,00 & Smart Solutions (20\%) & 1600 & 960 & 480 & 160 \\
\hline & & Network \& Internet (30\%) & 2400 & 1440 & 720 & 240 \\
\hline & & Infrastructure (30\%) & 2400 & 1440 & 720 & 240 \\
\hline & & Security $(20 \%)$ & 1600 & 960 & 480 & 160 \\
\hline & & & 8000 & & & \\
\hline \multirow[t]{5}{*}{ Sales } & 192000,00 & Service sales (33\%) & 63360 & 6336 & 9504 & 47520 \\
\hline & & Client management (33\%) & 63360 & 3168 & 6336 & 53856 \\
\hline & & Eng Pre-Sales (29\%) & 55680 & 1114 & 11136 & 43430 \\
\hline & & Strategy(5\%) & 9600 & 9120 & 480 & 0 \\
\hline & & & 192000 & & & \\
\hline \multirow[t]{5}{*}{ Operations } & 40000,00 & Deliverables (50\%) & 20000 & 4000 & 8000 & 8000 \\
\hline & & Strategic planning (10\%) & 4000 & 3800 & 200 & 0 \\
\hline & & Project drafts (30\%) & 12000 & 600 & 4800 & 6600 \\
\hline & & RAC (10\%) & 4000 & 400 & 2000 & 1600 \\
\hline & & & 40000 & & & \\
\hline \multirow[t]{5}{*}{ Product Engineering } & 164000,00 & Deliverables (70\%) & 114800 & 11480 & 22960 & 80360 \\
\hline & & Strategic planning (5\%) & 8200 & 7790 & 410 & 0 \\
\hline & & Project drafts (20\%) & 32800 & 1640 & 4920 & 26240 \\
\hline & & Evaluations (5\%) & 8200 & 2460 & 0 & 5740 \\
\hline & & & 164000 & & & \\
\hline
\end{tabular}


The hours were allocated to each activity and management level and could therefore allocate the cost to each management level.

\subsubsection{Artifact creation}

In the artifact creation phase, the costing system was implemented with the cost allocation distributed into each activity. The average hour rate for top-, middle- and first-level was costed as R2515, R879 and R380.

Table 4.6: Average hour rate

\begin{tabular}{|c|l|r|}
\hline & \multicolumn{1}{|c|}{$\begin{array}{c}\text { Management } \\
\text { Level }\end{array}$} & Rand value \\
\hline \multirow{2}{*}{$\begin{array}{c}\text { Average annual } \\
\text { salary in each } \\
\text { level }\end{array}$} & Top & 5030869 \\
\cline { 2 - 3 } & Middle & 1758892 \\
\cline { 2 - 3 } & First & 759005 \\
\hline \multirow{2}{*}{$\begin{array}{c}\text { Average Hour rate } \\
\text { (2000 hours) }\end{array}$} & Top & 2515 \\
\cline { 2 - 3 } & Middle & 879 \\
\cline { 2 - 3 } & First & 380 \\
\hline
\end{tabular}

Therefore, the average hour rates were allocated to top-, middle- and first-level. The direct labour of the supporting department's costing system was to be fully developed, as indicated in the table below:

Table 4.7: Rate allocation to management level

\begin{tabular}{|c|c|c|c|c|c|c|}
\hline Department & Total hours & Activity Capacity & Top-level & Middle-level & First-level & $\begin{array}{c}\text { Activity cost per } \\
\text { year }\end{array}$ \\
\hline \multirow[t]{5}{*}{ IT } & 8000,00 & Smart Solutions (20\%) & R 2414400 & R 421920 & R 60800 & R 2897120 \\
\hline & & Network \& Internet (30\%) & R 3621600 & R 632880 & R 91200 & R 4345680 \\
\hline & & Infrastructure (30\%) & R 3621600 & R 632880 & R 91200 & R 4345680 \\
\hline & & Security $(20 \%)$ & R 2414400 & R 421920 & $R 60800$ & R 2897120 \\
\hline & & & & & & R 14485600 \\
\hline \multirow[t]{5}{*}{ Sales } & 192000,00 & Service sales (33\%) & R 15935040 & R 8354016 & R 18057600 & R 42346656 \\
\hline & & Client management (33\%) & R7967520 & R5569344 & R 20465280 & R 34002144 \\
\hline & & Eng Pre-Sales (29\%) & R 2800704 & R9788544 & R 16503552 & R 29092800 \\
\hline & & Strategy(5\%) & R 22936800 & R 421920 & $\mathrm{RO}$ & R 23358720 \\
\hline & & & & & & R 128800320 \\
\hline \multirow[t]{5}{*}{ Operations } & 40000,00 & Deliverables (50\%) & R 10060000 & R 7032000 & R 3040000 & R 20132000 \\
\hline & & Strategic planning (10\%) & R9557000 & R 175800 & $\mathrm{RO}$ & R9732800 \\
\hline & & Project drafts (30\%) & R1509000 & R 4219200 & R2508000 & R8236200 \\
\hline & & RAC (10\%) & R 1006000 & R 1758000 & R 608000 & R 3372000 \\
\hline & & & & & & R 41473000 \\
\hline \multirow[t]{5}{*}{ Product Engineering } & 164000,00 & Deliverables (70\%) & R 28872200 & R 20181840 & R 30536800 & R 79590840 \\
\hline & & Strategic planning (5\%) & R 19591850 & R 360390 & $\mathrm{RO}$ & R 19952240 \\
\hline & & Project drafts (20\%) & R 4 124 600 & R 4324680 & R9971200 & R 18420480 \\
\hline & & Evaluations (5\%) & R6186900 & $\mathrm{RO}$ & R 2181200 & R 8368100 \\
\hline & & & & & & R 126331660 \\
\hline
\end{tabular}


The activity cost per year could be calculated, and that enabled the costing system to calculate the average hour rate per activity.

Table 4.8: Average hour rate per activity

\begin{tabular}{|c|c|c|c|c|c|}
\hline Department & Total hours & Activity Capacity & $\begin{array}{c}\text { Activity } \\
\text { capacity hrs }\end{array}$ & $\begin{array}{c}\text { Activity cost per } \\
\text { year }\end{array}$ & $\begin{array}{c}\text { Average rate per } \\
\text { hour }\end{array}$ \\
\hline \multirow[t]{5}{*}{ IT } & 8000,00 & Smart Solutions (20\%) & 1600 & R 2897120 & R 1811 \\
\hline & & Network \& Internet (30\%) & 2400 & R 4345680 & R 1811 \\
\hline & & Infrastructure (30\%) & 2400 & R 4345680 & R 1811 \\
\hline & & Security $(20 \%)$ & 1600 & R 2897120 & R 1811 \\
\hline & & & 8000 & R 14485600 & R1811 \\
\hline \multirow[t]{5}{*}{ Sales } & 192000,00 & Service sales (33\%) & 63360 & R 42346656 & R 668 \\
\hline & & Client management (33\%) & 63360 & R 34002144 & R 537 \\
\hline & & Eng Pre-Sales (29\%) & 55680 & R 29092800 & R 523 \\
\hline & & Strategy(5\%) & 9600 & R 23358720 & R2 243 \\
\hline & & & 192000 & R 128800320 & R 671 \\
\hline \multirow[t]{5}{*}{ Operations } & 40000,00 & Deliverables (50\%) & 20000 & R 20132000 & R 1007 \\
\hline & & Strategic planning (10\%) & 4000 & R9732800 & R 2433 \\
\hline & & Project drafts (30\%) & 12000 & R 8236200 & R 686 \\
\hline & & $\operatorname{RAC}(10 \%)$ & 4000 & R 3372000 & $\mathrm{R} 843$ \\
\hline & & & 40000 & R 41473000 & R1 037 \\
\hline \multirow[t]{5}{*}{ Product Engineering } & 164000,00 & Deliverables (70\%) & 114800 & R 79590840 & R 693 \\
\hline & & Strategic planning (5\%) & 8200 & R 19952240 & R 2433 \\
\hline & & Project drafts (20\%) & 32800 & R 18420480 & R 562 \\
\hline & & Evaluations (5\%) & 8200 & R 8368100 & R 1021 \\
\hline & & & 164000 & R 126331660 & R 770 \\
\hline
\end{tabular}

Thus, the direct labour in the services department was calculated to the specific activity within each department. The supporting departments' direct labour was included in the indirect cost pools, which was allocated to the four service departments.

Table 4.9: Total indirect cost

\begin{tabular}{|c|c|c|c|c|c|c|c|c|c|c|c|}
\hline \multicolumn{12}{|l|}{ Property Rent $\left(\mathrm{m}^{2}\right)$} \\
\hline & & Finance & HR & IT & \multirow{2}{*}{\begin{tabular}{|l|l|}
\multicolumn{2}{|l}{ Sales } \\
1400
\end{tabular}} & \multirow{2}{*}{\begin{tabular}{|c|} 
Operations \\
250
\end{tabular}} & \multirow{2}{*}{\begin{tabular}{|c|} 
Product Engineers \\
1300 \\
\end{tabular}} & Project & Legal & \multirow{2}{*}{\begin{tabular}{|c|} 
Marketing \\
250 \\
\end{tabular}} & \multirow{2}{*}{\begin{tabular}{|c|} 
CEO Office \\
40 \\
\end{tabular}} \\
\hline Capacity $\left(\mathrm{m}^{2}\right)$ & 4000 & 250 & 70 & 70 & & & & 330 & 40 & & \\
\hline Unit cost (Rvalue) & R75 & R75 & R75 & R75 & R75 & R75 & R75 & R75 & $R 75$ & $R 75$ & $R 75$ \\
\hline Total cost (R value) & R300000 & R18750 & R5250 & R5250 & R 105000 & R18750 & R97500 & $\mathrm{R} 24750$ & R3000 & R18750 & R3000 \\
\hline \multicolumn{11}{|c|}{ Water \& Electricity (kW) } & \\
\hline & & Finance & HR & IT & Sales & Operations & Product Engineers & Project & Legal & Marketing & CEO Office \\
\hline Capacity (kW) & 15000 & 900 & 150 & 150 & 5400 & 900 & 5200 & 1200 & 100 & 900 & 100 \\
\hline Unit cost (Rvalue) & $\mathrm{R} 2$ & R2 & R2 & R2 & $\mathrm{R} 2$ & R2 & R2 & R2 & R2 & R2 & R2 \\
\hline Total cost (Rvalue) & R30000 & R1800 & R300 & R300 & R10800 & R1800 & R10400 & R2400 & R200 & R1800 & R 200 \\
\hline \multicolumn{12}{|c|}{ Computer Depreciation (units) } \\
\hline & & Finance & HR & IT & Sales & Operations & Product Engineers & Project & Legal & Marketing & CEO Office \\
\hline Capacity (units) & 300 & 25 & 6 & 4 & 100 & 20 & 96 & 25 & 2 & 20 & 2 \\
\hline Unit cost (Rvalue) & R15000 & R15000 & R15000 & R15000 & R15000 & R15000 & R15000 & R15000 & R15000 & R15000 & R15000 \\
\hline Total cost (R value) & R4500000 & $R 375000$ & $R 90000$ & R 60000 & R1500000 & $R 300000$ & R1440000 & R375000 & R 30000 & $R 300000$ & R 30000 \\
\hline \multicolumn{2}{|c|}{ Supporting department (Direct labour cost) } & R5 948082 & R2167288 & Ro & Ro & Ro & Ro & R3106208 & R297467 & R3259333 & R811067 \\
\hline Total Indirect cost & R20419445 & $R 6343632$ & R2262838 & $R 65550$ & R1615800 & R320550 & R1547900 & R3508358 & R330667 & R3579883 & R 844267 \\
\hline
\end{tabular}


With the total indirect cost calculated, the allocation of the indirect cost could be allocated to the service departments. Note that, as indicated in the document analysis, the CEO office and Legal Supporting Department did not have a trace towards the service department. Thus they were not allocated to the service.

Table 4.10: Allocation of indirect cost

\begin{tabular}{|c|c|c|c|c|c|c|}
\hline & & IT & Sales & Operations & Product Engineers & \\
\hline Finance & R6343632 & $5 \%$ & $60 \%$ & $10 \%$ & $25 \%$ & $100 \%$ \\
\hline HR & R 2262838 & $5 \%$ & $30 \%$ & $10 \%$ & $55 \%$ & $100 \%$ \\
\hline Project & R 3508358 & $10 \%$ & $30 \%$ & $20 \%$ & $40 \%$ & $100 \%$ \\
\hline \multirow[t]{2}{*}{ Marketing } & R 3579883 & $5 \%$ & $70 \%$ & $15 \%$ & $10 \%$ & $100 \%$ \\
\hline & & IT & Sales & Operations & Product Engineers & \\
\hline Finance & R6343632 & R 317181,60 & R 3806 179,20 & R 634363,20 & R 1585908,00 & \\
\hline HR & R 2262838 & R 113141,88 & R 678851,25 & R 226283,75 & R 1244560,63 & \\
\hline Project & R 3508358 & R 350835,83 & R 1052507,50 & R 701671,67 & R 1403343,33 & \\
\hline Marketing & R 3579883 & R 178994,17 & R 125295,92 & R 18794,39 & R 1879,44 & \\
\hline Total & R 15694711 & R 960153,48 & R 5662833,87 & R 1581 113,00 & R4 235691,40 & \\
\hline \multicolumn{2}{|c|}{ Plus indirect cost } & R 65550 & R 1615800 & R 320550 & R 1547900 & \\
\hline \multicolumn{2}{|c|}{ Total indirect cost } & R 1025703,48 & R7 278 633,87 & R 1901663,00 & R 5783591,40 & \\
\hline \multicolumn{2}{|c|}{ Total Capacity Hours (monthly) } & 666,67 & 16000 & 3333,33 & 13666,67 & \\
\hline \multicolumn{2}{|c|}{ Cost per hour } & R 1538,56 & R 454,91 & R 570,50 & $\mathrm{R} 423,19$ & \\
\hline
\end{tabular}

The indirect cost per hour was calculated within each of the service departments and could then be allocated to the direct object or client.

\subsubsection{Evaluation}

The evaluation phase included the artifact practical example that will be used to illustrate and be evaluated against a potential client for Firm A. Therefore, the costing system will help Firm A to ensure that there is enough capacity in each department/activity to accept the potential client's offer. It will also cost the client's request for the use of Firm's A services.

\subsection{3.i Artifact practical example (Client X)}

Client $X$ approaches Firm $A$ to implement/use their services and resources. The following questions should be answered:

What activities are going to be used?

How many hours per month are going to be used in each activity requested?

Client $X$ should answer these questions through their request, as they want to be quoted by Firm A. Thus, Firm A can calculate the cost of activities (and their usage) and can also ensure that the firm does have enough capacity to accept the request. 
We suppose Client $X$ sent the following activities and hours that they wanted to make use of each month:

- Service sales (Sales) $=\mathbf{2}$ hours

- Client management (Sales) $=\mathbf{3}$ hours

- Smart Solutions (IT) $=\mathbf{9 0}$ hours

- $\quad$ Network and internet $(\mathrm{IT})=\mathbf{9 0}$ hours

- Deliverables (Operations) $=\mathbf{1 0}$ hours

- $\quad$ Strategic planning (Operations) $=\mathbf{5}$ hours

- Deliverables (Product Engineer) $=\mathbf{5 0}$ hours

- $\quad$ Project Drafts (Product Engineer) $=\mathbf{2 5}$ hours

Total hours $=\mathbf{2 7 5}$ hours

Thus, if Firm A does have enough capacity in each activity, they may accept the offer and start calculating the cost. If not, Firm A could still accept the offer, but its employees might then have to work over-time, or the firm could outsource the activities that are more than it is capacitated to do.

Let us assume Firm A does have enough capacity and is going to accept the service to Client X.

Table 4.11: Costing Client $X$

\begin{tabular}{|l|c|c|c|c|c|}
\hline \multicolumn{1}{|c|}{ Activity } & Hours & Direct labour rate & Indirect labour rate & Total rate (direct + indirect) & Total cost \\
\hline Service sales & 2 & $\mathrm{R} 668$ & $\mathrm{R} 454,91$ & $\mathrm{R} 1122,91$ & $\mathrm{R} 2245,82$ \\
\hline Client management & 3 & $\mathrm{R} 537$ & $\mathrm{R} 454,91$ & $\mathrm{R} 991,91$ & $\mathrm{R} 2975,73$ \\
\hline Smart Solutions & 90 & $\mathrm{R} 1811$ & $\mathrm{R} 1538,56$ & $\mathrm{R} 3349,56$ & $\mathrm{R} 301460,40$ \\
\hline Network and internet & 90 & $\mathrm{R} 1811$ & $\mathrm{R} 1538,56$ & $\mathrm{R} 3349,56$ & $\mathrm{R} 301460,40$ \\
\hline Deliverables & 10 & $\mathrm{R} 1007$ & $\mathrm{R} 570,50$ & $\mathrm{R} 1577,50$ & $\mathrm{R} 15775,00$ \\
\hline Strategic planning & 5 & $\mathrm{R} 2433$ & $\mathrm{R} 570,50$ & $\mathrm{R} 3003,50$ & $\mathrm{R} 15017,50$ \\
\hline Deliverables & 50 & $\mathrm{R} 693$ & $\mathrm{R} 423,19$ & $\mathrm{R} 1116,19$ & $\mathrm{R} 55809,50$ \\
\hline Project drafts & 25 & $\mathrm{R} 562$ & $\mathrm{R} 423,19$ & $\mathrm{R} 985,19$ & $\mathrm{R} 24629,75$ \\
\hline Total & $\mathbf{2 7 5}$ & & & & $\mathrm{R} \mathrm{719} 374,10$ \\
\hline
\end{tabular}

Thus, Client $X$ could be costed at R719 374,10 per month for the service of 275 hours. Therefore, the cost of $\mathrm{R} 719374,10$ would be the minimum value that Firm A would accept. 


\subsection{SUMMARY}

The aim of this chapter was to address the secondary objective that was set in Chapter 1 , namely to collect, review and analyse data obtained through interviews, document analysis and observations from the digital service firm to develop a new costing system.

This chapter introduced the empirical study conducted on the selected case study and the findings thereof. The firm's current costing system was also investigated through interviewing, observation and questionnaires sent to the research participants. This enabled the researcher to collect and analyse data obtained from the firm to develop the new costing system.

The costing system was developed through the use of the TDABC method. The total capacity in each department in Firm A was calculated, and that enabled the researcher to assign the time allocation into their specific activities. The activities were then assigned into the three management levels and each one's specific time consumption. Firm A could use the costing system for client's costing and for their use to manage resources (including their time). Performance management (through the use of the new costing system) could also be a tool for Firm A to monitor and evaluate its employees' work. With the new costing system developed for Firm A, the costing could be more accurate (including revisits activity, etc.) which would enable them to do better digital costing. This costing system would also be compatible to work with any adequate ERP system.

The qualitative approach was applied to this case study and all appropriate procedures to the approach was complied with. The credibility of this study was build on the in-depth explanation of each participant's feedback using their direct words. Furthermore, the reliability and validity are trusted to enable qualitative research to be trustworthy. Evidence of the findings, including documents and voice recordings, are stored safely for adequate trustworthiness. 


\section{CHAPTER 5: CONCLUSION}

\subsection{INTRODUCTION}

The objective of this chapter is to address the last secondary objective stated in Chapter 1 , namely that of concluding the study and indicating how the results of this study might benefit Firm A. This chapter will also conclude the study and how the results support the systems theory. The conclusion will also indicate to what extent the main objective has been achieved, namely: to develop a costing system for a digital technology service firm.

In Chapter 1 the research problem stated that Firm A competes with similar service providers in a highly competitive global market. Increasing global competitiveness has forced many organisations to render services at a competitive cost and price. In order to achieve the above, service providers such as Firm A should adopt a more proactive approach to cost management, rather than being reactive when they are already facing financial challenges (Aguilar \& Ittner, 2018). A digital technology firm may face different challenges with their costing systems and/or processes compared to a conventional business. The question then arose what a costing system for a digital technology service firm should look like.

Chapter 5 is constructed in accordance with the diagram below and flows as follows:

Figure 5.1: Flow diagram of Chapter 5

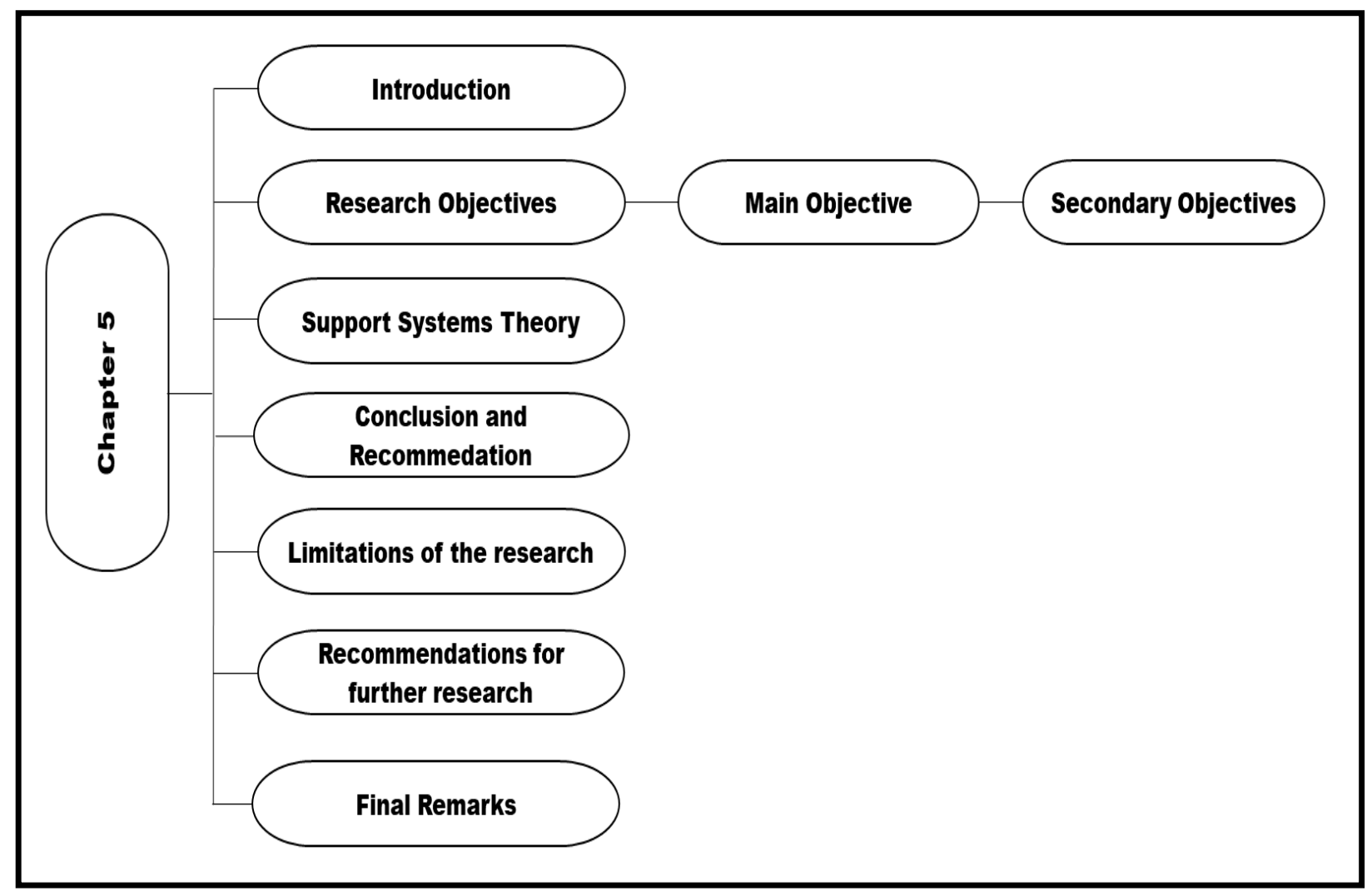

Source: Own Research 


\subsection{RESEARCH OBJECTIVES}

The TDABC was developed and has been evaluated by using an artifact practical example. Therefore, the costing system could be tested with the use of Client $X$ that was created. The activities that Client $X$ required Firm $A$ to deliver, as well as the amount of hours needed for the activities, were determined. Thus, these activities were quoted through the use of management levels (top-, middle- and first-level) and their different time consumptions. This enabled Firm A to calculate a minimum value to quote Client $X$ and gave Firm $A$ an approximate guideline for an entry point to start their costing, which could also be connected to their ERP system. This costing system could help Firm A to make better financial/strategic decisions, which would enable them to save more money that could be reinvested into the Firm (digital costing). The costing system could also be used in performance management, ensuring each department and each activity stays within its maximum capacity.

\subsubsection{Main Objective}

The main objective of this study was to develop a costing system for a digital technology service firm. Thus, the objective of this study was to investigate the current costing model of a digital technology service firm to establish if it offers reliable costing information. If it is found that the information is not reliable, the information obtained could be used in identifying the components for the development of a costing system that would improve cost management, also providing data for informed decision-making in an effort to maximise value and to remain relevant in the market.

The motivation to choose Firm A emanated from the view expressed by the firm's Chief Executive Officer (CEO) that its current costing system mainly focused on firm growth - which was a priority in the past - without giving consideration to the appropriateness of the costing system.

\subsubsection{Secondary Objectives}

To successfully achieve the main objective of developing a costing system for a digital technology service firm, secondary objectives that would enable the study to reach its main objective, were set in Chapter 1.

The first secondary objective of this study was to review the literature on the nature and benefits of TCS, ABC and TDABC, and this objective was conducted in Chapter 2. This included discussions of the nature of TCS, ABC and TDABC and their differences, as well as previous studies on the development of costing systems and a discussion of digital costing. 
The second secondary objective of this study was to discuss and select an appropriate research methodology and design to reach the primary objective, and this was conducted in Chapter 3. The research onion was used in the research methodology process and consisted of the following six categories: philosophies, approaches, strategies, method choices, time horizons and techniques/procedures. Each category was discussed in depth to enable the researcher to apply the most applicable methods to the study.

The third secondary objective of this study was to collect, review and analyse data obtained through interviews, document analysis and observations from the digital service firm to develop a new costing system. This objective was conducted in Chapter 4. A time-driven activity-based costing system was developed for Firm A, and it was evaluated against an artifact practical example. This would allow Firm A to calculate a minimum value when approached by a client.

The fourth secondary objective of this study was to conclude the study and to indicate how the results of this study may benefit Firm $A$. This was done in this chapter, Chapter 5 , and indicated how the main objectives have been achieved and how this study supports the systems theory.

\subsection{SUPPORT THE SYSTEMS THEORY}

Systems theory is used to explain problems holistically, which differs from the Western science on how it was originally applied. The use of the systems theory as a contextual framework is an underexplored theory in management studies, seemingly owing to its integrated approach (Teece, 2018:366).

Checkland (1981:12) argues that "systems thinking starts from noticing the unquestioned Cartesian assumption: namely that a component part is the same when separated out as when it is part of the whole". The two pillars of systems theory, namely 'social' and 'process', strongly indicate the relevance of the theoretical framework in this study.

The first pillar, social systems, is complex and does not serve one purpose (Hutchins, 1996). Hutchins further believes that the individual perspectives on the purpose of a system could not be set or attached to it, due to its diversity of perspectives. Each employee in Firm A would define and use the costing system differently, as each employee's perspective differs. This would allow different purposes for each individual, but in this case study it is the purpose and use of cost accounting. Therefore, the observer defines the purpose of the system.

The second pillar of the systems theory is that one should understand the ways and purpose of a system to understand the process as a whole. To understand the Hutchins (1996) framework, the systems theory should be divided into the following four components: 
- The description of the aspects/nature of the specific system: The nature of the costing system is a TDABC system that is time-based, allowing Firm $A$ to integrate the costing system with their ERP system. Therefore, the costing system could be updated automatically through the ERP system that would equip them with a quicker response towards the costing system.

- The explanation of how the components in the system interacts: The components in the systems are based on the TDABC, where time is the main overhead activity driver. The time is then allocated to their departments, activities and then to management level(s). The management level cost driver is then multiplied with their specific times, enabling the system to cost their activities.

- The determination whether the system is effective: The costing system that was developed for Firm A was evaluated against an artifact practical example. This would illustrate how the costing system works and whether it is adequate for Firm A to implement it in their costing processes.

- The Identification to which extent the systems can function in practice compared to the ideal jointed use of archival material: This costing system is functional in the (in)direct labour hours system, as Firm A is a digital technology service firm, providing mostly labour hours (time) to their clients.

\subsection{CONCLUSION AND RECOMMENDATION}

The researcher found that Firm A did not have a trustworthy costing system when quotations were given to clients. Firm A currently does not cost their customer service, installation teams, project management teams and revisits. The researcher used the inductive approach to develop the new costing system for Firm A. In conclusion, the new costing system is needed for Firm A to quote their clients more accurately and also to eliminate cross-subsidy.

The recommendation is that Firm A should implement the new costing system as a foundation, and then adapt/change/integrate/improve the costing system - as this is only an example. The rand values were only $80 \%$ accurate and the working hours were only a calculated estimated value.

\subsection{LIMITATIONS OF THE RESEARCH}

The purpose of this study, namely developing a costing system for a digital technology service firm, required that assumptions had to be made. This study assumed that the financial information received from Firm $A$ to develop the costing system was correct. It has also been accepted that the head of management in each department allocated the time distribution in each activity and at management levels adequately/accurately. It has been assumed that all the 
participants that were interviewed reflected the truth when expressing their opinions. Therefore, the participants that gave verbal information did it in an unbiased manner to ensure that the best feedback is given in order to develop the costing system.

Due to the COVID-19 pandemic, the semi-structured interviews could not be conducted face-toface in person and were held with Microsoft Teams meetings. The lockdown regulations in Level 3 were still strict and human interaction limited and to some extent illegal in some instances. Therefore, some aspects of the human experience, interactions and atmosphere could not be fully experienced as in a normal face-to-face semi-interview. The one interview with the CFO was also limited to a phone call due to power outage (unscheduled load shedding). While face time was thus unavailable, the researcher still received all the feedback adequately.

This study was also limited by using only two of the four ADR cycles, as the size of this study is only that of a mini-dissertation. Thus, within each cycle, only the first three segments (problem formulation/planning, artifact creation and evaluation) of the five segments could be used to develop the costing system. The case study was however still conducted and tended to be fully functional and able to develop the costing system.

Lastly, the costing system that was developed for Firm A is only a model for Firm A, as other firms would not be able to use it as it is. Some adjustments should be made for other firms, as departments and activities differ from firm to firm. The costing system is only a stepping stone for Firm A to use, as it is not a full costing system that includes all the phases; this is only the first phase of the business support function of the employees' labour.

\subsection{RECOMMENDATIONS FOR FURTHER RESEARCH}

Therefore, the following topics could be investigated in the future:

- This study developed a TDABC as an alternative costing system for Firm A. In cost accounting, the processes and thinking could always improve, as digital technology increases and the market/industry demand/outputs are constantly changing. Thus, new or other costing methods could be developed or investigated.

- This costing system that was developed for Firm A could be extended or built upon, as this costing system was only focused on the services that Firm A provides to clients. A further investigation could be done on more products, facilities, assets, etc. Thus, more specific resources that could include more (in)direct costs could be focused on. 
- Furthermore, it could be investigated to what extent a TDABC could impact digital costing, as well as the future of finance (including digital currencies), namely whether costing systems are still going to be effective in the future of finance and transactions.

- A further investigation on the assessment of performance management and the use of TDABC could be done, namely whether TDABC could be a financial tool that management could use to monitor, evaluate and improve employee's performance.

\subsection{FINAL REMARKS}

The aim of this study has succesfully been reached. The scientific research process was followed with the ADR as the paradigm. All the objectives have been achieved, as discussed in Chapter 5 (5.2). The research onion was used to identify and select the most appropriate methodology for this study. The data was collected through the semi-structured interviews, document analysis and observations. Care was taken that this study meets the requirements of reliability, validity, credibility and trustworthiness.

The originality of the study lies therein that, although there are many examples (studies) that have developed/implemented new ABC/TDABC systems, this one is unique because there are no similar examples for a digital service firm. The value of the study is that Firm A can make use of this new costing system which would enable them to qoute their clients more accurately. This study may serve as an example for similar firms, although this is only tailor-made for Firm $A$. 


\section{REFERENCING LIST}

Accenture, 2019. The post-digital era is upon us. Are you ready for what's next? https://www.accenture.com/ acnmedia/pdf-108/accenture-communications-technology-vision2019-full-report.pdf Date of access: 12 Jan. 2020.

Accounting for Management. 2020. Service department costing. https://www.accountingformanagement.org/direct-method-of-cost-allocation/ Date of access: 12 Nov. 2020.

Aguilar, O.I. \& Ittner, C.D. 2018. Cost management in the digital era. China Management Review, 4(2):14-21.

Akyol, D., Tuncel, G. \& Bayhan, M. 2007. A comparative analysis of activity-based costing and traditional costing. International Scholarly and Scientific Research \& Innovation, 1(3):136-139.

Back, E. Maxwell, D. \& Isidore, L. 2000. Activity-based costing as a tool for process improvement evaluations. Journal of Management in Engineering, 16(2):48-58.

Baxter, P. \& Jack, S. 2008. Qualitative case study methodology: Study design and implementation for novice researchers. The Qualitative Report, 13(4):544-559.

Bernard, H.R. 2017. Research Methods in Anthropology. 6th ed. Lanham: Rowman \& Littlefield.

Bhimani, A. \& Bromwich, M. 2009. Management accounting in a digital and global economy: The interface of strategy, technology, and cost information. London: Oxford University Press.

Bisman, J. 2010. Post-positivisam and accounting research: A (personal) primer on critical realism. Australasian Accounting, Business and Finance Journal, 4(4):3-25.

Black, I. 2006. The presentation of interpretivist research. Qualitative Market Research: An International Journal, 9(4):319-324.

Boulding, K.E. 1956. General systems theory the skeleton of science. Management Science, 2:197-208.

Bryman, A. \& Bell, E. 2011. Business research methods. 3rd ed. Oxford: Oxford University Press.

Bryman, A. 2012. Social research methods. 5th ed. Oxford: Oxford University Press.

Burrell, G. \& Morgan, G. 1979. Sociological paradigms and organisational analysis. London: Heinemann.

Bvumbi, M.N. 2017. An analysis of the implementation of activity based costing at the Water Trading Entity. Pretoria: UNISA. (Dissertation - MPhil).

Cagwin, D. \& Bouwman, M.J. 2002. The association between activity-based costing and improvement in financial performance. Management Accounting Research, 13(1):1-39. 
Campbell, R.J. 1995. Steeling time with ABC or TOC. Management Accounting (US), 76(7):3136.

Cardos, I. \& Pete, S. 2011. Activity-based costing (ABC) and activity-based management (ABM) implementation - Is this the solution for organizations to gain profitability? Romanian Journal of Economics, 32(1):151-168.

Carson, D., Gilmore, A., Perry, C. \& Gronhaug, K. 2001. Qualitative Marketing Research. London: Sage.

Chan, E.A., Jones A. \& Wong, K. 2013. The relationships between communication, care and time are intertwined: a narrative inquiry exploring the impact of time on registered nurses' work. Leading Global Nursing Research, 69(9):2020-2029.

Chea, A.C. 2011. Activity-based costing system in the service sector: A strategic approach for enhancing managerial decision making and competitiveness. International Journal of Business and Management, 6(11):3-10.

CIMA. 2013. Activity-Based Costing (ABC). https://www.cgma.org/resources/tools/essentialtools/activity-based-costing.html Date of access: 5 Feb. 2020.

CIMA. 2019. Re-inventing finance for a digital world. https://www.cimaglobal.com/Future/thefuture-of-finance/ Date of access: 5 Feb. 2020.

Cokins, G. \& Căpuşneanu, S. 2010. Cost Drivers. Evolution and Benefits. Theoretical and Applied Economics, 8(549):7-16.

Collis, J. \& Hussey, R. 2003. Business research: A practical guide for undergraduate and postgraduate students. Hampshire: Palgrave Macmillan.

Cooper, R. \& Kaplan, R.S. 1991. Profit priorities from activity-based costing. Harvard Business Review, 69(3):130-135.

Creswell, J.W. 1998. Qualitative inquiry and research design: Choosing among traditions. Thousand Oaks, CA: Sage.

Creswell, J. 2014. Research design: Qualitative, quantitative and mixed methods approaches. 4th ed. CA: Sage.

Crowther, D. \& Lancaster, G. 2008. Research methods: A concise introduction to research in management and business consultancy. Oxford: Elsevier Butterworth-Heinemann.

Danbolt, J., Siganos, A. \& Vagenas-Nanos, E. 2015. Investor sentiment and bidder announcement abnormal returns. Journal of Corporate Finance, 33(1):164-179.

Daugherty, P. 2019. Managing technology for the post-digital era. https://sloanreview.mit.edu/article/managing-technology-for-the-post-digital-era/ Date of access: 24 Nov. 2019. 
De Villiers, R.R. 2015. Evaluating the effectiveness of a newly developed simulation in improving the competence of audit students. Potchefstroom: North-West University. (Thesis PhD).

De Vos, A.S., Strydom, H., Fouche, C.B. \& Delport, C.S.L. 2005. Research at grass roots: For the social sciences and human service professions. 3rd ed. Hatfield, Pretoria: Van Schaik.

Deloitte. 2019. Save-to-transform as a catalyst for embracing digital disruption.

https://www2.deloitte.com/us/en/pages/operations/articles/global-cost-management-survey.html Date of access: 27 Feb. 2020.

Demeere, N., Stouthuysen, K. \& Roodhooft, F. 2009. Time-driven activity-based costing in an outpatient clinic environment: Development, relevance and managerial impact. Health Policy, 92:296-304.

Drury, C. 2012. Management and Cost Accounting. 8th ed. Hampshire: Cengage Learning.

EduPristine. 2017. Costing methods \& important cost terms.

https://www.edupristine.com/blog/costing-methods. Date access: 12 Jul. 2020.

Elden, M. \& Chisholm, R.F. 1993. Emerging Varieties of Action Research: Introduction to the Special Issue. Human Relations, 46:121-142.

Feilzer, M.Y. 2010. Doing mixed methods research pragmatically: Implications for the rediscovery of pragmatism as a research paradigm. Journal of Mixed Methods Research, $4(1): 6-16$.

Flick, U. 2011. Introducing research methodology: A beginner's guide to doing a research project. London: Sage.

Gaille, B. 2018. Traditional costing system advantages disadvantages.

https://brandongaille.com/13-traditional-costing-system-advantages-disadvantages/Date of access: 2 May. 2020.

Gillham, B. 2008. Case study methods. 1st ed. London: Biddles Ltd.

Glad, E. \& Becker, H. 1996. Activity-based costing and management. New York: John Wiley and Sons.

Goddard, W. \& Melville, S. 2004. Research methodology: An introduction. 2nd ed. Hoboken, $\mathrm{NJ}$ : Blackwell Publishing.

Granof, M.H., Platt, D.E. \& Vaysman, I. 2000. Using activity-based costing to manage more effectively department of accounting. PricewaterhouseCoopers Endowment for Business of Government.

Gulati, P.M. 2009. Research management: Fundamental and applied research. New Delhi: Global India Publications.

Gunasekaran, A., Williams, H.J. \& MacGaughey, R.E. 2005. Performance measurement and costing system in a new enterprise. Technovation, 25:523-533. 
Herbst, F. \& Coldwell, D. 2004. Business research. New York: Juta.

Heron, J. 1996. Co-operative inquiry: Research into the human condition. London: Sage.

Hevner, A., March, S., Park, J. \& Ram, S. 2004. Design science in information systems research. MIS Quarterly, 28(1):75-105.

Howell, K.E. 2013. An Introduction to the philosophy of methodology. 1st ed. London: Sage.

Hutchins, L.C. 1996. Systems thinking: Solving complex problems. Saint Louis, MO:

Professional Development Systems.

IDC (International Data Corporation). 2018. Worldwide Spending on Digital Transformation Will Reach \$2.3 Trillion in 2023.https://www.idc.com/getdoc.jsp?containerld=prUS45612419 Date access: 24 Nov. 2019.

Jan, O. 2013. Cost Accounting Systems. https://xplaind.com/360325/cost-systems Date of access: 10 Apr. 2020.

Ittner, C.D., Lanen, W.N. \& Larcker, D.F. 2002. The association between activity-based costing and manufacturing performance. Journal of Accounting Research, 40(3):711-726.

Ivankova, N., Creswell, J. \& Plano Clark, V. 2016. Foundations and approaches to mixed methods research. (In Maree, K., ed. First step into Research. 2nd ed. Pretoria: Van Schaik, pp. 305-336).

Johnson, H.T. \& Kaplan, R.S. 1987. Relevance lost: The rise and fall of management accounting. Boston: Harvard Business School Press.

Kaplan, R.S. \& Bruns, W. 1987. Accounting and management: A field study perspective. Boston: Harvard Business School Press.

Kaplan, R.S. 1998. Cost \& effect: Using integrated cost systems to drive profitability and performance. Boston: Harvard Business School Press.

Kaplan, R.S. \& Anderson, S.R. 2003. Time-driven activity-based costing. 1st ed. Boston: Harvard Business School Press.

Kaplan, R.S. \& Anderson, S.R. 2004. Time-driven activity-based costing. Harvard Business Review, 131-138.

Kaplan, R.S. \& Anderson, S.R. 2007. Time-driven activity-based costing. Boston: Harvard Business School Press.

Kessler, E.H. 2017. Encyclopaedia of management theory. London: Sage.

Kothari, C. 2004. Research methodology: Methods \& techniques. 2nd ed. New Delhi: New Age International. 
Kowsari, F. 2014. Changing in costing models from traditional to performance focused activity based costing (PFABC). European Online Journal of Natural Social Science, 2(3):2497-2508.

Krishnan, A. 2007. An application of activity based costing in higher learning institution: A local case study. Contemporary Management Research, 2(2):75.

Lelkes, A-M.T. 2009. Simplifying activity-based costing. Oklahoma State University. (Thesis $\mathrm{PhD})$.

Lewis, J.L. \& Sheppard, S.R.J. 2006. Culture and communication: can landscape visualization improve forest management consultation with indigenous communities? Landscape and Urban Planning, 77:291-313.

Lind, G.H. 2001. Activity based costing: Challenging the way we cost underground coal mining systems. The Journal of the South African Institute of Mining and Metallurgy, 77-83.

Lodico, M.G., Spaulding, D.T \& Voegtle, K.H. 2010. Methods in educational research: From theory to practice. Hoboken, NJ: John Wiley \& Sons.

Mackenzi, D. 2014. A sociology of algorithms: High-frequency trading and the shaping of markets. University of Edinburgh.

Mahal, I. \& Hossain, A. 2015. Activity-based costing (ABC) - An effective tool for better management. Research Journal of Finance \& Accounting, 6(4):66-73.

Maluleke, M.J. 2019. Comparative analysis of activity based costing as an alternative to the traditional costing methods in SASSA. Pretoria: UNISA. (Thesis - MPhil).

Maree, K. 2016. Planning a research proposal. (In: Maree, K. First steps in research. 2nd ed. Pretoria: Van Schaik Publishers, pp. 26-47).

Maree, K. \& Pietersen, J. 2016. Planning a research proposal. (In: Maree, K. First steps in research. 2nd ed. Pretoria: Van Schaik Publishers, pp. 192-202).

Marshall, C. \& Rossman, G.B. 1999. Designing qualitative research. 3rd ed. London: Sage.

McKay, J. \& Marshall, P. 2001. The dual imperatives of action research. Information Technology \& People, 14(1):46-59.

McKerchar, M. 2008. Philosophical paradigms, inquiry strategies and knowledge claims: Applying the principles of research design and conduct to taxation. eJournal of Tax Research, 6(1):5-22.

Meriläinen, M., Kyngäs, H. \& Ala-Kokko, T. 2010. 24-hour intensive care: An observational study of an environment and events. Intensive \& Critical Care Nursing, 26(5):246-253.

Mishra, B. \& Vaysman, I. 2001. Cost-system choice and incentives - Traditional vs. activitybased costing. Journal of Accounting Research, 39(3):619-641. 
Moorthy, M., Voon, O., Samsuri, C., Gopalan, M. \& Yew, K. 2012. Application of information technology in management accounting decision making. International Journal of Academic Research in Business and Social Sciences, 2(3):1-16.

Mouton, J. 2015. How to succeed in your Master's \& Doctoral Studies. A South African guide and resource book. 2nd ed. Pretoria: Van Schaik.

Mullarkey, M.T. \& Hevner, A.R. 2019. An elaborated action design research process model. European Journal of Information Systems, 28(1):6-20.

Namazi, M. 2016. Time-driven activity-based costing: Theory, applications and limitations. Iranian Journal of Management Studies, 9:457-482.

Ngcobo, N.L. 2019. An evaluation of an activity-driven operational cost accounting framework in an electricity distribution company. Potchefstroom: North-West University. (Mini-dissertation MCom).

Nkuna, M.R. 2018. Developing an activity-driven costing framework for a South African cash service company. Potchefstroom: North-West University. (Mini-dissertation - MCom).

Noah, A. 2019. The Future of finance: How to thrive in the digital age. https://www.cimaglobal.com/Members/Insights/The-Future-of-Finance-How-to-thrive-in-thedigital-age/ Date of access: 12 Feb. 2020.

Osanloo, A. \& Grant, C. 2016. Understanding, selecting, and integrating a theoretical framework in dissertation research: Creating the blueprint for 'house'. Administrative Issues Journal: Connecting Education, Practice and Research, 4(2):7.

Patton, M.Q. 2002. Qualitative evaluation and research methods. 3rd ed. Thousand Oaks, CA: Sage.

Phan, T., Baird, K. \& Blair, B. 2014. The use and success of activity-based management practices at different organisational life cycle stages. International Journal of Production Research, 52(3):787-803.

Plummer, P. 2017. Focus group methodology. Part 1: Design considerations. International Journal of Therapy and Rehabilitation, 24(7):297-301.

Popesko, B. 2009. How to implement an accurate and effective costing system in manufacturing organizations. European Financial and Accounting Journal, 4(4):35-49.

Reynolds, A. \& Van der Poll, H. 2015. ABC implementation in the Nelson Mandela Bay Metropole: How far should manufacturing organizations go? South African Business Review, 19(2):118-136.

Richmond, B. 1994. Systems Thinking/System Dynamics: Let's Just Get on with It. System Dynamics Review, 10:135-157.

Rule, P. \& John, V. 2011. Your guide to case study research. 1st ed. Pretoria: Van Schaik. 
Saunders, M., Lewis, P. \& Thornhill, A. 2007. Research methods for business students. 6th ed. London: Pearson.

Schutte, D.P., Nkuna, N.R., Middelberg, S.L. \& Oberholzer, M. \& 2019. A time-driven activitybased framework for a cash service company. Paper in proceedings of the $13^{\text {th }}$ annual International Business Conference, Kleinmond, South Africa. pp. 665-680.

Scott, W.R. 1998. Organizations: Rational, natural, and open systems. 4th ed. Upper Saddle River, NJ: Prentice Hall.

Shanks, G., Rouse, A. \& Arnott, D. 1993. A review of approaches to research and scholarship in information systems. Paper in Proceedings of the 4th Australian Conference on Information Systems, University of Queensland, Brisbane.

Smith, E.M. 2005. Telephone interviewing in healthcare research: A summary of the evidence. Nurse Researcher, 12(3):32-41.

Srinivasan, P. 2008. Activity based costing-concepts and cases. The Icfai University Press.

Stewart, J. 1996. Solving the riddle of industrial policy: A comparative perspective. Australian Journal of Political Science, 31(1):25-36.

Stouthuysen, K., Schierhout, K., Roodhooft, F. \& Reusen, E. 2014. Time-driven activity-based costing for public services. Public Money \& Management, 34(4):289-296.

Stout, D.E. \& Propri, J.M. 2011. Implementing time-driven activity-based costing at a mediumsized electronics company. Management Accounting Quarterly, 12(3):1.

Szychta, A. 2010. Time-driven activity-based costing in service industries. Social Sciences, $1(67): 49-60$.

Teece, D. 2018. Dynamic capabilities as (workable) management systems theory. Journal of Management \& Organization, 24(3):359-368.

Thomas, R. \& Hardy, C. 2011. Reframing resistance to organizational change. Scandinavian Journal of Management, 27:322-31.

Turney, P.B.B. 1996. Activity based costing the performance breakthrough. London: Kogan Page.

Twycross, A. \& Shorten, A. 2016. Using observational research to obtain a picture of nursing practice. Evidence-Based Nursing, 19(3):66-67.

Van der Linde, M. 2011. Embedding an activity driven operational accounting framework in a fertilizer. Potchefstroom: North-West University. (Mini-dissertation - MCom).

Viljoen, I.M. 2018. Die toepassing van aktiwiteitsgebasserde kostebeginsels op 'n gemengde boerdery. Potchefstroom: North-West University. (Mini-dissertation - MCom). 
Wegmann, G. 2009. The activity-based costing method: Development and applications. The IUP Journal of Accounting Research and Audit Practices, 8(1):7-22.

Wicander, G. 2011. Mobile supported e-Government systems - Analysis of the education management information system (EMIS) in Tanzania. Karlstad University. (Dissertation - PhD).

Wiesche, M., Jurisch, M.C., Yetton, P.W. \& Krcmar, H. 2017. Grounded theory methodology in information systems research. MIS Quarterly, 41(3):685-701.

Wiles, R., Crow, G. \& Pain, H. 2011. Innovation in qualitative research methods: a narrative review. Qualitative Research, 11(5):587-604.

Wilson, J. 2010. Essentials of business research: A guide to doing your research project. Newbury Park, CA: Sage.

Woodruff, J. 2019. Traditional Costing Vs. Activity-Based Costing.

https://smallbusiness.chron.com/traditional-costing-vs-activitybased-costing-33724.html Date of access 2 May. 2020.

Yin, R. 1993. Applications of case study research. Beverly Hills, CA: Sage Publishing.

Yin, R. 2009. Case study research: Design and methods. 1st ed. Thousand Oaks, CA: Sage.

Zikmund, W.G., Babin, B.J., Carr, J.C. \& Griffin, M. 2010. Business research methods. 9th ed. London: Cengage Learning. 


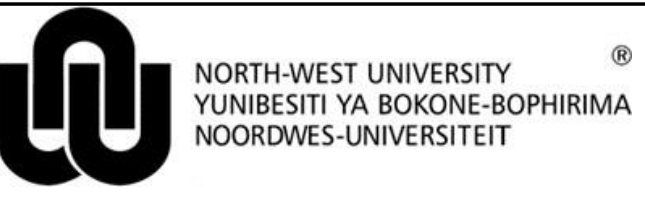

Private Bag X6001, Potchefstroom South Africa 2520

Tel: $\quad 018299-1111 / 2222$

Web: http://www.nwu.ac.za

Economic and Management Sciences Research Ethics Committee (EMS-REC)

29 May 2020

Prof Merwe Oberholzer and Prof Danie Schutte

Per e-mail

Dear Prof Oberholzer and Prof Schutte,

\section{EMS-REC FEEDBACK: 29052020}

Student: Holtzhausen, HC (32907575)(NWU-00674-20-A4)

Applicant: Prof Merwe Oberholzer and Prof Danie Schutte - MCom in Management Accountancy

Your ethics application on, Developing a costing system for a digital technology service firm, which served on the EMS-REC meeting of 29 May 2020, refers.

\section{Outcome:}

Approved as a minimal risk study. A number NWU-00674-20-A4 is given for one year of ethics clearance.

Due to the Covid-19 lock down ethics clearance for applications that involve data collection or any form of contact with participants are subject to the restrictions imposed by the South African government.

Kind regards,

Mark

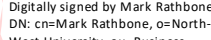

Rathbone

Prof Mark Rathbone

Chairperson: Economic and Management Sciences Research Ethics Committee (EMS-REC) 
Private BagX6001, Potchefstroom South Africa 2520

Tel: $\quad$ 018299-1111/2222

Web:http://www.nwu.ac.za

Applied Research in Management Cybernetics

Tel: $\quad 0182991340$ / 0835643391

Email: merwe.oberholzer@nwu.ac.za

20 April 2020

To Whom It May Concern

\section{PERMISSION TO CONDUCT RESEARCH AT IOT.nXt}

Mr. Cronjé Holtzhausen (student number 32907575) is currently enrolled as a master's student in Management Accounting at the North-West University. Your permission is herewith requested to allow Mr. Holtzhausen to conduct his academic research project in your firm.

The objective of the study is to understand the operations/systems/processes in a typical digital technology service firm to enable him to develop an appropriate cost allocation system, which will probably be based on the principles of the activity-based costing approach. This investigation necessitates that semi-structured interviews will be conducted with approximately three to five senior employees. It will also be appreciated if documentation such as system-flowcharts, hierarchal charts and the general ledger will be made available.

Your time in considering this request is greatly appreciated. Please sign below to indicate your willingness to participate in the study and return to me at your earliest convenience.

Yours sincerely

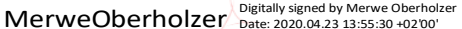

Merwe Oberholzer (Professor)

North-West University: Applied Research in Management Cybernetics - niche area Cell: 0835643391

E-mail: merwe.oberholzer@nwu.ac.za 


\section{RESEARCH PROJECT: DEVELOPING A COSTING SYSTEM FOR A DIGITAL TECHNOLOGY SERVICES FIRM}

\section{The researchers}

The primary researchers participating in this study are Mr. Cronjé Holtzhausen (master's student in Management Accounting), Prof. Merwe Oberholzer (Management Cybernetics) and Prof.Danie Schutte (Accounting Sciences) who will act as supervisor and co-supervisor, respectively.

\section{How many employees will be participating in the study?}

In order to obtain a clear understanding of the firms' operations, systems and processes approximately three to five semi-structured interviews need to be conducted with senior employees, of whom the Chief Financial Officer and the Chief Operational Manager or their equivalent, or delegates, should be included. This will be the CEO's prerogative to assign the most appropriate individuals to this project.

\section{Where and when will the interviews take place and how long does an interview take?}

An appointment will be made to meet for an interview with each assigned employee at the firm's premises. Alternatively, as a result of the Covid-19, Skype interviews may be considered. The interviews will take place during June/July 2020. Each interview will be scheduled for no longer than an hour.

After the new costing model is developed, each of the participants will be e-mailed to evaluate (give their opinion) the model. Further suggestions or comments can be made by returning the email.

\section{Should any other documentation be needed?}

To better understand the operations, systems and processes of the firm it would be helpful if documentation such as flowcharts, hierarchal charts and the general ledger will be made available. However, this is the CEO's prerogative to decide whether any further documentation will be made available.

\section{What about anonymity?}

In the documentation of the research the participants' names will not be mentioned and the report will only indicate, if necessary, to the opinions of, for example Interviewee $\mathrm{X}$, Interviewee $\mathrm{Y}$, etc.

\section{What about confidentiality?}

All data obtained is stored electronically and will be password protected. Any hard copies will be stored in a locked cupboard at the researcher's home for a period of maximum three years after which they will be destroyed.

In case the researchers find it necessary to use monetary values related to the firm, such numbers will be adapted with a factor, only known to Mr Holtzhausen.

\section{How will the results be distributed?}

The results of the study will be discussed in a mini-dissertation as part of Mr. Holtzhausen's masters' studies, which will become available on the North-West University website. The researchers are also of the opinion that the results of this study will bring new insights in the modern business environment, especially the digitalisation of operations. For this reason the researchers aim to publish the results in the form of an article in an academic journal and/or present the results at an academic conference. A copy of the article will be sent to the firm for approval prior publication.

\section{Any more questions?}

For questions about this study do not hesitate to contact the researchers, i.e. Mr. Holtzhausen (071 409 5360), Prof.Oberholzer (083 564 3391) or Prof.Schutte (064 971 4638). 
Private Bag X6001, Potchefstroom South Africa 2520

Tel: $\quad 018299-1111 / 2222$

Web:http://www.nwu.ac.za

Applied Research in Management Cybernetics

Tel: $\quad 0182991340 / 0835643391$

Email: merwe.oberholzer@nwu.ac.za

\section{Dear participant}

\section{RESEARCH PROJECT: DEVELOPING A COSTING SYSTEM FOR A DIGITAL TECHNOLOGY SERVICES FIRM}

We at the Faculty of Economic and Management Sciences, of which the School of Accounting Sciences and the niche area Applied Research in Management Cybernetics are part, are currently conducting research and would like you to form part of it. The ethical clearance number for the project is NWU-00674-20-A4 (ethical number). The primary objective of this research is to develop a new costing system/model for a digital technology services firm. We belief that such a system/model will enhance the firm's current costing system. Consequently, information about the firm's operations, including activities, systems and processes are critical for discerning an appropriate model.

Please note the following:

- Your participation in this research is completely voluntarily, and you will receive no form of compensation.

- To get an understanding of the firm's operations, activities, systems and processes you are required to answer a number of open-ended questions.

- Your expertise and knowledge of the firm are highly appreciated and the aim of the openended questions is to obtain an in-depth view of your opinion.

- Your answers and opinions will remain anonymous. The final report of the study's aim is rather to aggregate the opinions of a variety of individuals. The final report will not mention your name and may only refer to you if necessary, for example as IntervieweeX.

- All data obtained is stored electronically and will be password protected. Any hard copies will be stored in a locked cupboard at the researcher's home for a period of maximum three years after which they will be destroyed.

- If you feel, at any time, that you want to halt participation in this study, please feel free to do so without judgement.

- This interview should take no longer than one hour to complete.

- If anything is unclear, you are welcome to raise any question during the interview.

- Please note that this interview will be recorded only with your consent.

By continuing with this interview, you agree to the terms and conditions of this research. For any further information, feel free to contact the study's supervisors, Prof Merwe Oberholzer (083 564 3391 or merwe.oberholzer@nwu.ac.za) or Prof DanieSchutte $\left(\begin{array}{llll}064 & 971 & 4638\end{array}\right)$ danie.schutte@nwu.ac.za).

Yours sincerely 
Cronje

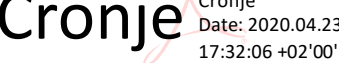

Merwe Oberholzer Digtally signed by Merwe obertholee

Mr H.C. Holtzhausen

Prof M Oberholzer

(Researcher)

(Supervisor -

Management Cybernetics)

$\mathrm{I}$,

[name of firm employee], hereby give my permission

to be interviewed for the above-mentioned study. I hereby also give you permission to record our

conversation: (Chose the appropriate box by an "X"):

Agree

Not Agree

Signature

Date 
Interview questions

Do you think the following conditions would be a problem for your company when implementing a costing system? Yes or No, if Yes then why?

\begin{tabular}{|c|c|c|c|c|}
\hline No. & Conditions & Yes & No & If Yes, then why? \\
\hline a) & Resistance to change & & & \\
\hline b) & High implementation cost & & & \\
\hline c) & Lack of time & & & \\
\hline d) & $\begin{array}{l}\text { Lack of commitment and cooperation } \\
\text { amongst department }\end{array}$ & & & \\
\hline e) & Lack of top management support & & & \\
\hline f) & The importance of the project & & & \\
\hline g) & $\begin{array}{l}\text { Not capable to implement the } \\
\text { costing system }\end{array}$ & & & \\
\hline
\end{tabular}




\section{Verbal response}

With the company growing at a rapid pace and expanding into different regions. Do you think that a new customised costing system should be considered?

What should be the purpose of costing? For example what should be "costed"? Departments (e.g. X, Y and Z), Client (e.g. A, B and C) and or types of services (e.g. development of software, implementation of software, "running" and monitor clients' facilities), etc.

Can you explain the level of how sophisticated this firm's costing should be? (For example how accurate should it be? Also keep in mind that a higher level sophistication/accuracy, the higher the cost to develop and operate such a system.)

What computer or software system is used for your current costing system in your firm?

What type of main activities take place when the service is delivered to the clients? Could there be specific cost pools? (Note that "time" may be the main activity. Could a time-driven activity-based costing system then be appropriate?)

How does the current flow of activities and the flow of costs works in the Firm's system/processes/operations? 
Cost hierarchies in activity-based costing is divided into four activity levels such as unit level, batch level, service level or facility level. Can you give examples of cost-items included in these different categories?

To ensure the costing system implementation is successful, management should be $100 \%$ committed with the initiative. What team or individuals would you recommend to help with the costing system implementation initiative and why?

The current allocation system provides management with financial and non- financial information to make informed decisions. How accurate and sufficient is the available information provided to management to make strategic financial decisions?

What improvements could be made on the current allocation system and why?

The nature of $A B M$ is that it enhances operational efficiency, focuses on doing things right the first time and performing activities more efficiently. What is your expectation regarding the efficiency aspect when the costing system is fully implemented for your company? 
The use of the customised costing system as a management tool will contribute to more accurate budgeting practices, improve monitoring controls and better decision making. Do you agree/disagree with the statement made above and why?

Is there anything else on this topic that you would like to add or tell me? 


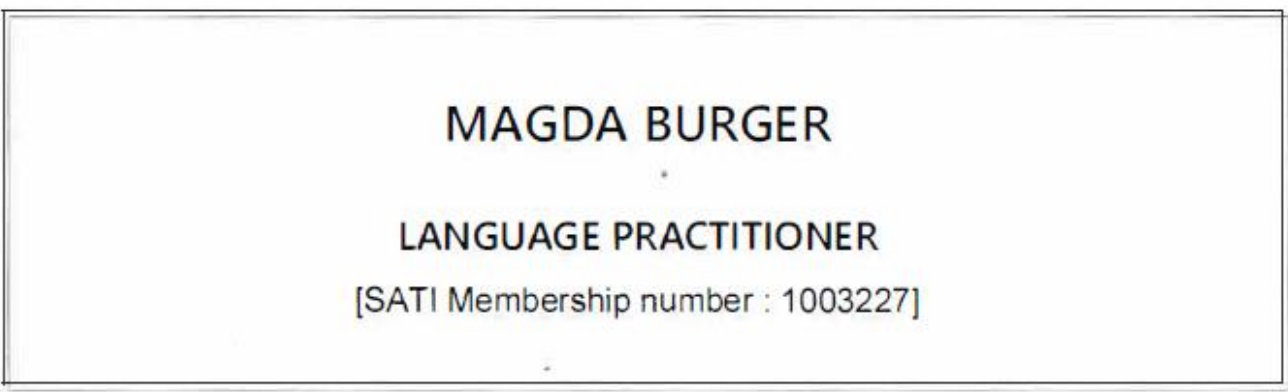

75 Munnik Street

STRAND

7140

Cell: 0823337541

$2020-12-03$

TO WHOM IT MAY CONCERN

\section{LINGUISTIC REVISION OF MINI-DISSERTATION}

SUBMITTED IN PARTIAL FULFILMENT OF THE REQUIREMENTS FOR THE DEGREE MASTER OF COMMERCE IN MANAGEMENT ACCOUNTANCY

AT THE NORTH-WEST UNIVERSITY

For

HC Holtzhausen : Student number: $\mathbf{3 2 9 0 7 5 7 5}$

I, Magda Burger, ID number 5210060038 080, hereby deciare that I have linguistically revised the mini-dissertation Developing a costing system for a digital technology service firm for student $\mathrm{HC}$ Holtzhausen.

Yours sincerely

\section{MAGDA BURGER}

LANGUAGE PRACTITIONER

BA (Languages) (UFS) (1973); MEd (UFS) (1987) 
APPENDIX D: SUPPORTING DEPARTMENTS

\begin{tabular}{|c|c|c|c|c|c|c|c|c|c|c|c|c|c|c|c|c|}
\hline Department & $\begin{array}{l}\text { Hours per } \\
\text { employee }\end{array}$ & Total hours & Activity Capacity & $\begin{array}{c}\text { (100\% per } \\
\text { activity) }\end{array}$ & Top-level & Middle-level & First-level & $\begin{array}{c}\text { Activity } \\
\text { capacity hrs }\end{array}$ & \begin{tabular}{|l|} 
Top- \\
level \\
\end{tabular} & $\begin{array}{l}\text { Middle- } \\
\text { level }\end{array}$ & $\mid$ First-level $\mid T$ & Top-level & Middle-level & First-level & \begin{tabular}{|c|} 
Activity cost per \\
year
\end{tabular} & $\begin{array}{c}\text { Average rate per } \\
\text { hour }\end{array}$ \\
\hline \multirow[t]{12}{*}{ Finance } & 2000,00 & 42000,00 & Financial Analysis (3\%) & $3 \%$ & $50 \%$ & $50 \%$ & $0 \%$ & 1260 & 630 & 630 & 0 & R1584450 & R553770 & RO & R2138220 & R1697 \\
\hline & & & Budgeting (3\%) & $3 \%$ & $90 \%$ & $10 \%$ & $0 \%$ & 1260 & 1134 & 126 & 0 & R2852010 & R 110754 & RO & R2962764 & R2351 \\
\hline & & & Cost Reports (3\%) & $3 \%$ & $60 \%$ & $40 \%$ & $0 \%$ & 1260 & 756 & 504 & 0 & R1901340 & R 443016 & RO & R2344356 & R1861 \\
\hline & & & Cashflow Analysis (3\%) & $3 \%$ & $20 \%$ & $80 \%$ & $0 \%$ & 1260 & 252 & 1008 & 0 & $\mathrm{R} 633780$ & R 886032 & RO & R1519812 & R1206 \\
\hline & & & Financial reporting (3\%) & $3 \%$ & $70 \%$ & $30 \%$ & $0 \%$ & 1260 & 882 & 378 & 0 & R2218230 & R332262 & RO & R2550492 & R2024 \\
\hline & & & Supply chain $(10 \%)$ & $10 \%$ & $30 \%$ & $70 \%$ & $0 \%$ & 4200 & 1260 & 2940 & 0 & R3168900 & R2584260 & RO & R5753160 & R1370 \\
\hline & & & Regulatory and Compliance (12\%) & $12 \%$ & $50 \%$ & $50 \%$ & $0 \%$ & 5040 & 2520 & 2520 & 0 & R6337800 & R2215080 & RO & R8552880 & R1697 \\
\hline & & & Risk Management (15\%) & $15 \%$ & $50 \%$ & $50 \%$ & $0 \%$ & 6300 & 3150 & 3150 & 0 & R7922 250 & R2768850 & RO & R 10691100 & R1697 \\
\hline & & & Transactional (20\%) & $20 \%$ & $15 \%$ & $35 \%$ & $50 \%$ & 8400 & 1260 & 2940 & 4200 & R3168900 & R2584260 & R1596000 & R7349 160 & R 875 \\
\hline & & & Strategy $(15 \%)$ & $15 \%$ & $80 \%$ & $20 \%$ & $0 \%$ & 6300 & 5040 & 1260 & 0 & R 12675600 & R1107540 & Ro & R 13783140 & R2 188 \\
\hline & & & Board Meetings (13\%) & $13 \%$ & $100 \%$ & $0 \%$ & $0 \%$ & 5460 & 5460 & 0 & 0 & R 13731900 & Ro & RO & R 13731900 & R2515 \\
\hline & & & & $100 \%$ & & & & 42000 & & & & & & & R 71376984 & R1699 \\
\hline \multirow[t]{5}{*}{ HR } & 2000,00 & 12000,00 & Customer service (50\%) & $50 \%$ & $90 \%$ & $0 \%$ & $10 \%$ & 6000 & 5400 & 0 & 600 & R 13581000 & Ro & R 228000 & R 13809000 & R2302 \\
\hline & & & Revisits (5\%) & $5 \%$ & $50 \%$ & $35 \%$ & $15 \%$ & 600 & 300 & 210 & 90 & R754 500 & R 184590 & R34200 & R 973290 & R1622 \\
\hline & & & Staff recruitment (30\%) & $30 \%$ & $60 \%$ & $40 \%$ & $0 \%$ & 3600 & 2160 & 1440 & 0 & R5 432400 & R1265760 & Ro & R6698160 & R1861 \\
\hline & & & Marketing $(15 \%)$ & $15 \%$ & $100 \%$ & $0 \%$ & $0 \%$ & 1800 & 1800 & 0 & 0 & R4527000 & RO & RO & R4527000 & R2515 \\
\hline & & & & $100 \%$ & & & & 12000 & & & & & & & R26007450 & R2167 \\
\hline \multirow[t]{5}{*}{ Project } & 2000,00 & 50000,00 & Deliverables (65\%) & $65 \%$ & $5 \%$ & $30 \%$ & $65 \%$ & 32500 & 1625 & 9750 & 21125 & R 4086875 & R8570250 & R 8027500 & R 20684625 & $R 636$ \\
\hline & & & Strategic planning (5\%) & $5 \%$ & $95 \%$ & $5 \%$ & $0 \%$ & 2500 & 2375 & 125 & 0 & R5 973125 & R 109875 & RO & R6083000 & $R 2433$ \\
\hline & & & Project drafts (25\%) & $25 \%$ & $5 \%$ & $30 \%$ & $65 \%$ & 12500 & 625 & 3750 & 8125 & R1571875 & R3296250 & R3087500 & R7955625 & $\mathrm{R} 636$ \\
\hline & & & Evaluations (5\%) & $5 \%$ & $30 \%$ & $0 \%$ & $70 \%$ & 2500 & 750 & 0 & 1750 & R1 1886250 & RO & R 665000 & R2551250 & R1021 \\
\hline & & & & $100 \%$ & & & & 50000 & & & & & & & R 37274500 & R7 745 \\
\hline \multirow[t]{5}{*}{ Legal } & 2000,00 & 4000,00 & Deliverables (85\%) & $85 \%$ & $20 \%$ & $0 \%$ & $80 \%$ & 3400 & 680 & 0 & 2720 & R1710200 & Ro & R1 033600 & R2743800 & R 807 \\
\hline & & & Strategic planning (5\%) & $5 \%$ & $100 \%$ & $0 \%$ & $0 \%$ & 200 & 200 & 0 & 0 & R 503000 & Ro & Ro & R 503000 & R2515 \\
\hline & & & Project drafts (5\%) & $5 \%$ & $10 \%$ & $0 \%$ & $90 \%$ & 200 & 20 & 0 & 180 & R50300 & Ro & R 68400 & R 118700 & R 594 \\
\hline & & & Evaluations (5\%) & $5 \%$ & $30 \%$ & $0 \%$ & $70 \%$ & 200 & 60 & 0 & 140 & R 150900 & Ro & R53200 & R204 100 & R1021 \\
\hline & & & & $100 \%$ & & & & 4000 & & & & & & & R3569600 & $\mathrm{R} 892$ \\
\hline \multirow[t]{5}{*}{ Marketing } & 2000,00 & 40000,00 & Deliverables (85\%) & $85 \%$ & $25 \%$ & $0 \%$ & $75 \%$ & 34000 & 8500 & 0 & 25500 & R 21377500 & Ro & R9690000 & R 31067500 & R 914 \\
\hline & & & Strategic planning (5\%) & $5 \%$ & $100 \%$ & $0 \%$ & $0 \%$ & 2000 & 2000 & 0 & 0 & R5 030000 & Ro & RO & R5 030000 & R2515 \\
\hline & & & Global Channel PM (5\%) & $5 \%$ & $5 \%$ & $0 \%$ & $95 \%$ & 2000 & 100 & 0 & 1900 & R 251500 & Ro & R722000 & $\begin{array}{ll}\text { R } 973500 \\
\end{array}$ & R 487 \\
\hline & & & Evaluations (5\%) & $5 \%$ & $30 \%$ & $0 \%$ & $70 \%$ & 2000 & 600 & 0 & 1400 & R1509000 & Ro & R532000 & R2041000 & R1021 \\
\hline & & & & $100 \%$ & & & & 40000 & & & & & & & R 39112000 & R 978 \\
\hline \multirow[t]{4}{*}{ CEO Office } & 2000,00 & 4000,00 & Strategic planning (50\%) & $50 \%$ & $95 \%$ & $5 \%$ & $0 \%$ & 2000 & 1900 & 100 & 0 & R4778500 & R 87900 & RO & R4 4866400 & R2433 \\
\hline & & & Execution (25\%) & $25 \%$ & $95 \%$ & $5 \%$ & $0 \%$ & 1000 & 950 & 50 & 0 & R2389 250 & R 43950 & RO & R2433200 & $R 2433$ \\
\hline & & & Performance (25\%) & $25 \%$ & $95 \%$ & $5 \%$ & $0 \%$ & 1000 & 950 & 50 & 0 & R2389 250 & R 43950 & RO & R2433200 & $R 2433$ \\
\hline & & & & $100 \%$ & & & & 4000 & & & & & & & R9732800 & R2433 \\
\hline
\end{tabular}

